Report No: DOE-99049-1381

\title{
PROTECTED POLYCRYSTALLINE DIAMOND COMPACT BITS FOR HARD ROCK DRILLING
}

\section{R. Cardenas}

Foster-Miller, Inc.

350 Second Avenue

Waltham, MA 02451

781-684-4000

October 2000

Period Covered: $9 / 1 / 98-8 / 21 / 00$

Draft Final Report

Contract Number: DE-FG07-98ID13685

Contract Amount: $\$ 216,916.00$

Competitively Awarded

COTR: Ms. Willettia Amos

This report was prepared with the support of the U.S. Department of Energy (DOE) Award No. DEFG07-98ID13685. However, any opinions, findings, conclusions, or recommendations expressed herein are those of the author(s) and do not necessarily reflect the views of DOE.

Prepared for:

U.S. Department of Energy

Idaho Operations Office 850 Energy Drive, MS 1225

Idaho Falls, ID 83401-1563 


\section{DISCLAIMER}

This report was prepared as an account of work sponsored by an agency of the United States Government. Neither the United States Government nor any agency thereof, nor any of their employees, make any warranty, express or implied, or assumes any legal liability or responsibility for the accuracy, completeness, or usefulness of any information, apparatus, product, or process disclosed, or represents that its use would not infringe privately owned rights. Reference herein to any specific commercial product, process, or service by trade name, trademark, manufacturer, or otherwise does not necessarily constitute or imply its endorsement, recommendation, or favoring by the United States Government or any agency thereof. The views and opinions of authors expressed herein do not necessarily state or reflect those of the United States Government or any agency thereof. 


\section{DISCLAIMER}

Portions of this document may be illegible in electronic image products. Images are produced from the best available original document. 
PART I (DOE, DOE Contractors, Grantees, and Awardees complete)

\section{A. Product/Report Data}

1. (Award) Contract No. DE-FG07-98ID13685--5

2. Title Protected Polycrystalline Diamond Bits for Hard Rock Drilling

\section{Product/Report Description}

$\square$ a. Report (Complete all that apply)

(1) QXPrint $\square$ Nonprint (specify)

(2) Q Quarterly $\square$ Semiannual $\square$ Annual $\triangle$ Final

$\square$ Topical $\square$ Phase I Q Phase II

$\square$ Other (specify)

Dates covered Sept 1999 thru Aug 2000

$\square$ b. Conference/Meeting/Presentation (Complete all that apply)

(1) $\square$ Print $\square$ Nonprint (specify)

$\square$ Published proceedings

$\square$ Other (specify)

(2) Conference Title (no abbreviations)

Location (city/state/country)

Date(s) $(m / d / y)+L L$ thru $(m / d / y)+1$

Sponsor $\square$ c. Software-Additional forms are required. Follow instructions on the back of this form.

$\square$ d. Other (Provide complete description)

\section{Patent Information}

Yes No

\ $\square$ ls any new equipment, process, or material disclosed? If yes, identify page numbers P. 13-56

Q $\square$ Has an invention disclosure been submitted? If yes, identify the disclosure number and to whom it was submitted. Disclosure number Submitted to

a $\square$ Are there patent-related objections to the release of this STI product? If so, state the objections.

C. Contact (Person knowledgeable of content)

Name Robert Lee Cardenas

Phone 781-684-4283

Position Senior Engineer

Organization Foster-Miller, Inc.

PART II (DOEIDOE Contractors complete/or as instructed by DOE contracting officer)

\section{A. DOE Identifiers}

1. Product/Peport Nos, -DOE/ID 13685

2. Funding Office(s) (NOTE: Essential data)

DOE Idaho Operations Office

B. Copies for Transmittal to AD-21 (OSTI)

(STI must be of sufficient quality for microfilming/copying.)

Q 1. One for classified processing

व2. ....... (number) for standard classified distribution

3. Two unclassified for processing

ב4. - _.. (number) for program unclassified distribution

口5. UC/C Category

๑ 6. Additional instructions/explanations

$$
\cdots
$$$$
\text { .... }
$$

$$
\left[\begin{array}{r}
\cdot \\
\hline
\end{array}\right.
$$$$
\because
$$$$
\text { -............ }
$$

(Do not identity Sigma categories for Nuclear Weapons Data reports, and do not provide additional instructions that are inconsistent with $C$ below.)

C. Recommendation (" $X$ " at least one)

コ 1. Program/Standard Announcement/Distribution (Avallable to U.S. and foreign public)
D2. Classified (Standard Announcement only)

R3. Special Handling (Legal basis must be noted below.) $\square$ a. Unclassified Controlled Nuclear Information (UCNI)

口b. Export Control/TAR/EAR

$\square$ c. Temporary hold pending patent review

$\square$ d. Translations of copyrighted material

$\square$ e. Smail Business Innovation Research (SBIR)

$\otimes$ f. Commercializable information
Q(1) Proprietary
$\square$ (2) Protected CRADA information Release date 1
$\square$ (3) Other (explain)

口 4. Program Directed Special Handling (copy attached)

D. Releasing Official

A. Patent Clearance (" $X$ " one)

$\square$ Has been submitted for DOE patent clearance

$\square$ DOE patent clearance has been granted

B. Released by

(Name)

(Signature)

(Phone)

(Date) 


\section{INSTRUCTIONS}

Purpose: This form provides the Office of Scientific and Technical Information (OSTI), AD-21, the data elements required to accurately process and/or announce and disseminate the result of work funded by the U.S. Department of Energy (DOE) or performed in DOE facilities.

When to use: Submit this form with each Scientific and Technical Information (STI) product/report title. When submitting electronically, include all relevant data elements, and prior to submission contact AD-21 at 615-576-1261.

1. DOE and DOE Contractors: Complete the entire form and submit with the STI product to AD-21 (OSTI) for processing in accordance with the requirements of DOE $1430.1 \mathrm{C}$ and $1430.2 \mathrm{~B}$. Reporting that may be required under the terms of the contract but is not appropriate for transmittal to AD-21 includes such things as contract proposals, funding status, routine construction or inventory reports, etc.(Call 615-576-1261 for further clarification.) Submit to:

U.S. Department of Energy
Office of Scientific and Technical Information (AD-21)
175 Oak Ridge Tumpike (for shipments)
P.O. Box 62 (for mail)
Oak Ridge. TN 3783 t

2. Financial Assistance Recipients: Normally, only Part I is to be completed. When completed, forward the form along with the STI product/report to the DOE Contracting Officer who will complete Part ll and submit the package to AD-21. However, the DOE Contracting Officer may require the awardee to complete portions of Part II and also may require that the form and productreport be lorwarded directly to $A D-21$. Check your specific requirements.

\section{PART I}

\section{A. Product/Report Data}

1. Contract (Award) No. Insert the DOE award or contract number(s) under which the work was funded.

2. Title. Provide the title exactly as on the product itself.

3.a., 3.b. and, 3.d. Self-explanatory.

3.c. Software. STI software must be submitted to the Energy Science and Technology Software Center (ESTSC). To obtain required forms and instructions, contact ESTSC at 615-576-2606.

\section{B. Patent Information. Self-explanatory.}

C. Contact. Self-explanatory.

\section{PART II}

\section{A. DOE Identifiers}

1. Product/Report Number. This is a unique identifier. A complete and accurate number is essential. AD-21 has approved identifiers for use by most DOE offices and Management and Operating (M\&O) Contractors (see examples below). For others, use DOEl and the final seven characters from the applicable contract or grant number. A slash mark must separate the letters from the number. Complete the number with dashes followed by a sequential number for each product/report generated under the contract. For example, the first product/report number generated under contract number DE-AC03-79NE01834 should have the number DOE/NE/01834-1. The following are examples of format for multivolumes, parts, or revisions.

DOE/NE/01834-1-Vol. 1

DOE/NE/01834-1-Pt. 1

DOE/NE/01834-1-Rev. 1

Product/Report numbers are to be structured exactly as specified in these instructions. Any modification must be approved by AD-21. The following are examples of approved identifiers.

$\begin{array}{ll}\begin{array}{l}\text { Product } \\ \text { Producer }\end{array} & \begin{array}{l}\text { Approved } \\ \text { Sequential Identifier }\end{array} \\ \text { Headquarters DOE } & \text { DOE } N E-193 \\ \text { DOE Field Offices } & \text { DOE/OR-759 } \\ \text { Mlajor Project Offices } & \text { DOE/LLW-198 } \\ \text { M\&O Contractors } & \text { ANUTM--482 }\end{array}$

For work pertormed for other agenctes. the funding agency may assign their product/report number. If so, provide therr number.
2. Funding Office. This information is essential. Insert the name, symbol B\&A code of the DOE office providing supportfunding. For projects funde by more than one office, indicate all sources of DOE funding. For work for others, indicate funding agency.

\section{B. Copies for Transmittal to AD-21 (OSTI)}

All STI products must be in a form that can serve as the record copy and: of sufficient quality for successful reproduction (optical scanning, microfict and other media). For nonprint media, refer questions to $A D-21$ at 615-576-1268.

1. and 3. For printed products, one copy must be original ribbon or offset . be completely legible according to DOE 1430.2B. A high-contrast photoco is acceptable as a second reproducible copy.

2. and 4. When submitting print copies for distribution by $A D-21$, forward number of copies specified in DOE/OSTI-3679-Rev. 75 or DOE/OSTI-45

5. UC/C Category This code identifies the appropriate distribution of the product/report. Provide the appropriate unclassified code from DOEIOST1-4500 or classified code from DOE/OST1-3679-Rev.75. For copies of these documents contact $A D-21$ at 615-576-8401.

6. Provide sufficient instructions for AD-21 to accurately process, announc or distribute the STI product. Include complete funding information when requesting services. Use this block to note when mailing labels are include

\section{Recommendation}

$D O E$ is obligated to make available the results from federally funded work the widest extent possible. AD-21 makes distribution of STI products on behalf of DOE strictly in accordance with existing laws, regulations, and/or written DOE Program Office guidance. Recommendations to restrict acces to STI products must have a legal basis or be accompanied by written programmatic guidance. Questions concerning current laws and guidance may be referred to $A D-21$ at $615-576-1268$.

1. Program/Standard Announcement/Distribution. The unrestricted, unlimited distribution of the product includes abstracting in Energy Researt Abstracts (ERA), DOE distribution to appropriate addressees listed in DOE/OSTI-4500, to those Govemment Printing Otfice (GPO) Depository Libraries maintaining energy collections, and to the National Technical Information Service (NTIS) for sale to the U.S. and foreign public.

2. Classified. STI products will be announced by $A D-21$ in accordance witl DOEIOSTI-3679-Rev. 75.

3. Special Handling. The specific legal basis for restricting access must b checked. All STI products will be announced/distributed strictly in accordan with existing laws, regulations, or official guidance.

CRADAS-STI products generated under Cooperative Research and Development Agreements (CRADAs) under the National Competitiveness and Technology Transfer Act of 1989. Please include the estimated releast date for the STI product in accordance with the terms of the agreement.

4. Program Directed. A copy of the specific guidance (or if the guidance is lengthy, a reference will be acceptable) must be attached.

\section{Releasing Official}

The appropriate official differs based on the source of STI, the contracting instrument, and the intemal organizational responsibilities. Do not forward this form to AD-21 until after appropriate review and release.

\section{OMB BURDEN DISCLOSURE STATEMENT}

Public reporting burden for this collection of information is estimated to average 5 minutes per response, including the time for reviewing instructior searching existing data sources, gathering and maintaining the data neede and completing and reviewing the collection of information. Send comment regarding this burden estimate or any other aspect of this collection of information, including suggestions for reducing this burden, to the Office of Information Resources ivanagement, AD-244-GTN, Paperwork Reduction Project (1910-1400), U.S. Department of Energy. Washington, DC 205a5: and to the Office of Wianagement and Budget (OMB), Paperwork Reduction Project (1910-1 +CO). Washıngton, DC 20503. 


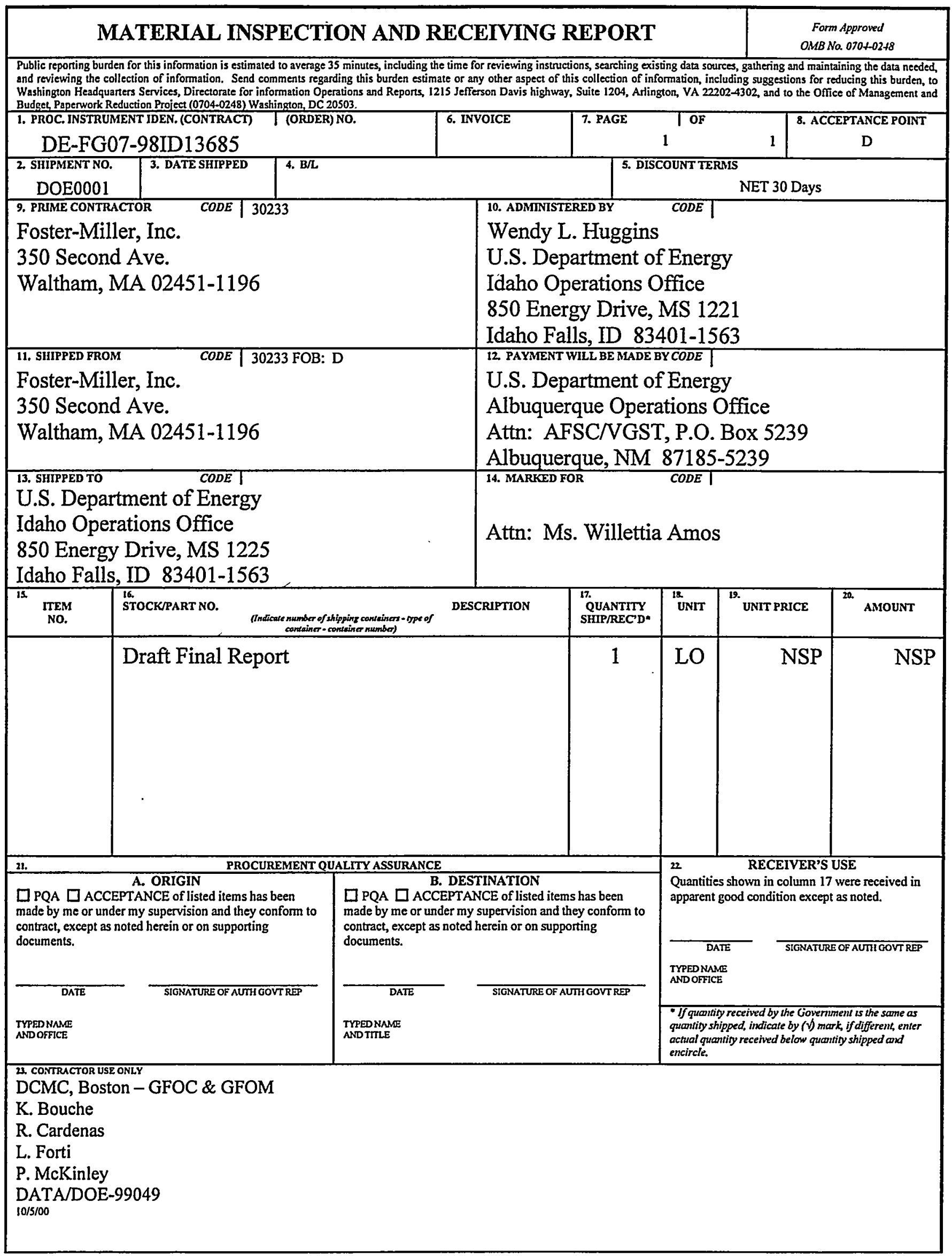


Report No: DOE-99049-1381

\title{
PROTECTED POLYCRYSTALLINE DIAMOND COMPACT BITS FOR HARD ROCK DRILLING
}

\author{
R. Cardenas \\ Foster-Miller, Inc. \\ 350 Second Avenue \\ Waltham, MA 02451 \\ 781-684-4000
}

October 2000

\author{
Period Covered: 9/1/98 - 8/21/00 \\ Draft Final Report \\ Contract Number: DE-FG07-98ID13685 \\ Contract Amount: $\$ 216,916.00$ \\ Competitively Awarded \\ COTR: Ms. Willettia Amos
}

This report was prepared with the support of the U.S. Department of Energy (DOE) Award No. DE-FG07-98ID13685. However, any opinions, findings, conclusions, or recommendations expressed herein are those of the author(s) and do not necessarily reflect the views of DOE.

Prepared for:

U.S. Department of Energy

Idaho Operations Office

850 Energy Drive, MS 1225

Idaho Falls, ID 83401-1563 



\section{CONTENTS}

Section

Page

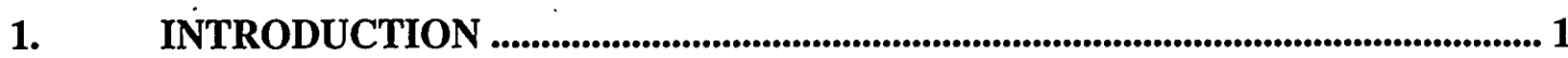

1.1 Problem Definition and Potential for Improvement .......................................................... 2

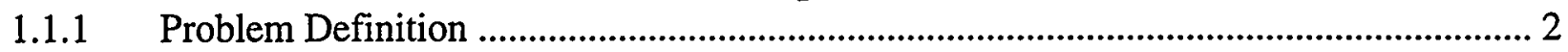

1.1.2 Description of the Concepts .................................................................................. 3

1.1.3 Cost Savings and Technical Advantages ....................................................................... 11

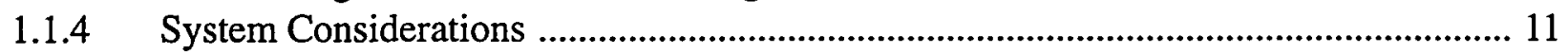

$1.2 \quad$ Phase I Objectives and Accomplishments .................................................................... 11

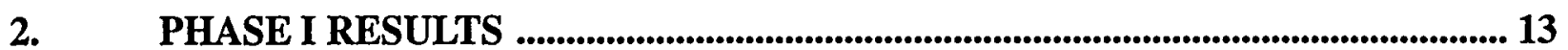

2.1 Identification of Commercializer .......................................................................... 13

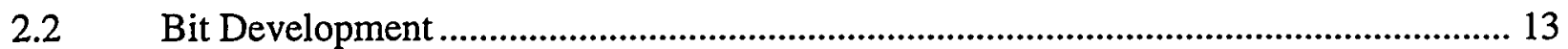

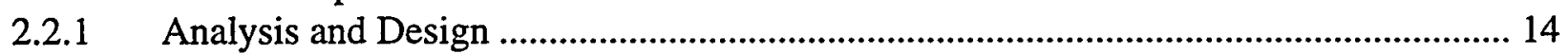

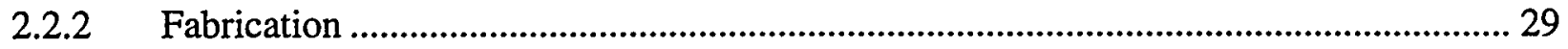

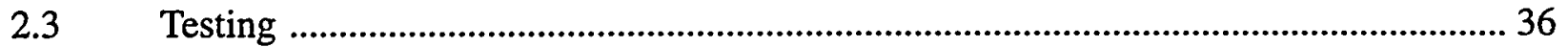

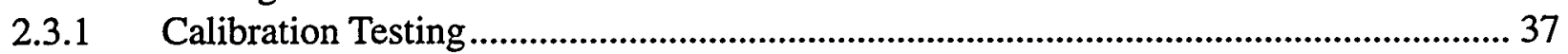

2.3.2 Laboratory Testing ....................................................................................................... 37

2.3.3 Test Results ............................................................................................................. 40

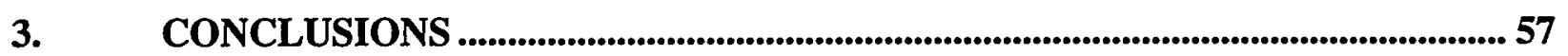

4. RECOMMENDATIONS ..................................................................................................... 58

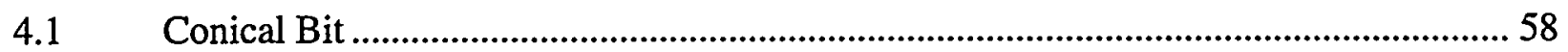

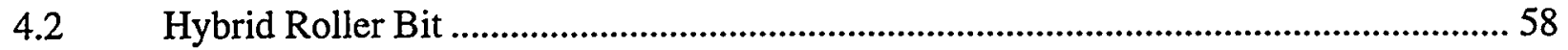

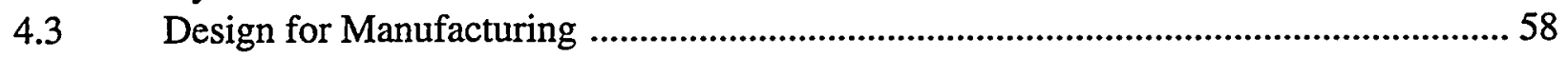

APPENDIX A - LABORATORY TEST FACILITY ..................................................................... 59 


\section{ILLUSTRATIONS}

Figure

Page

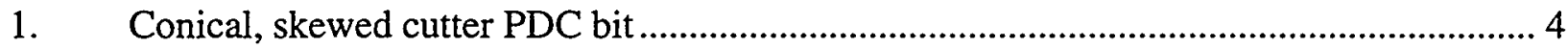

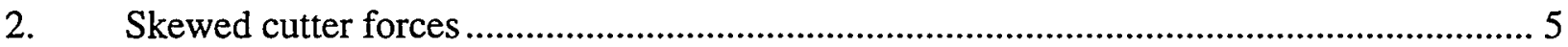

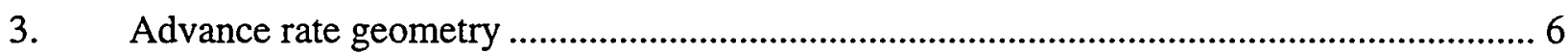

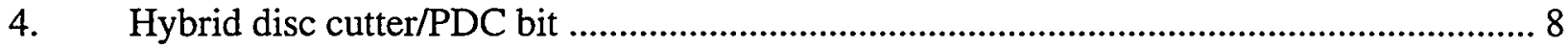

5. Two embedded cutter configurations ......................................................................... 15

6. Exposed cutter configuration ……............................................................................ 16

7. Rapid prototype model of conical drill bit..................................................................... 17

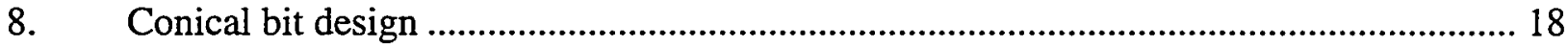

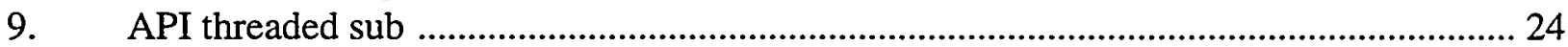

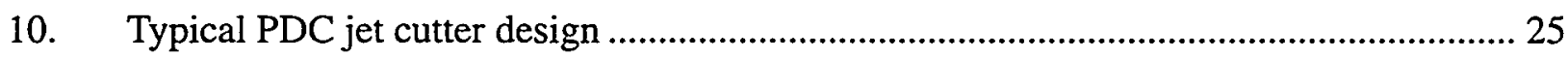

11. Conceptual design for Foster-Miller PDC hybrid roller cone bit assembly ..................... 26

12. Design sketch of hybrid bit assembly (bottom view) ………………………………….... 27

13. Design sketch of hybrid bit assembly (section through cutter) ........................................ 28

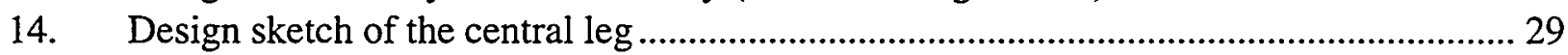

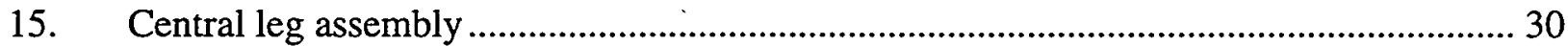

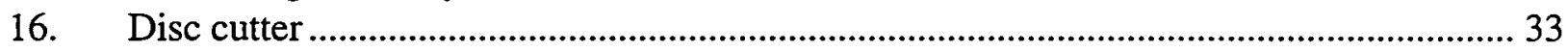

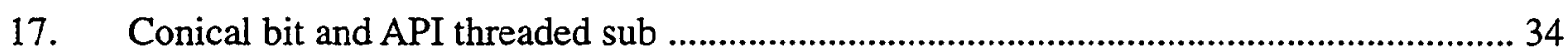

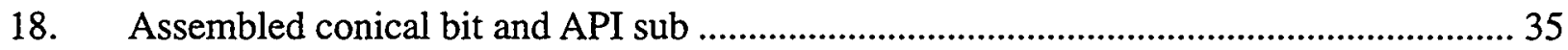

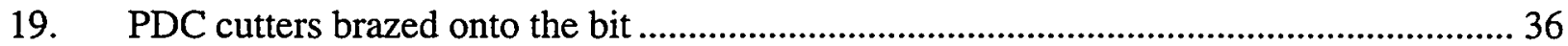

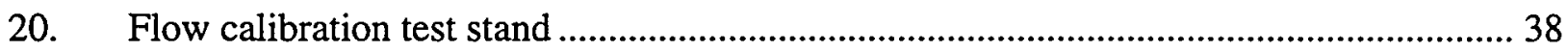

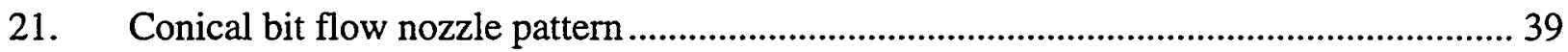

22. Terra-Tek's laboratory drilling test rig ......................................................................... 42

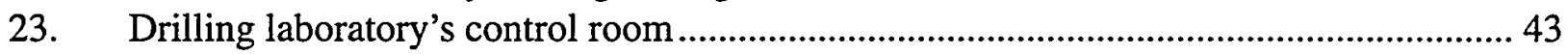

24. Test bits (Foster-Miller conical bit with well screen (top), Varel PDC bit (left), Varel L121 Tricone bit (right)) ....................................................................................... 44

25. Conical bit on drill string at full flow ............................................................................. 45

26. Water box locked down during testing (hose returned flow to the pump sump) .............. 46

27. Bit comparison, penetration rate in feet per hour (Carthage Marble) ............................... 49

28. Bit comparison, penetration rate in inches per revolution (Carthage Marble) ..................50 50

29. Bit comparison, torque (Carthage Marble) ………..................................................... 51

30. Bit comparison, penetration rate in $\mathrm{ft} / \mathrm{hr}$ (Sierra White Granite) ..................................... 53

31. Bit comparison, penetration rate in in./rev (Sierra White Granite) ................................... 54

32. Bit comparison, torque (Sierra White Granite) ................................................................. 55

33. Comparison of new bit nose cutters to tested bit nose cutters .......................................... 56 


\section{TABLES}

Table

Page

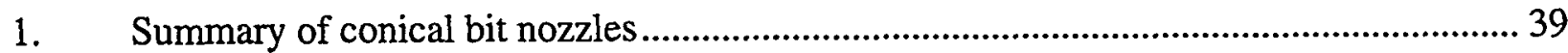

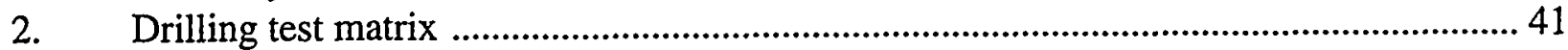

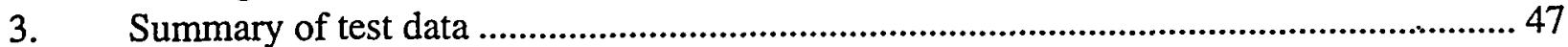

4. Summary of corrections for pressure drop across filter .............................................. 48 
Under Contract No. DE-FG07-98ID13685 with the U.S. Department of Energy Idaho Operations Office, Foster-Miller evaluated two novel designs for "Protected Polycrystalline Diamond Compact (PDC) Bits for Rock Drilling." The period of performance was from September 1998 to August 2000.

During the program, working agreements were made with industry leaders in PDC products manufacturing and drill bit manufacturing for future development and manufacture of the drill bits should they prove worthy. Dennis Tool Company, Houston, TX and Varel International, Dallas, TX provided valuable technical and manufacturing support during the conduct of this program.

Two bits were designed. One bit was fabricated and tested at Terra-Tek's Drilling Research Laboratory. Fabrication of the second bit was not completed due to complications in fabrication and meeting scheduled test dates at the test facility. A conical bit was tested in a Carthage Marble (compressive strength $14,500 \mathrm{psi}$ ) and Sierra White Granite (compressive strength 28,200 psi). During the testing, Hydraulic Horsepower, Bit Weight, Rotation Rate, were varied for the Conical Bit, a Varel Tricone Bit and a Varel PDC bit. The Conical Bit did cut rock at a reasonable rate in both rocks. Beneficial effects from the near and through cutter water nozzles were not evident in the marble due to test conditions and were not conclusive in the granite due to test conditions. At atmospheric drilling, the Conical Bit's penetration rate was as good as the standard PDC bit and better than the Tricone Bit. Torque requirements for the Conical Bit were higher than that required for the Standard Bits. Spudding the conical bit into the rock required some care to avoid overloading the nose cutters. The nose design should be evaluated to improve the bit's spudding characteristics.

The Conical bit could have a longer bit life, however, this could not be tested in the laboratory setting. Field testing is required for life testing. The bit tested in Phase I could be used in a field test, after some refurbishment.

The Hybrid Roller Bit is a unique design that required different jigging and fabricating techniques to produce the bit. Lessons learned during the Phase I effort will support future fabrication efforts. Future work should include laboratory testing of the Hybrid Roller Bit.

Brazing techniques for brazing PDC cutters with water orifices in the cutter were developed by Dennis Tool. The bit design and fabrication can be modified to improve this operation for future bits. 


\section{INTRODUCTION}

The Phase I program described in this final report was completed during the period from September 1998 to August 2000. The work was completed under Contract No. DE-FG0798ID13685 for the U.S. Department of Energy Idaho Operations Office.

The program was designed to investigate the feasibility of the two innovative bit designs. The successful development of the Conical bit and the Hybrid Roller Cone Bit promise to reduce rotating costs through increased penetration rate and increased bit life.

The Conical Bit's potential is for:

- Increased drill rate due to increased cutting structure.

- Increased drill rate due to inherent near cutter flushing.

- Increased bit life due to PCD cutter shock reduction and resistance.

Key issues to be resolved for a successful Conical Bit development include:

- Tip cutter configuration.

- Tip flushing jet configuration.

- Bit preload.

- Cutter Skew angle (limit lock-up yet reduce bounce).

The tip configuration is the controlling feature of the conical bit and was addressed in the Phase I development through the design, fabrication and testing of field quality test bit.

The Hybrid Roller Cone Bit's potential is for:

- Increased drill rate due to interaction of near cutter water jets, roller bits and drag bits.

- Increased drill rate in plastic formation due to interaction of roller and drag bit.

- Increased cutter life through reduced shock loading.

Key issues for Hybrid Roller Cone bit include:

- Roller spacing.

- Drag bit depth of cut.

- Jet location.

- Jet Hydraulic Horsepower.

- Drag bit Shock Loading (Reduction).

- Roller wear mitigation (review of potential materials). 
These issues were addressed in the Phase I design. Bit fabrication was started but was not completed as a result of manufacturing procedures. As a result, testing was not done and test data is not available for this bit design.

\subsection{Problem Definition and Potential for Improvement}

The following discussion provides a detailed description of the two bit designs evaluated in the Phase I effort.

\subsubsection{Problem Definition}

Polycrystalline Diamond Compact (PDC) bits have virtually revolutionized oil well drilling in many materials, offering something like double the penetration rate and bit life. In some cases, where multiple roller bits would be used to complete one hole, single PDC bits are used to complete multiple holes. Such performance gains would be welcomed in geothermal well drilling operations, where doubling penetration rates and bit life could decrease geothermal well costs from 15 to 20 percent. To date, PDC cutters have not proven satisfactory in the harder rocks and broken formations common to geothermal wells. Foster-Miller investigated two bit configurations that can make the PDC cutters very effective in typical geothermal formations.

Some of the PDC cutter limitations are attributable to temperature limitations imposed by significant differences in the coefficient of thermal expansion between polycrystalline diamond materials and the tungsten carbide materials used to support them. These shortcomings are being addressed through continuing materials research and development.

While the improved materials are important, and continuing work has been encouraged, that approach alone will do little to combat catastrophic failure of cutting elements when subjected to impact loads. Impact loads are frequently encountered in the field: from unsteady drilling assembly motion, from abrupt transition from soft materials to hard stringers, and especially while penetrating broken formations. The consequences of impact are of course increased in harder materials. Impact cutter failure can only be reduced by better bit designs that reduce the severity of impact loading and/or reduce the susceptibility of individual cutters to such loading. This document proposes the design of better bits that substantially reduce or eliminate the occurrence of catastrophic cutter failure from impact loading. The overall bit designs investigated in Phase I do not replace the effort to develop better materials. Thermally better materials are certainly necessary, but better bit designs are also necessary if these materials are to be effective in the field.

In Phase I, two bit designs were evaluated. The first is an all-drag-cutter bit with an overall geometry that will eliminate bit whirl, and with cutter orientations that should dampen longitudinal motions and resist longitudinal impact. The second is a hybrid design that combines roller (disc) cutters with drag cutters. It should retain the hard rock performance advantages of disc cutters while affording complete protection to the drag cutters. Both designs make optimum use of moderate pressure, locally directed water jets (or mud). 


\subsubsection{Description of the Concepts}

The analytical basis for a Conical PDC Bit and a Hybrid Tricone Bit is discussed in the following sections.

\subsubsection{Conical, Skewed Cutter PDC Bit}

The first improved bit design concept is illustrated in Figure 1. The wedge-like shape and skewed, self-advancing cutter action proved beneficial in the Rapidex Conical Reamer. The Rapidex reamer was a roller cutter "hole opener" that displayed smooth operation with high advance rates and with long life. The conical design cannot be extended to the center of the hole in a completely roller cutter bit design, but PDC cutters afford an opportunity to come very close to a completely conical drag cutter bit design. The expected advantages of such a design include:

- Smooth running, shock reduction.

- Rugged geometry, shock resistant.

- High penetration rate.

- Long life.

- Better flushing.

- Substantially reduced thrust requirement.

Most of the advantages of this concept follow from a simple geometric argument: the conic surface provides more space for cutting structure and bit flushing than does a conventional flat or nearly flat - bottomed design. The hole bottom area for a flat bottom is $\pi \mathrm{D}^{2} / 4$, where $\mathrm{D}$ is the hole diameter. The area for a (completely) conical bottom is $\pi \mathrm{D}^{2} / 4 \sin \alpha$, where $\alpha$ is the cone half-angle (Figure 1). For example, the 15 deg half-angle illustrated would provide about 3.9 times the surface area and, theoretically, for equal individual cutter actions, about 3.9 times the advance per revolution. Unfortunately, except for some slight increase in drilling efficiency (decrease in specific energy) this would also require about 3.9 times the torque as well.

The conic surface PDC cutters are skewed slightly, somewhat like the blade of a snowplow, to produce a downward force component, $\mathrm{F}_{\mathrm{s}}$, as illustrated in Figure 2. Other forces acting on the cutter include a normal force, $F_{n}$, necessary to engage and penetrate the rock, and a tangential force, $F_{t}$, which must be overcome to rotate the bit and excavate the rock. If the downward component of $F_{s}$, $\left(F_{S}\right.$ is tangential to the conic surface) equals or exceeds the upward component of $F_{n}$, the conic portion of the bit is self-advancing. That is:

$F_{s} \cos \alpha \geq F_{n} \sin \alpha$

or

$$
F_{s} / F_{n} \geq \tan \alpha
$$




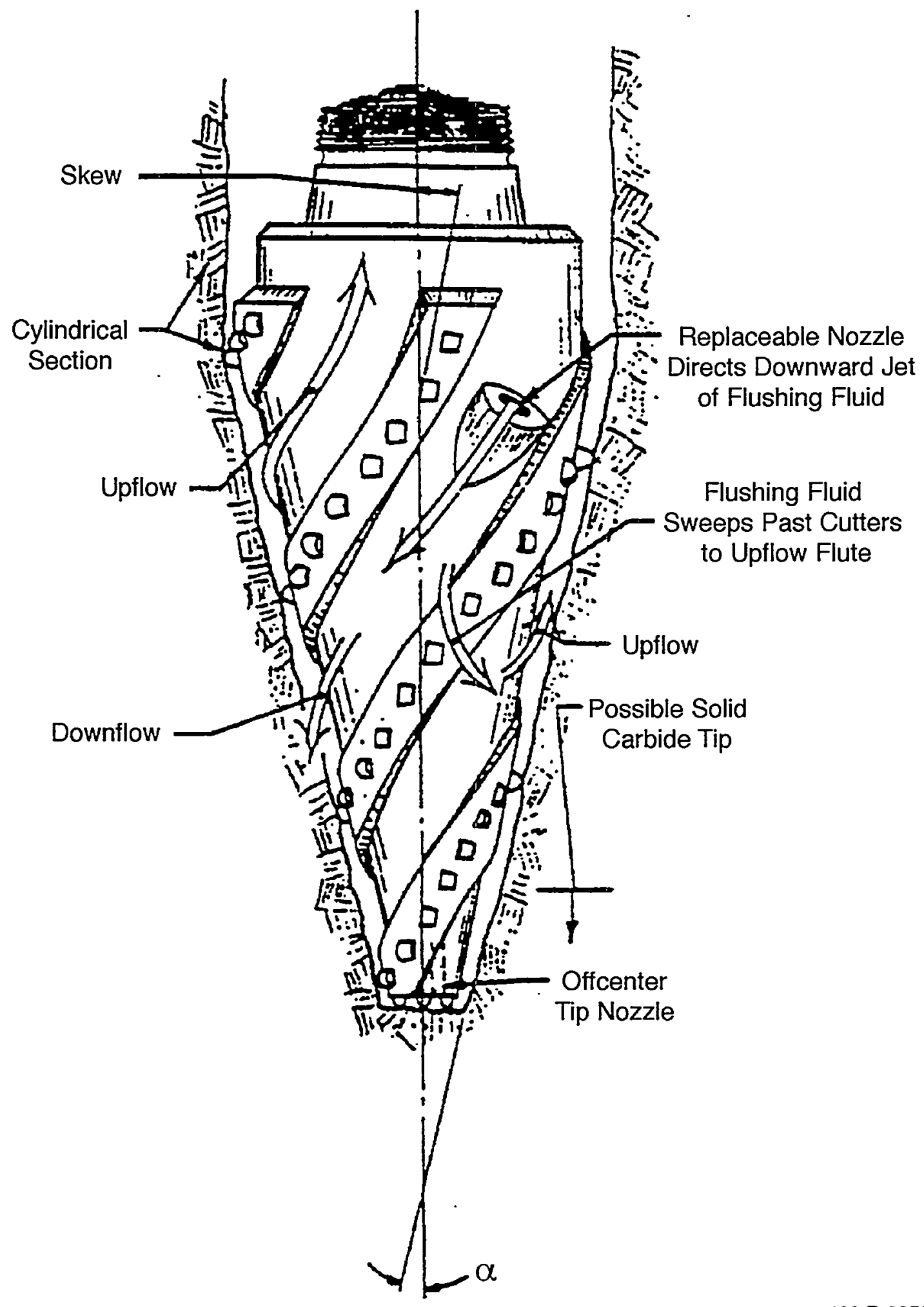

428-P-98586-1

Figure 1. Conical, skewed cutter PDC bit 

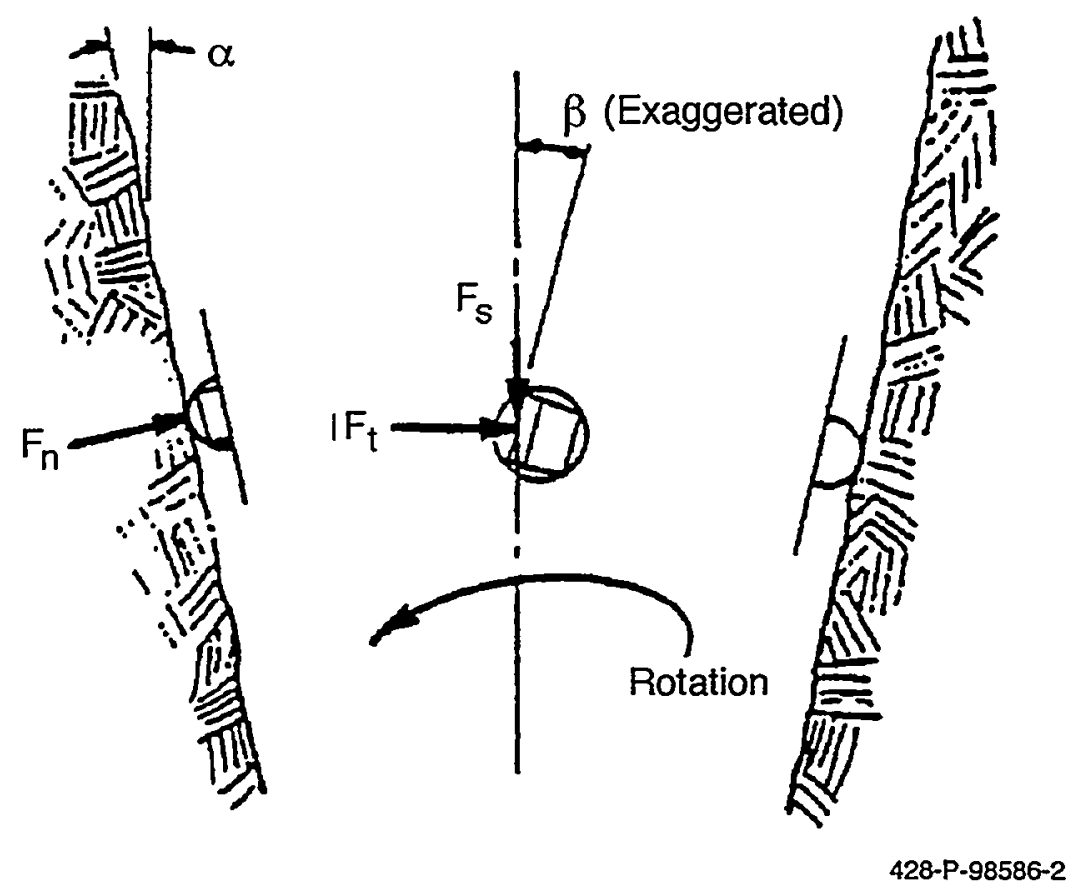

Figure 2. Skewed cutter forces

In general, $F_{s} / F_{n}$ can be expected to increase with skew angle $b$. Self-advancement for a complete bit would require that skewed cutters develop enough excess axial force to drive the bit tip forward, but that is an unnecessary (and perhaps unlikely) design goal for a practical bit. However, the downward force component when engaged with the rock would tend to maintain engagement and resist or dampen axial oscillations of the system. This behavior was markedly present with Rapidex Conical Reamers, even when relatively small reamers were used directly behind a large, undamped, flat-bottomed, tri-cone bit in very hard and broken rock (taconite).

With effective radial wedging of the conical device, major bit oscillation will be limited to axial excursions - damped, but probably not eliminated. For those cutters on the conical bit surface, impact loading from such motion would occur in the vertical direction, tangential to the cutting edge and a direction in which a circular profile cutter should be quite strong. The tip cutters will of course directly experience axial motion, but the other cutters distributed over the conical surface are extremely "dull" in the axial direction and will limit excessive axial penetration of the tip cutters. Penetration limiting pads, discussed in the following paragraph, will also limit axial penetration. These features are the rugged geometry that provides shock resistance, an advantage over and above shock reduction.

Very low or zero thrust requirement would actually result in extreme sensitivity to small variations in thrust or in rock properties, and to unacceptably unsteady operation. This can be overcome by providing blunt, penetration-limiting pads, which ride on the conic rock surface to 
limit cutter penetration (much like the rakers between teeth on a chain saw). These pads, not illustrated in Figure 1, also provide another means to minimize or avoid axial bit oscillations. If the bit is overloaded with weight on bit, the excess load (that above the slight axial load for cutter penetration) will provide a "preload" on the pads acting against the hole bottom.

Disturbances, which might excite axial oscillation, including those from the cutting structure itself, will have no effect whatsoever, unless and until they overcome this "preload." Preload pads were not included in the Phase I design.

The normal force, $F_{n}$, is generally large, but its largest component, that in the radial direction, is "free," as it is balanced by similar components from other cutters on the opposite side. That is the basic idea of the conic geometry: generate the largest portion of the rock penetrating force from the rock itself in opposing, wedging arrangements. In this case, the large, balanced radial loads will eliminate any tendency for bit whirl (again clearly demonstrated by the conical reamer). The axial frictional force associated with this normal force would also resist axial motion of the cutter, even in the absence of cutter skew.

As with any conical or wedge-shaped device, the real problems arise at the tip where practical design does not permit continuation to a sharp point, but in this case there are several mitigating features to overcome these problems. All cutting elements on the bit must advance by the same axial distance with each revolution of the bit. As seen in Figure 3, this might force the forward-facing nose cutters to penetrate more deeply (normal to the local surface) than those on the conic surface. If the bit is driven so that the conic surface cutters penetrated normal to the

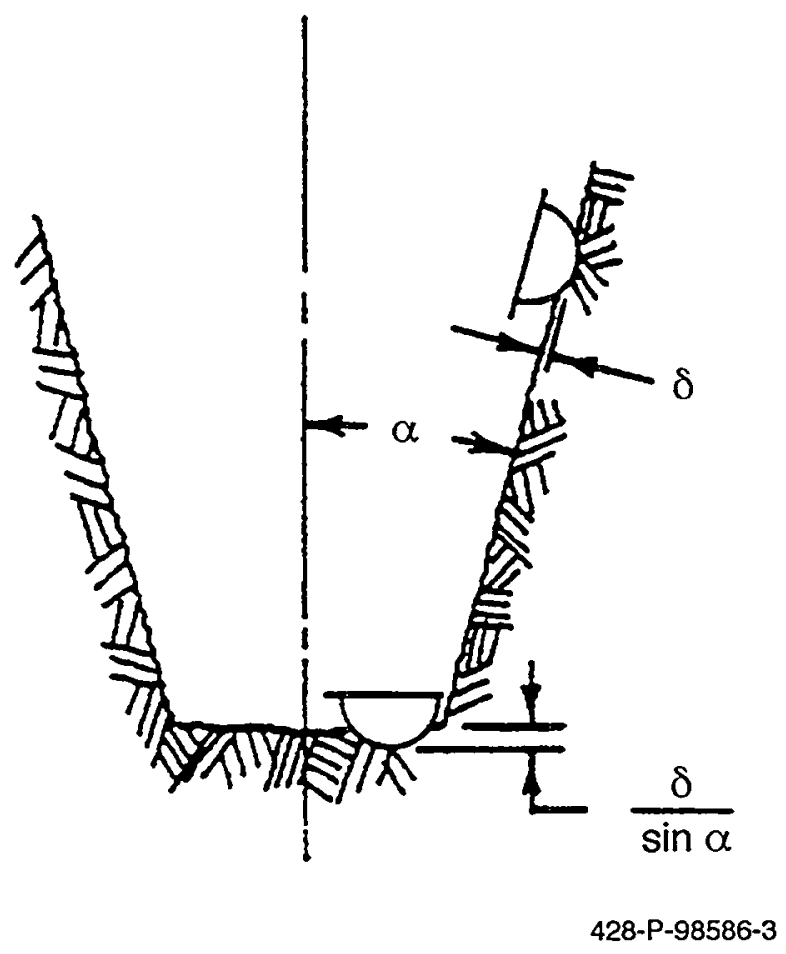

Figure 3. Advance rate geometry 
local surface, a dimension selected to optimize cutting action and/or life there, then a cutter at the nose must penetrate $\delta / \sin \alpha$, which may be too deep. This can be corrected by providing $1 / \sin \alpha$ times as many teeth per track at the nose. For example, for the rather extreme (i.e., narrow) 15 deg half-angle of Figure 1, a single tooth per track on the conic surface can be balanced by four teeth per track at the nose $(1 / \sin 15 \mathrm{deg}=3.9)$. As noted, this would permit 3.9 times the conventional advance rate (at the same rpm) without overloading the teeth, provided 3.9 times the torque was available.

Four teeth per track at the nose radius shown seems reasonable, but closer to the center there would not be enough space. That region would be recessed, like the "doughnut" shape of many conventional bits, such that the central rock element protrudes as a weakened pillar and is relatively easily cut or broken. Note also that all of the nose teeth travel at very low velocities relative to those at the outer diameter. This would mitigate both temperature problems and the consequences of superimposed dynamic loading.

Finally, the nose teeth can be significantly assisted by localized, moderately high pressure (5000 psi or less) water jets. First discovered by Hood in South Africa, and subsequently explored by others, it is known that such jets impinging just ahead of the cutter can reduce cutting forces by as much as a factor or four or five. The beauty of this design, in terms of exploiting this opportunity, is that the nose cutters to be jet-assisted are few in number and very clearly identified. All other cutters, on the conic surface, are subject to substantially lesser demands (and to a uniform set of demands except for the variation of cutter speed with radial position). This combination of geometric and fluid dynamic features can provide a significant advantage, over and above that already demonstrated by conventional PDC bits.

Further advantages of the enlarged cutting structure surface include a decreased sensitivity to sudden changes in rock properties and improved clearance for flushing. Teeth are mounted on ridges, which spiral to provide smoother running in broken ground. A non-random distribution of flushing flow consists of downflow of fluid in every other channel between ridges, followed by cross flow over and around the teeth, and upflow in intervening channels.

\subsubsection{Hybrid Disc Cutter/PDC Bit Design for Hard and Soft Rock}

The second improved bit design, a hybrid design incorporating disc cutters and PDC cutters, is illustrated schematically in Figure 4. In essence it is a three-cone roller bit with the cones spaced slightly apart, having frame extensions between the rollers which carry PDC cutters and fluid nozzles at their leading edge. Figure 4 is a kind of section view, illustrating one of the three rollers mounted opposite the frame element that extends between the other two rollers.

As can be seen, the roller carries multiple ridges or discs that roll on and penetrate the rock as the bit rotates and advances. (The discs are not independent elements as are those on tunnel borers.) The PDC cutters are mounted above the disc edges in a protected position where they can contact only the tops of rock ridges that may extend between discs. At first glance, this appears to be little more than an obvious way to protect the PDC cutters from impact loads. Indeed, they can be completely protected by simply mounting them high enough to avoid rock 


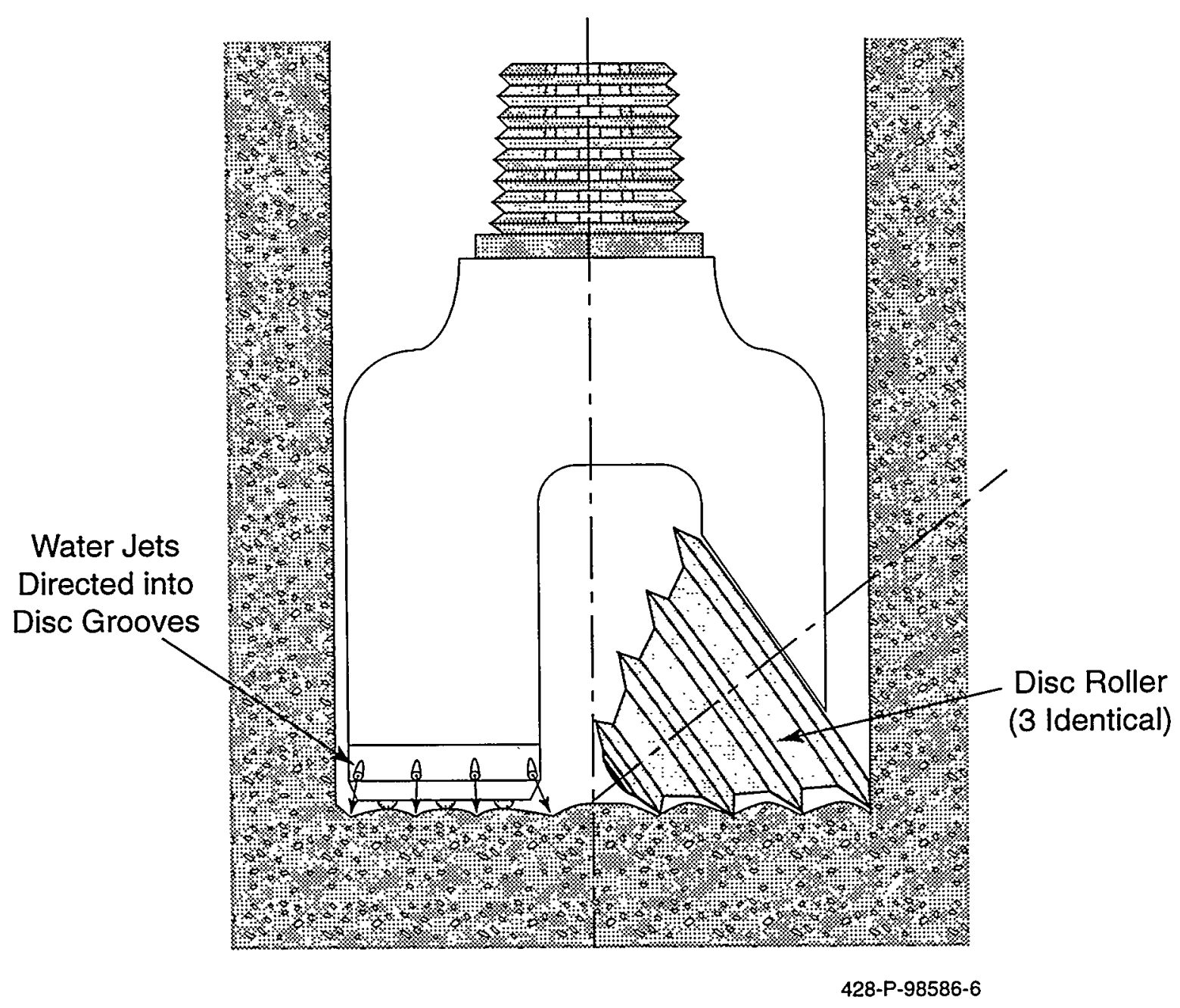

Figure 4. Hybrid disc cutter/PDC bit

contact altogether. But the design is actually a cooperative combination of three prominent advances in modern rock excavation:

- Moderate pressure water jet-assisted mechanical excavation.

- Disc cutters.

- PDC cutting elements.

Of these, the first two have not been properly exploited in bit design, and the third has been unsuited to hard rock. 


\section{Water Jet - Assisted Mechanical Excavation}

First demonstrated by Mike Hood in South Africa, moderate-pressure water jets directed close to the face of drag bit cutters have been shown to reduce cutting and penetrating forces (or increase penetration for a given force) by factors as high as four or five. Similar results have been demonstrated for indentors. The force reduction is believed to result from erosion of crushed material trapped beneath the cutter or indentor. One researcher demonstrated similar benefit from water jets forwardly directed from behind a drag cutter, thus confirming that material under the cutter, rather than that in front of it, is the important issue.

Ideal exploitation of this behavior would require water jets acting through the cutter or indentor. While some pursue this concept, it is at best difficult and probably unreliable (subject to plugging) in a practical bit. It is particularly impractical in a roller bit where indentors (teeth) rotate and make only momentary contact with the rock. Jet impingement near, rather than through, a roller cutter tooth is similarly impractical. An experimentally proven, acceptable approximation to this ideal is to make an indentation in a series of increments, removing the indentor and flushing crushed material from the indentation between increments. This requires that the indentor return to the same location with each increment - that the bit tooth "track" itself. Roller bit designers go to extremes to avoid tracking. Furthermore, indentations randomly distributed over the hole bottom do not lend themselves to flushing by a small number of water jets. Hence the interest in disc cutters.

\section{Disc Cutters}

Disc cutters have been highly successful in tunnel boring machines, where they have largely displaced the toothed roller cutters of early designs. This is particularly true in hard rock applications. A disc cutter is, in fact, nothing more than a large tooth in a geometrically and mechanically convenient form that permits large tooth spacing on a scale appropriate to a large diameter bore. Properly used, as on the flat portion of a tunnel borer face, disc cutters track themselves, traveling repeatedly in the same track and penetrating normal to the flat face. With repeated passes the track is deepened until large fragments are broken free between adjacent tracks. Clearly, this deliberate tracking design is ideally suited to the foregoing incremental penetration with intervening water jet flushing of the indentation. All that is needed for each disc is a single, steady jet mounted to the boring head at the radius of the disc cutter.

Although some interesting "Minidisc" work is underway (under NADET Institute funding) at Excavation Engineering Associates, Inc., the typical independent disc design is ultimately not compatible with relatively small bits. The disc should be small relative to the bore diameter, and small discs with small bearings tend to be fragile. Such discs also suffer excessive scuffing wear when mounted close to the center of the bore.

The "discs" shown in Figure 4 are on a conventional conical roller designed to experience pure rolling contact with the rock surface, thereby avoiding scuffing. Furthermore, the three rollers are identical, with the three discs tracking each other in each groove, water jets are positioned to flush each groove. Thus, each groove experiences three indentation increments and 
three flushing jets per bit rotation. Relatively wide groove spacing with efficient, jet-assisted indentation should result in high efficiency drilling.

The problem with this design, of course, is that rock ridges between the grooves may become tall enough to engage the roller surface between the discs. This can severely resist penetration, and it is very likely to destroy the bit. Similar bit designs have been used for very hard and brittle rocks, but the rollers were not identical. Hole bottom groove spacing was one-third the disc spacing on each roller, thereby assuring the ridges could not encounter the roller body (in brittle materials). However, the design presented here is dependent upon wide groove spacing for efficient drilling, and it must be able to penetrate a wide range of materials; hence, the introduction of PDC cutter.

\section{PDC Cutter}

The PDC cutters in this design are protected from excessive impact loading by their location - high enough to avoid contact with solid, undamaged rock, but low enough to assure no contact between rocks ridges and the roller body. There is even synergy between this design feature and typical rock behavior: the harder the rock and more likely impact damage, the less likely the persistence of strong, undamaged materials standing between grooves; the softer the rock the more likely a rock ridge, but the less likely the impact damage on a PDC cutter.

\section{General Comments}

The foregoing synergy comments are clearly skewed toward superior performance in hard rock. While there is little doubt that satisfactory performance can be achieved in hard, brittle formations, the design problem will be to find a compromise that provides superior performance in a wide range of formations. The significant design variable is the ratio of groove spacing to PDC cutter height above the groove bottom. In very brittle material, the discs can probably suffice on their own, but in softer materials they will not be effective. The PDC cutters must be placed low enough to be active in softer formations where they are very effective, but not so low as to be destroyed by hard rock. At worst, PDC penetration will not exceed one-third the bit advance per revolution, so this should provide significant protection. For the extreme of plastic rock behavior, as occurs in some formations at great depth, the disc elements and flushing jets will probably be ineffective in excavating material. However, the discs will displace (damaged) materials to the ridges where it can be easily excavated by the PDC cutter.

Frame extensions between rollers will require rollers of smaller than normal diameter. However, lacking tungsten carbide inserts, the roller wall thickness can be reduced somewhat so that bearing and pin size need not be reduced in proportion to roller diameter. Further, effective flushing of crushed materials from the groove bottom should significantly reduce the required weight on bit for a given penetration rate, thus decreasing bearing load. 


\subsubsection{Cost Savings and Technical Advantages}

The cost of drilling geothermal wells will be directly and straightforwardly reduced through the use of the proposed bits. The design objective of the program is to increase the penetration rate through geothermal formations by a factor of two. This will be achieved through use of novel bit design and diamond insert technology. These inserts will not wear significantly, so that an additional objective will be to drill an entire $10,000 \mathrm{ft}$ hole in a single trip. This will only be possible if dynamic loads on the diamond cutters are limited to forestall bit damage as, for example, mounting the cutters in highly survivable configurations, or designing bits that inherently damp unsteady bit motion.

Given a halving of the in-hole drilling time and the elimination of bit repair trips, it is reasonable to assume that we would reduce the overall cost of a hole by 30 percent. Assuming a typical hole costs about $\$ 2.5 \mathrm{MM}$, the projected savings amounts to about $\$ 650 \mathrm{~K}$.

\subsubsection{System Considerations}

The two bit designs evaluated fit in the same functional envelope as those in use today, so that there are minimal system impacts incurred in their use.

The doubling in penetration rate of a rotary bit must, in large part, be achieved by increasing the work done by the bit. If we assume that the drilling RPM is fixed, it will be necessary to roughly double the applied torque (although some increase will be obtained from lower specific energy cutting by PDC cutters). While this doubling is generally within the capabilities of existing rigs and drill steels, serious consideration should be given to enhancing the delivery of torque downhole through the use of high torque mud motors.

It must be noted that some care has to be exercised in high performance bit design to ensure that the torque delivered to the bit is in fact limited - that the bit does not jam in the hole with consequent breakage of the drill string. This is especially important in the case of the proposed conical PDC bit design where the combination of the cone angle, the cutter skew angle and penetration limiting devices (if necessary) must be chosen to ensure that torque is inherently limited by the bit geometry.

\subsection{Phase I Objectives and Accomplishments}

The Phase I effort had five objectives that apply to both bit configurations. These were:

- Analysis of bit designs and quantify key test parameters.

- Design and fabricate a Phase I test Prototype.

- Conduct key feature testing of the Phase I test prototype.

- Define a Phase II design based on Phase I test results.

- Identify potential Phase II commercialization partners. 
These objectives were accomplished in a six task program over a 24 month period. The six program tasks were:

- Task 1 - Analysis of Bit Design.

- Task 2 - Design and Fabricate Test Prototype.

- Task 3 - Key Feature Testing.

- Task 4 - Define Phase II Design.

- Task 5 - Identify Potential Phase II Commercial Partners.

- Task 6 - Management and Reporting.

Each task was geared toward achieving a program objective. Each objective was met for each bit with the exception of testing the Hybrid Roller Bit.

Early in the Phase I program, commercial partners were identified and provided invaluable assistance in designing and fabricating the test bits. Varel International, a world leader in bit manufacturing, provided bit design and manufacturing guidance for the Hybrid Roller Bit. Varel also provided standard bits for baseline testing during Task 3 testing. Dennis Tool Company, an industry leader in the manufacture of PDC cutters and products, provided assistance in cutter selection and PDC bit design. Dennis Tool had to develop techniques for brazing cutters with water orifices onto the bits without plugging the orifices. Dennis Tool also provided the invaluable service of introducing Foster-Miller to Varel International.

The early involvement of Varel and Dennis Tool accelerated the design process allowing Phase II quality prototypes to be designed in this Phase I program. After retipping, the Phase I Conical bit could be used for a field evaluation test. Manufacturing issues delayed the fabrication of the Hybrid Roller Bit and did not prevent the bit's fabrication. Unfortunately, the delay did not allow time to complete the bit and meet the very narrow test window.

Conical bit testing demonstrated rugged bit design that cut rock. The penetration rate did compare well with the standard PDC bit at atmospheric conditions. The Conical Bit's potential for increasing the bit life of a PDC bit could not be evaluated in the short test runs allowed in the laboratory drilling tests. The Conical Bit also demonstrated high torque requirements when compared to the standard PDC bit. The test data was not sufficient to judge the potential for improving the Conical Bit's penetration rate through optimization of the cutting structure. The relatively small nose design for the conical bit, required the drill operator to exercise great deal of care during spudding operations to prevent overstressing the nose cutter. 


\section{PHASE I RESULTS}

The major accomplishments of the Phase I effort were:

- Identification of a Commercializer.

- Designed two Protected PDC test bits.

- Fabricated a Conical Protected PDC test bit.

- Tested a Conical PDC bit.

These are discussed in the following sections.

\subsection{Identification of Commercializer}

Early in the Phase I program, Foster-Miller, Varel International and Dennis Tool Company entered working confidentiality agreements geared toward developing the two drill bits and bringing the bits to market should the designs show promise. Varel International, Inc. is a bit manufacturer from Dallas, TX. Varel offers a full line of bits for the drilling industry and are excited about the prospect of enhancing their product line. Varel offers a line of roller bits and PDC drag bits and is interested in both bit concepts. Dennis Tool Company is a Houston, TX based company that manufactures PDC cutters and diamond products for the drilling industry. Dennis Tool supplies PDC cutters to Varel and is in the bit development as a means of extending their product line.

Varel and Dennis Tool supported Foster-Miller's design and fabrication efforts throughout the program. Varel also supplied the program with two bits (one tricone and one PDC) for the test program. Throughout the program, several design meetings were held at Varel's facilities in Dallas, TX. During these meetings, Varel and Dennis Tool provided valuable input to both bit designs and fabrication options. Later in the program, Varel provided design and fabrication support.

Post program discussions will be held with both Varel International and Dennis Tool to determine the course and content of a Phase II development effort.

\subsection{Bit Development}

Prior to Varel's and Dennis Tool's involvement, Foster-Miller consulted with industry leaders knowledgeable in PDC bit manufacture and design for initial impressions of the two conceptual bits. Both the Conical bit and the hybrid roller bits were deemed feasible for development and testing. Preliminary designs were developed for both bits. 
During the preliminary design effort, two events which ultimately dictated the decision to design and fabricate to full-scale bits occurred. First, Sandia National Laboratory determined that they would be unable to accommodate scaled testing of the conical bit nose configuration. The only option left for evaluating the conical bit was full-scale bit testing at Terra Tek. Second, Veral International and Dennis Tool signed on to support the development program. With Varel's and Dennis Tool's support, Foster-Miller was able to produce bit designs worthy of Phase II prototype designs.

Full designs were completed for both bit concepts. Fabrication for both bits was started but only the conical bit was completed and tested. Manufacturing issues prevented completion of the hybrid-roller bit.

\subsubsection{Analysis and Design}

Both bits underwent several design cycles which included conceptual designs, design reviews, and finally a detailed design effort.

\subsubsection{Conical PDC Test Bit}

The tip of the bit was the controlling feature for determining how well the bit would cut hole. The Phase I effort is intended to investigate the tip geometry with only a short section on the conical bit body. To this end, the conical drag bit concepts all concentrated on the tip geometry. The designs included different cutter-shape geometry and different cutter-layout geometries. The design goal of the different design concepts was to maximize a uniform and symmetrical cutting structure on the tip with consideration given to flushing jets integral to the cutting structure.

Several of the more promising layouts were rapidly prototyped into physical models. The solid models are of novel approaches to maximize the cutter density at the critical tip area of the conical bit. Figure 5 illustrates two embedded cutter configurations. One configuration has six spiral rows of coin shaped cutters. Within each row, the cutters abut each other providing the nose with six continuous lines cutter length along the nose of the bit. The second cutter layout illustrated in Figure 5 has four spiral rows of cutters. Each row has fewer cutters but the cutters are arranged to provide complete cutter coverage for the nose of the bit. Figure 6 illustrates an exposed cutter configuration. The cutters are arranged to provide complete nose coverage and are attached to the bit through right angle posts pressed into the bit. Figure 6 also illustrates the gaps for the water channels and the ridges where the body cutters will be positioned. The conical bit was intended to have flushing jets only near the nose of the bit.

Discussions with Dennis Tool indicated that although the cutters are unique they are easily fabricated. The water orifice through the cutter would require developing brazing techniques that would not plug the water passages. The cutters illustrated in the second configuration of Figure 5 closely resembled Dennis Tools standard cutters. Since in Phase I, Foster-Miller was more interested in defining a cutting structure that will cut hole reasonably well without developing special cutter shapes, we elected to modifying Dennis Tool's standard cutter shapes by adding water jets to the cutters as needed. 


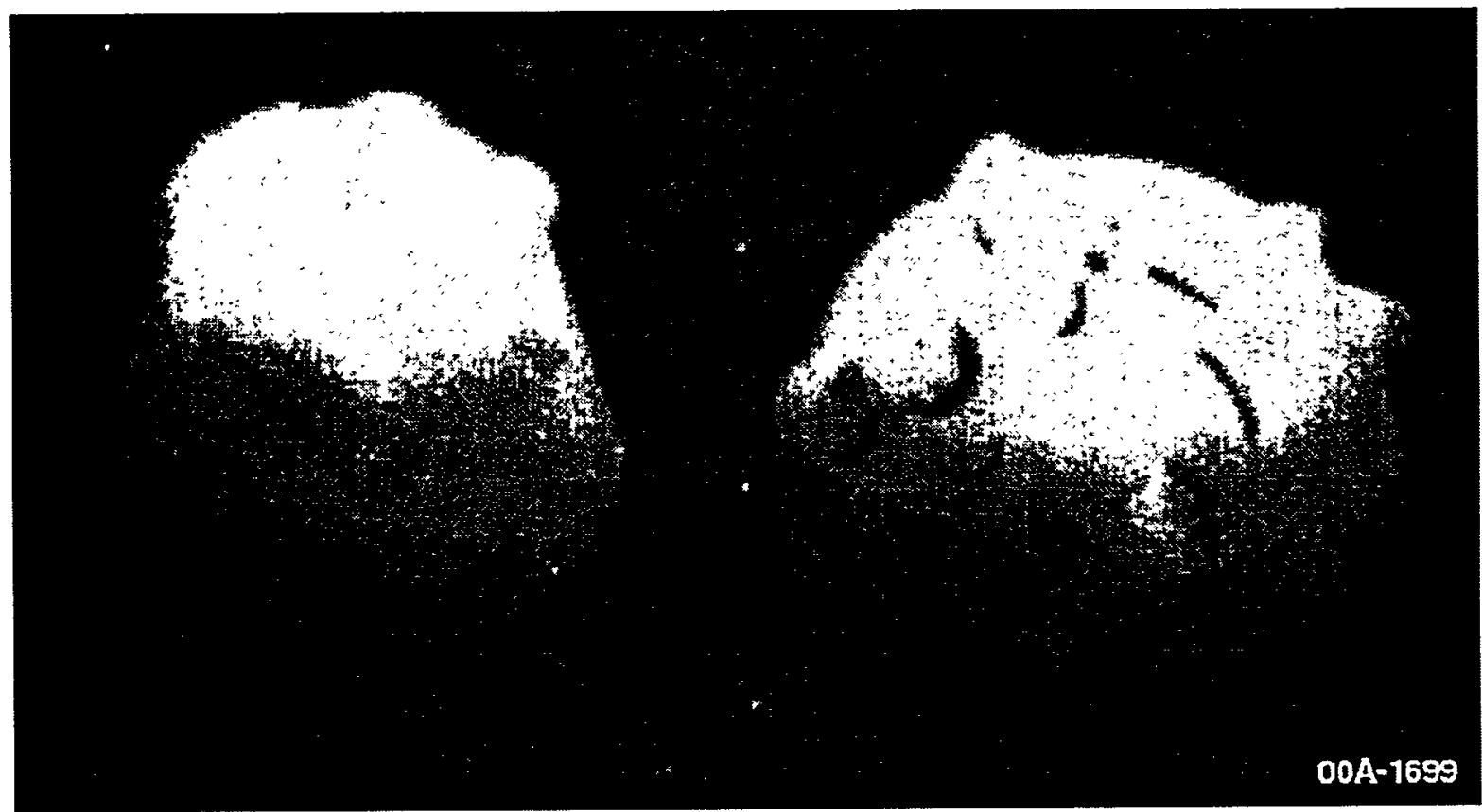

Rapid Prototype Model

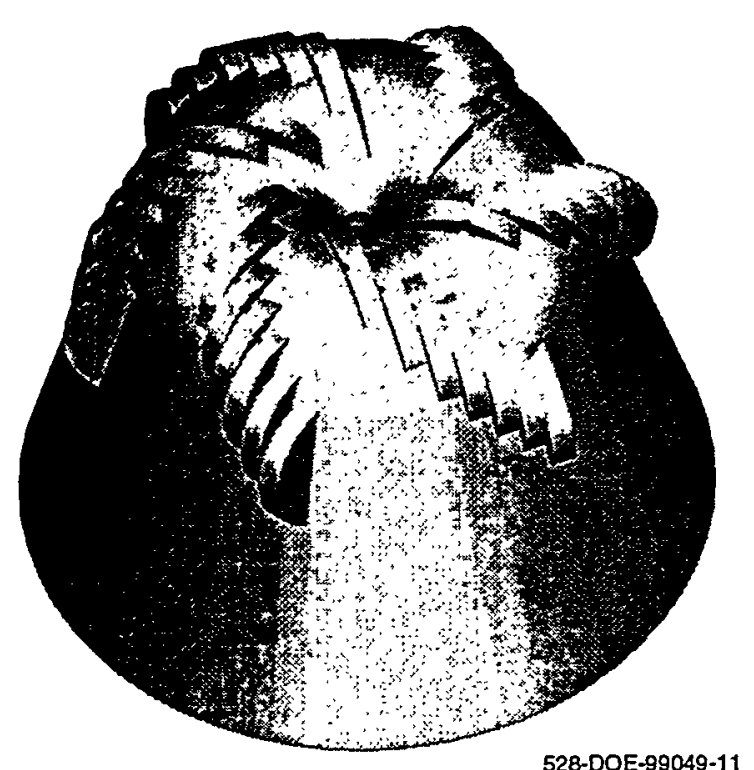

Concept Design (1)
Rapid Prototype Model

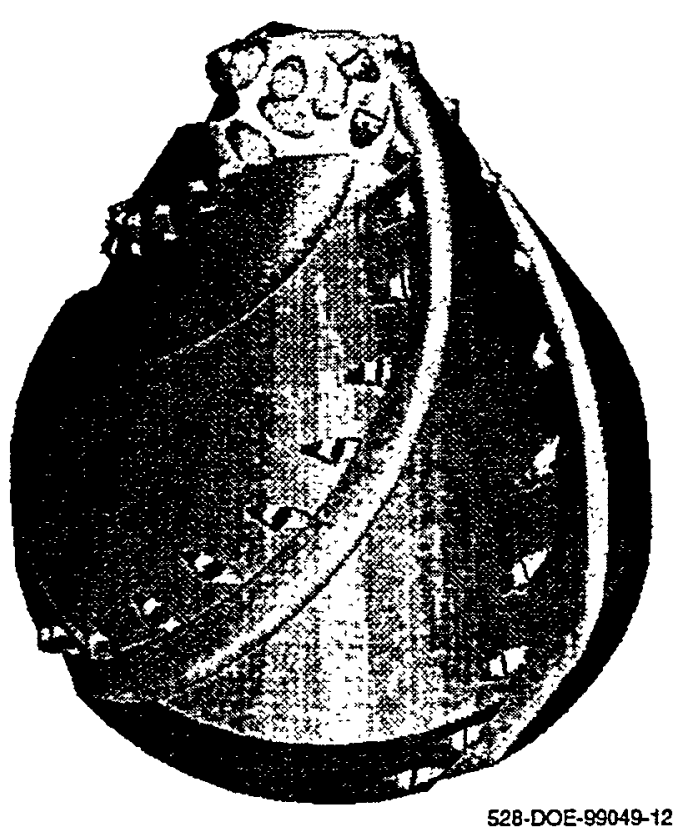

Concept Design (2)

Figure 5. Two embedded cutter configurations 


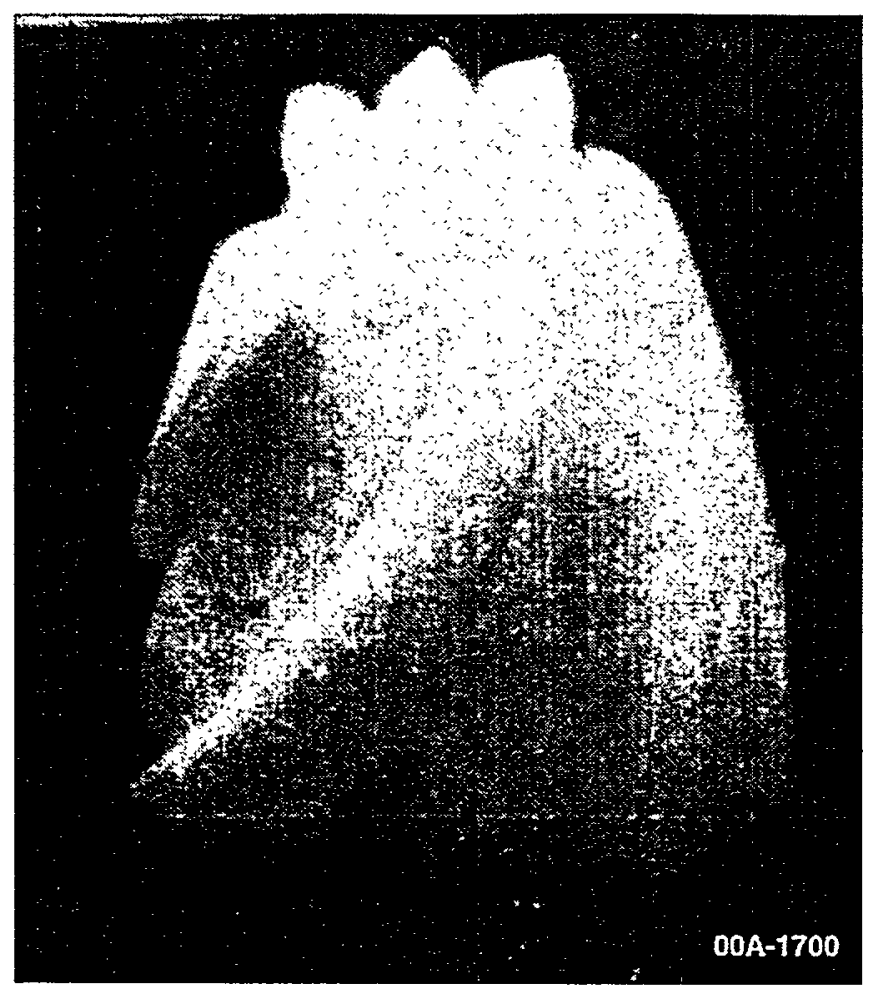

Figure 6. Exposed cutter configuration

The design exercise was then to arrange the standard size cutters onto the conical bits nose while allowing for water jets, flow passages and enough bit to provide the required strength to hold the cutters during drilling.

After several attempts at balancing the different design parameters, a configuration was defined and a rapid prototype model was made of the design. The model illustrated in Figure 7 was used during design reviews with Dennis Tool and Varel International. Suggestions offered during these reviews were incorporated into the final design shown in Figure 8. Drawing on the bit design experience of both Dennis Tool and Varel, Foster-Miller was able to design a Phase II quality bit.

Referring to Figure 8, the conical bit was a 6.25 in. diameter bit fabricated from 4140 steel. The bit illustrated in Figure 8 required that an API threaded sub be welded onto the bit thus providing the threaded connection for the drill string. This operation is common for retipped bits. Figure 9 illustrates the sub (a purchased item) that was threaded and then welded onto the bit. The bit also featured four rows of $8 \mathrm{~mm}$ PDC cutters arranged in a spiral pattern around the bit. A total of 50 cutters populated the bit. The 12 nose cutters were $8 \mathrm{~mm}$ long and featured a $1 / 16$ in. diameter jet hole through the cutter. The 38 body cutters were $13 \mathrm{~mm}$ long and did not have jet holes. After fabrication, additional jet holes were required to provide a water flow rate through the bit of $325 \mathrm{gpm}$ at $3000 \mathrm{psi}$. Four flow channels are provided in the body of the bit. Figure 10 illustrates a typical PDC cutter with a jet hole in the cutter. This design was typical for both bits. 


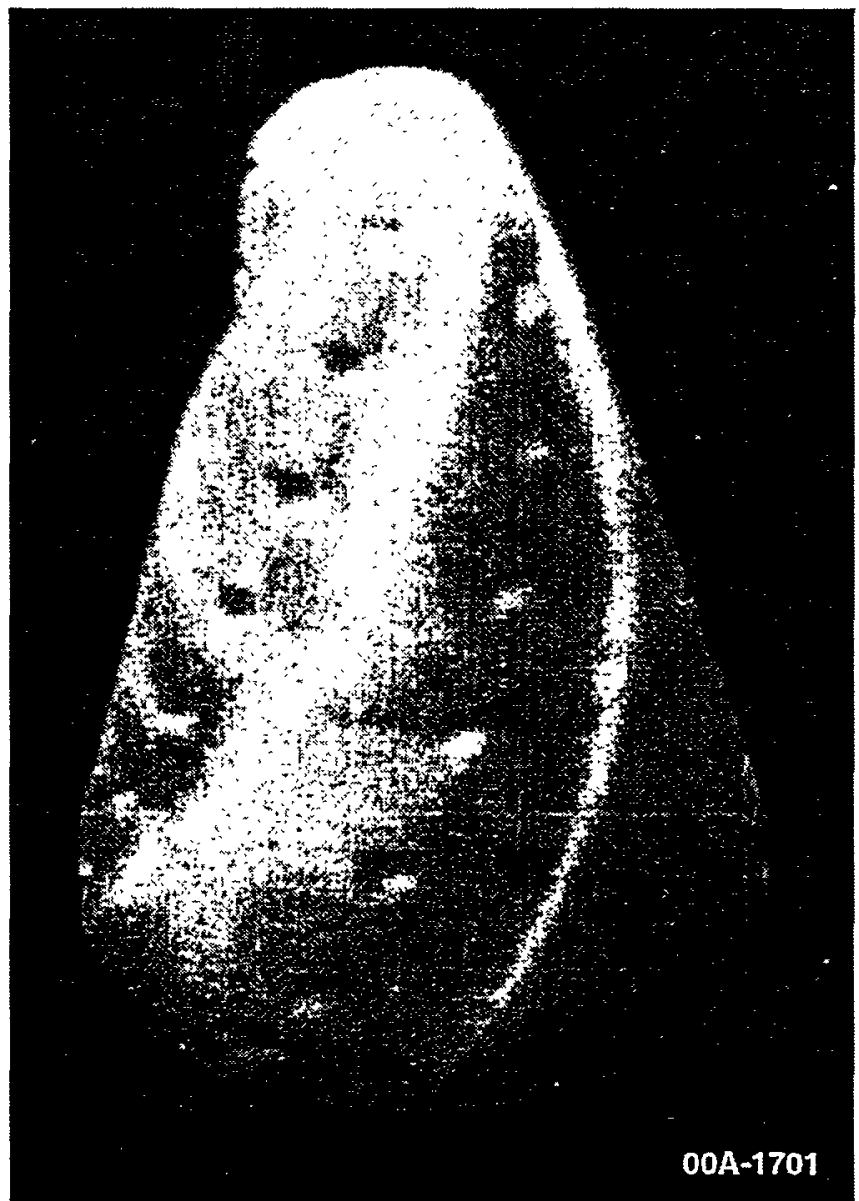

Figure 7. Rapid prototype model of conical drill bit

\subsubsection{Hybrid Roller Cone Bit}

The Hybrid Roller Cone Bit was designed to take advantage of standard tricone design, structure and fabrication by modifying existing tricone bit assemblies. Roller bit concepts were modeled using our Pro-E Cad software. The concepts were presented to Varel International to determine if there were any manufacturing limitations. Through these discussions, it was determined that the bit could be fabricated by modifying tricone bearing leg assemblies as they came off the assembly line and prior to welding. Figure 11 illustrates the Hybrid Roller Cone Concept. The figure illustrates that three standard tricone bearing assemblies are welded to a central leg assembly that holds the 24 PDC cutters. The central leg assembly also supports all the water passages through the bit. The standard tricone cutters are replaced with three disc cutters designed specifically to fit the tricone bearing assemblies. As with the conical bit, the 12 center most cutters have water nozzles in the cutter as illustrated in Figure 10. 


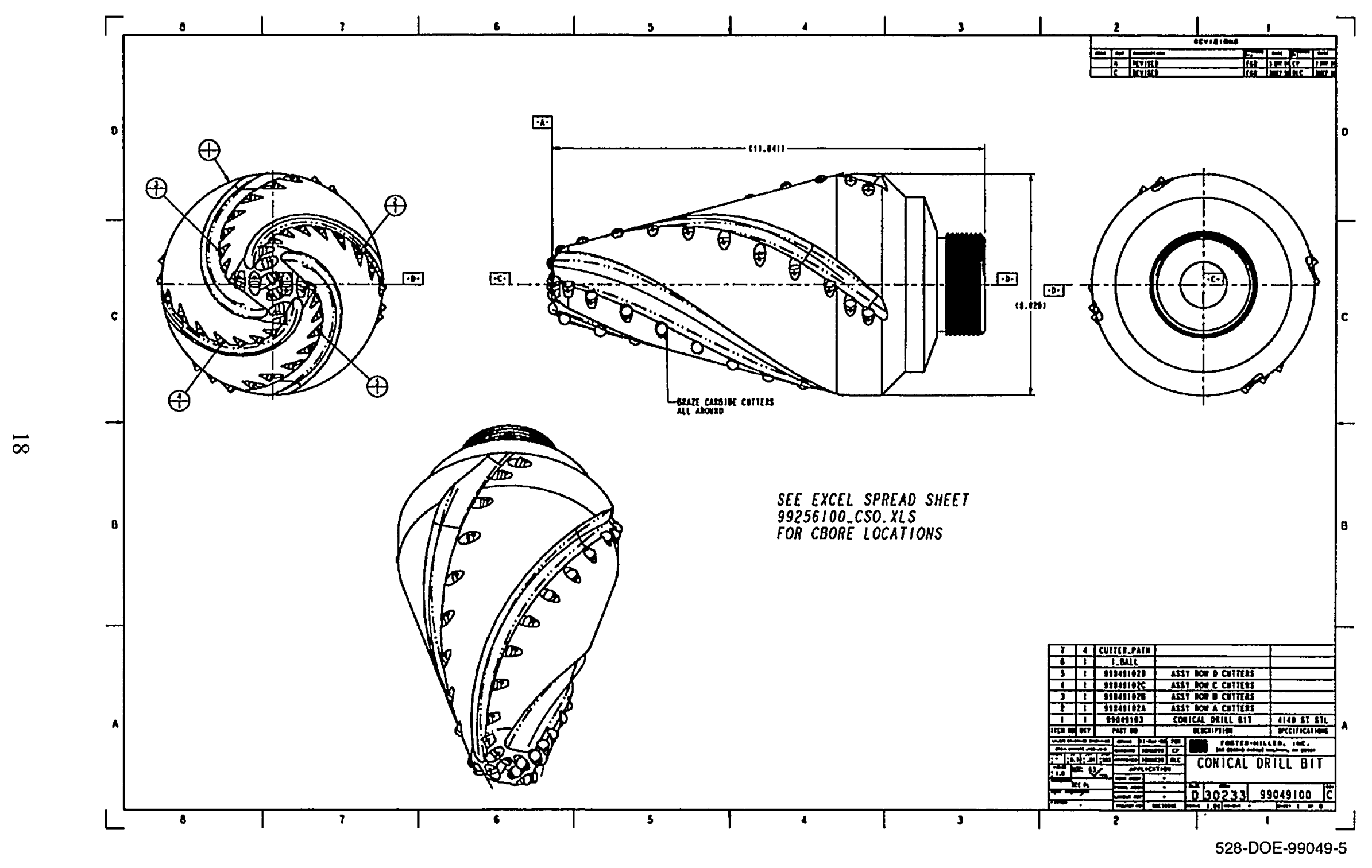

Figure 8. Conical bit design 


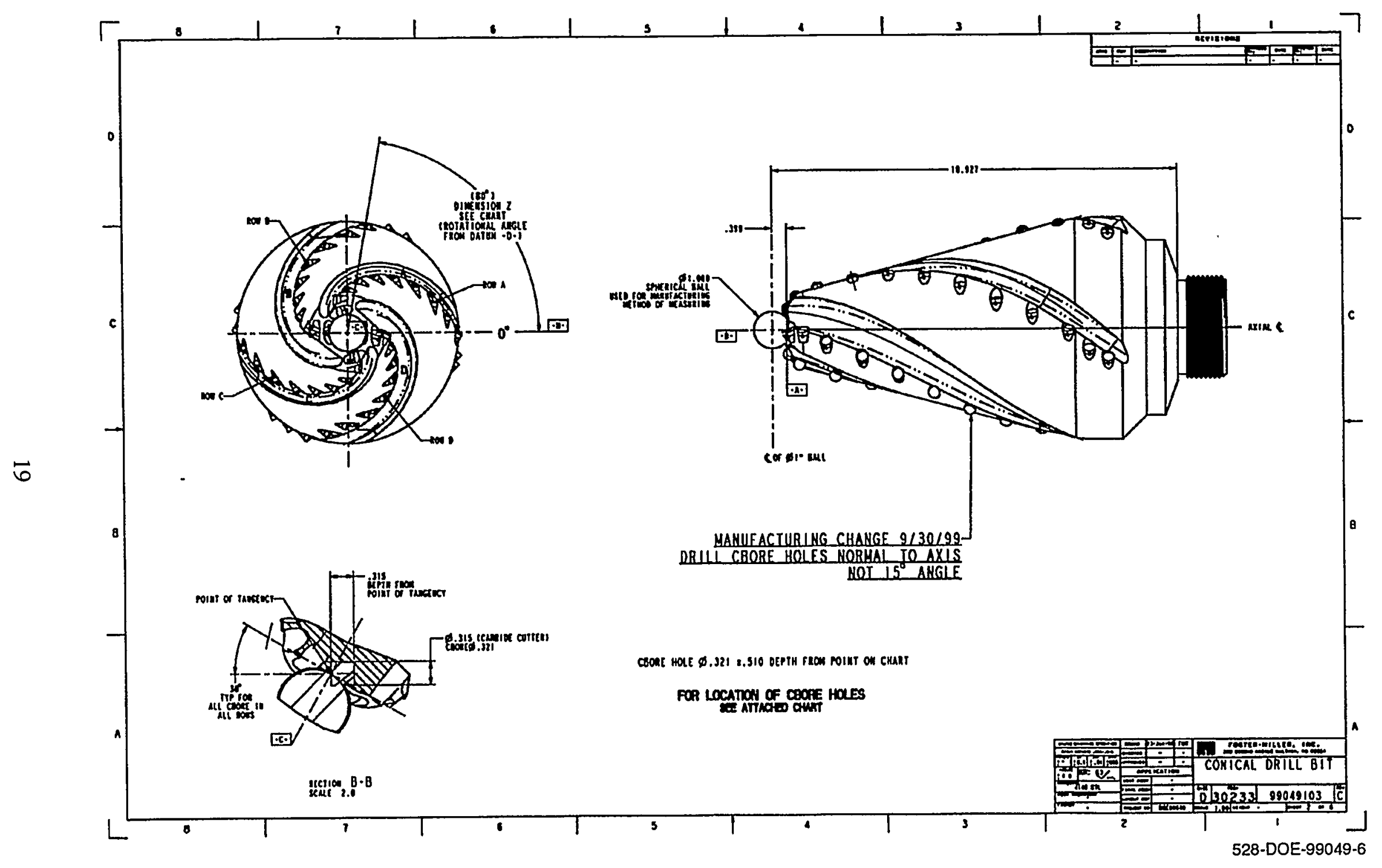

Figure 8. Conical bit design (continued) 


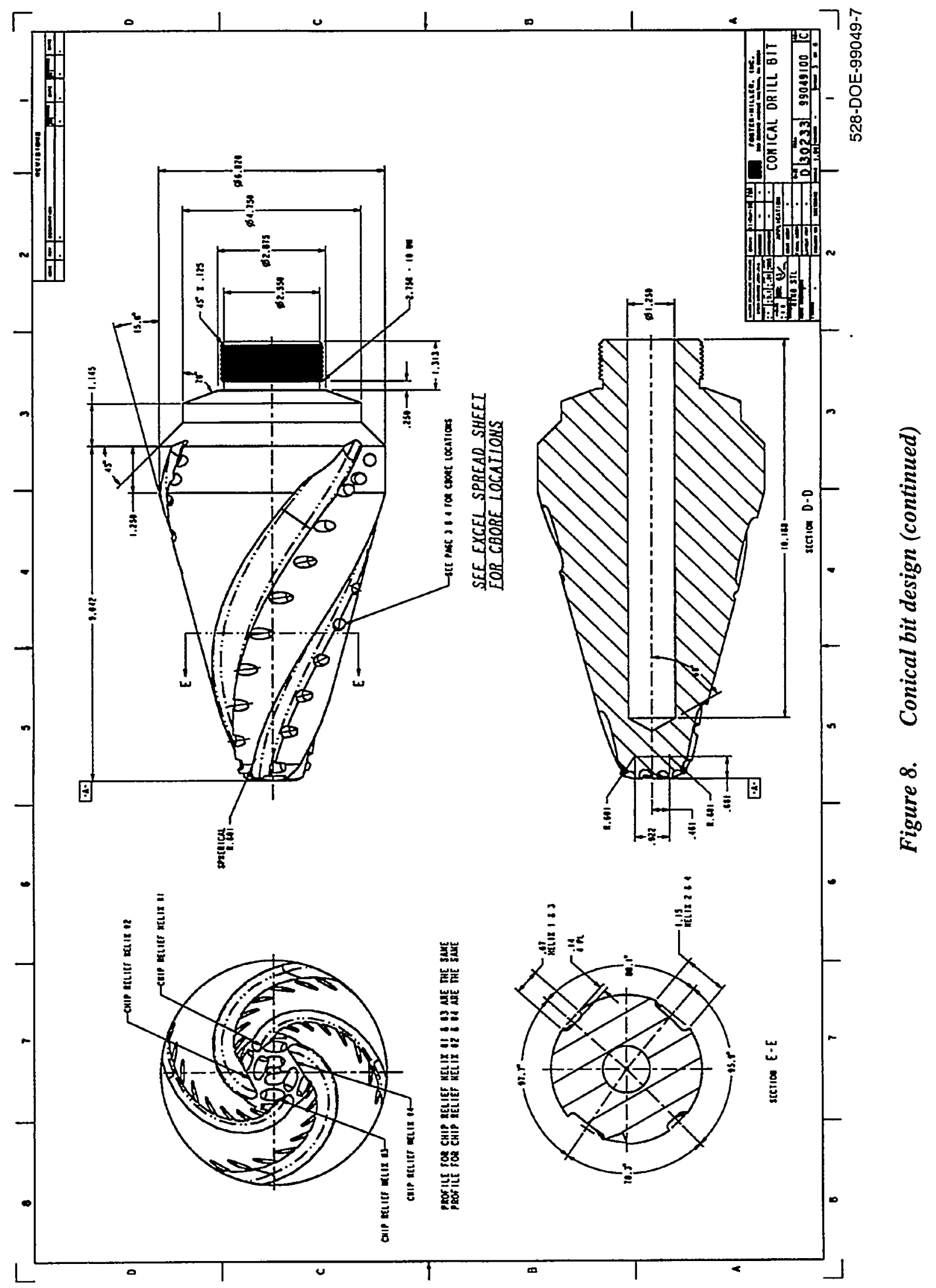




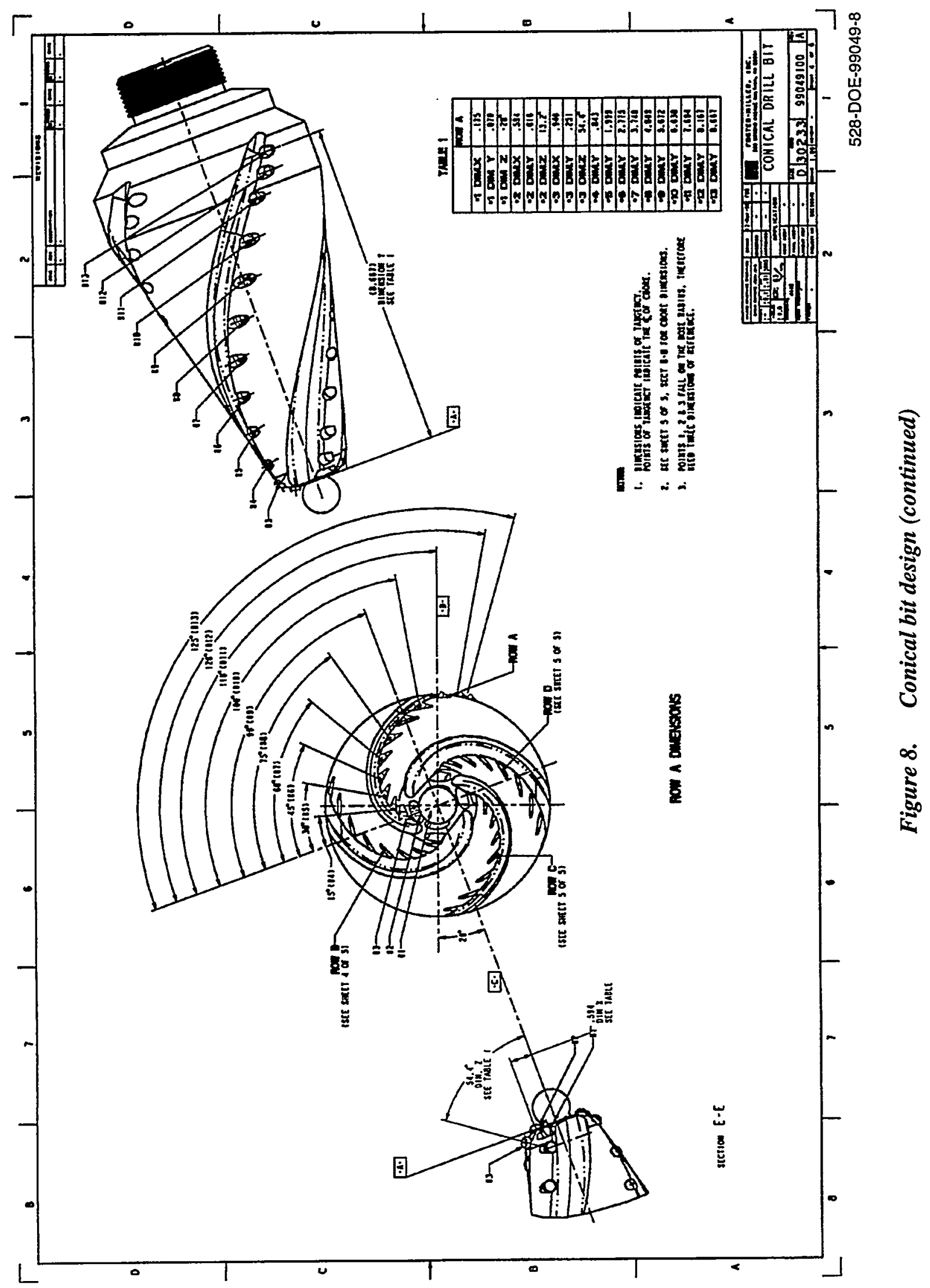




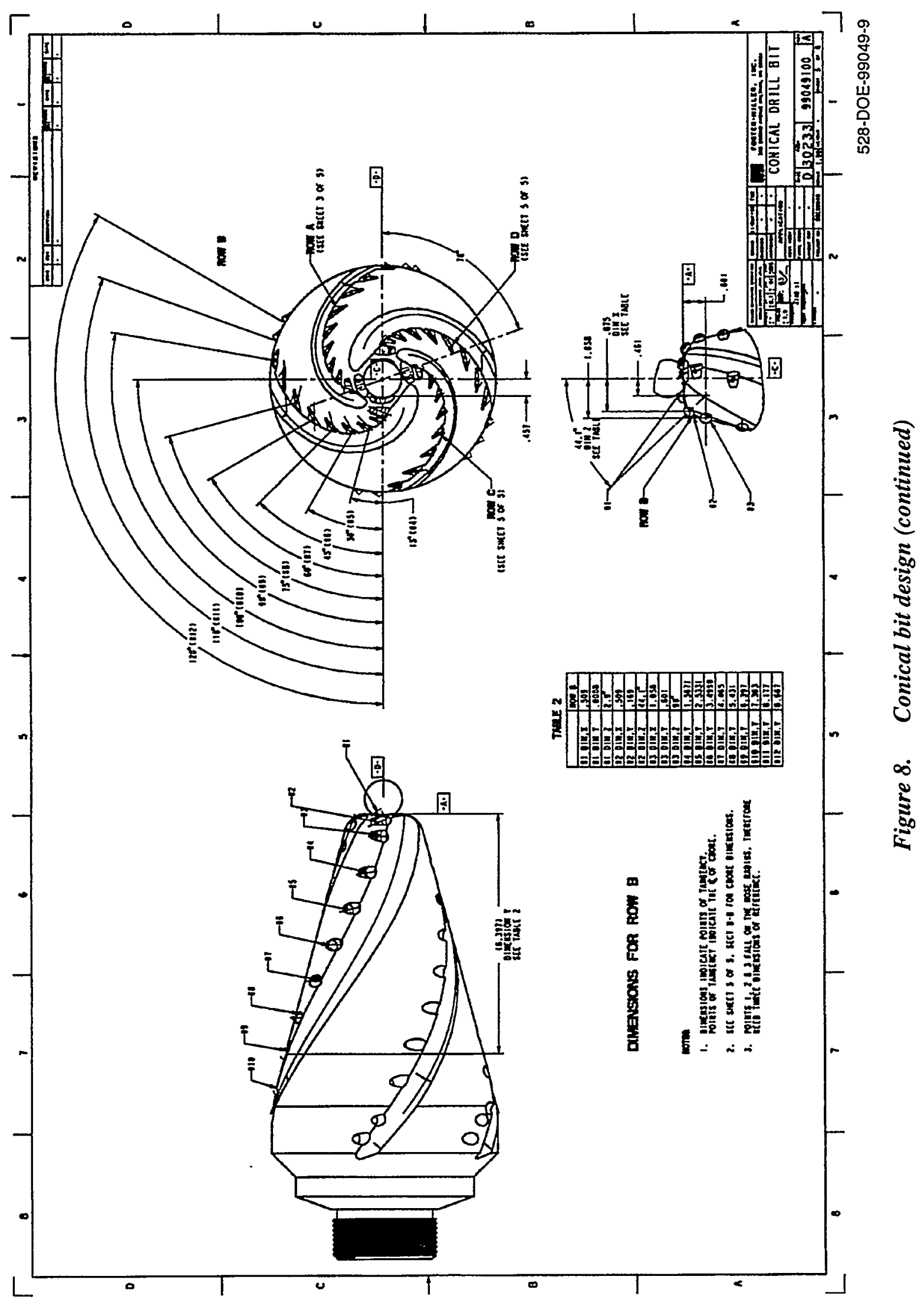




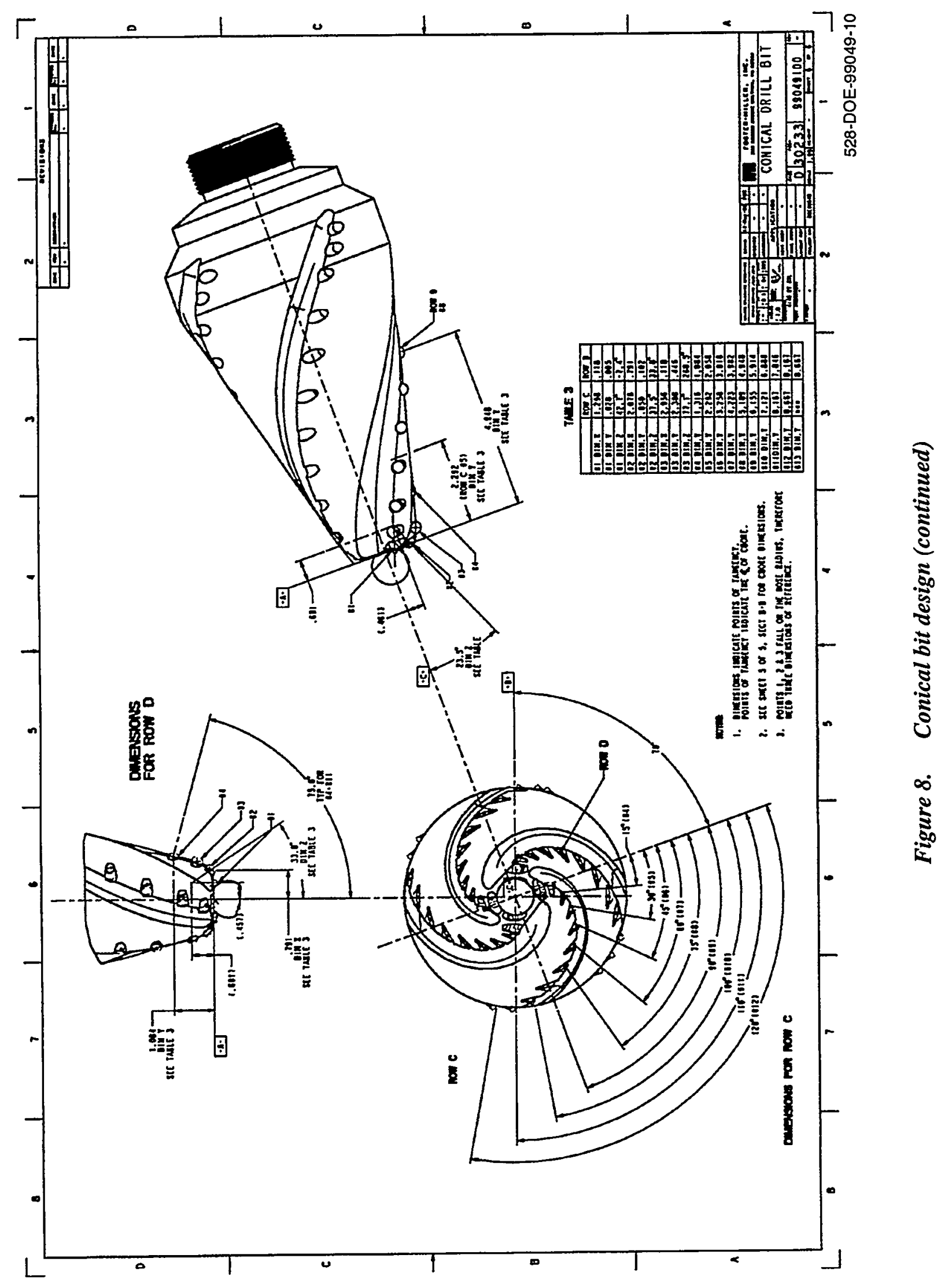




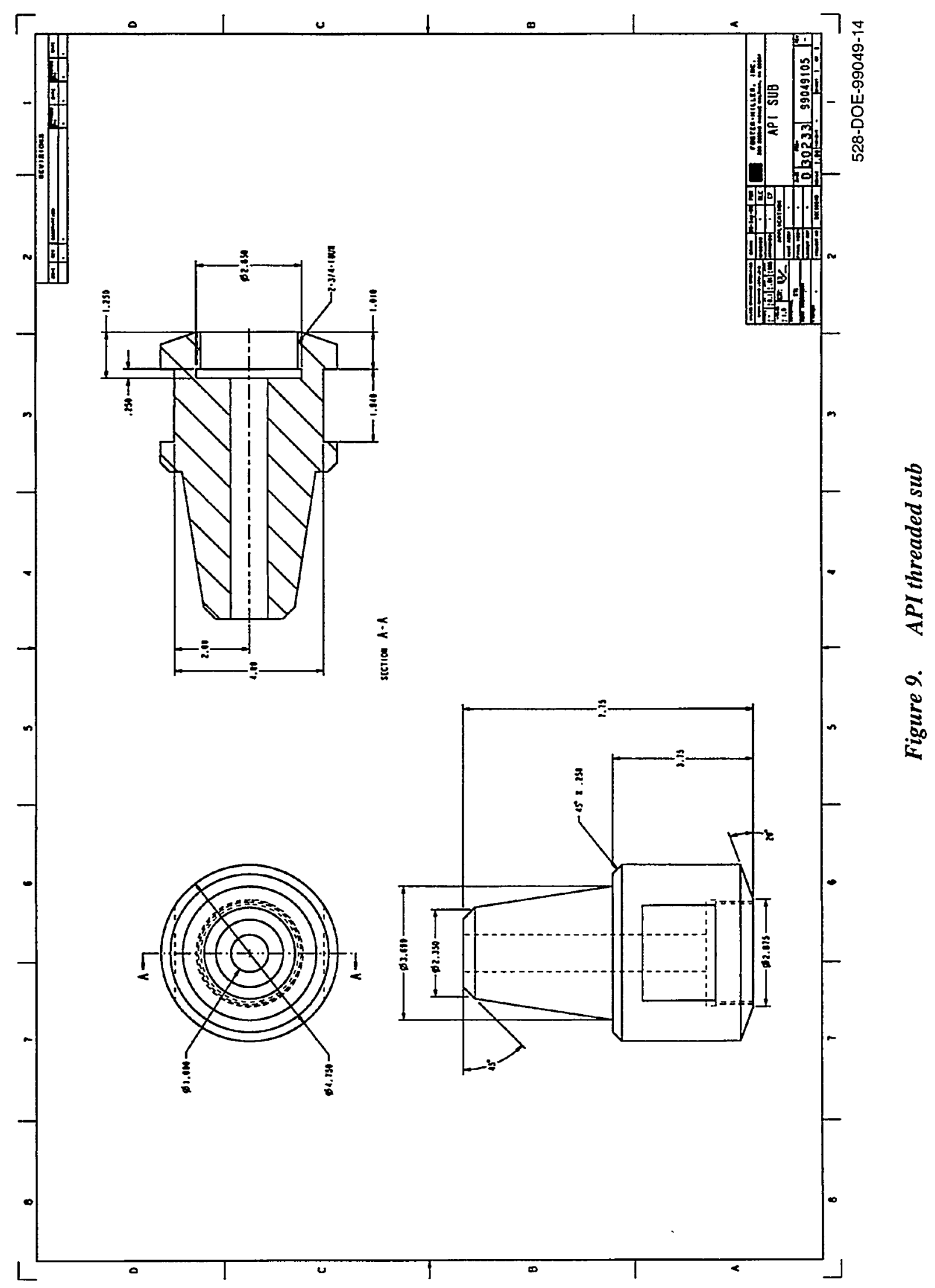




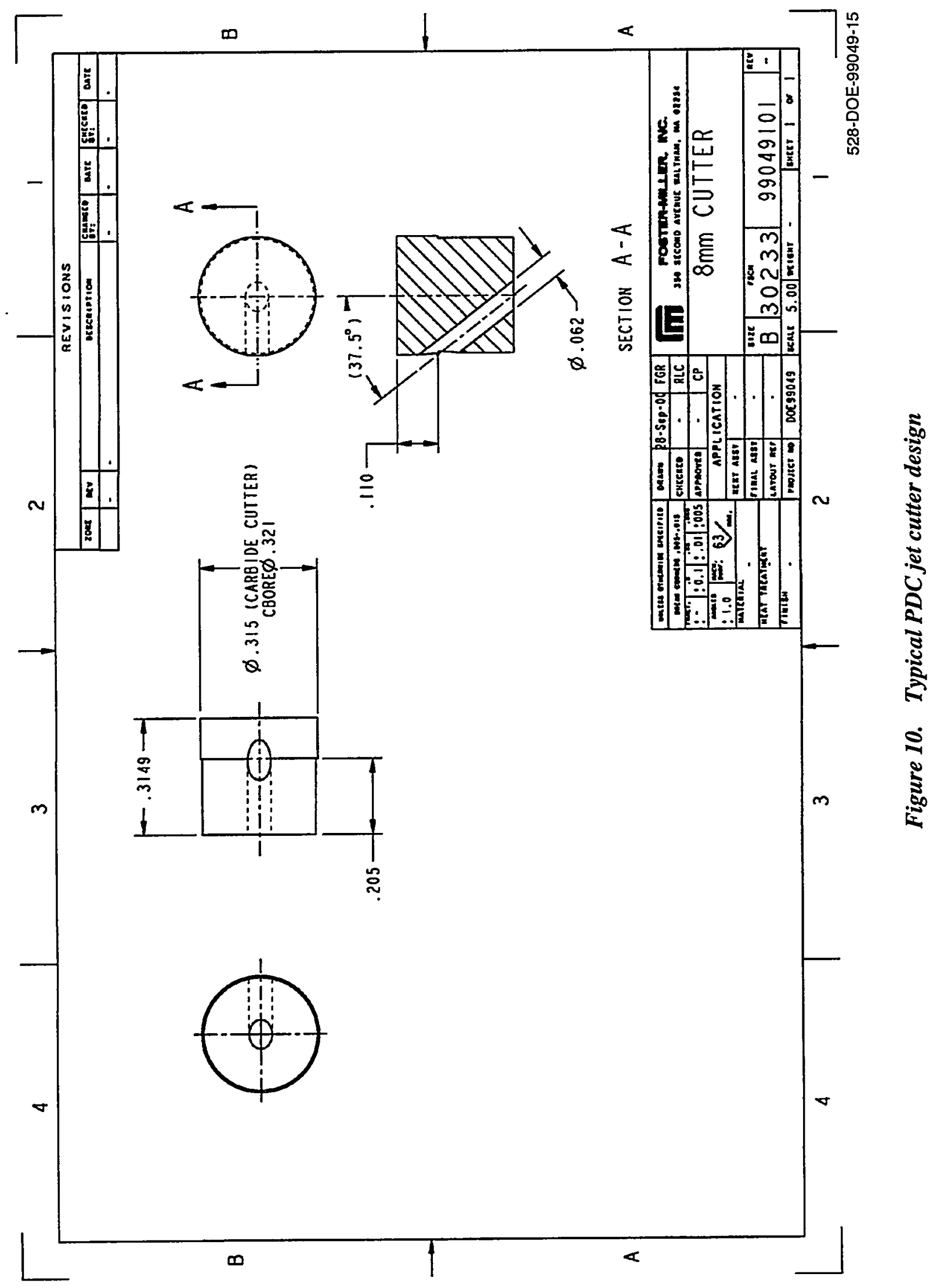




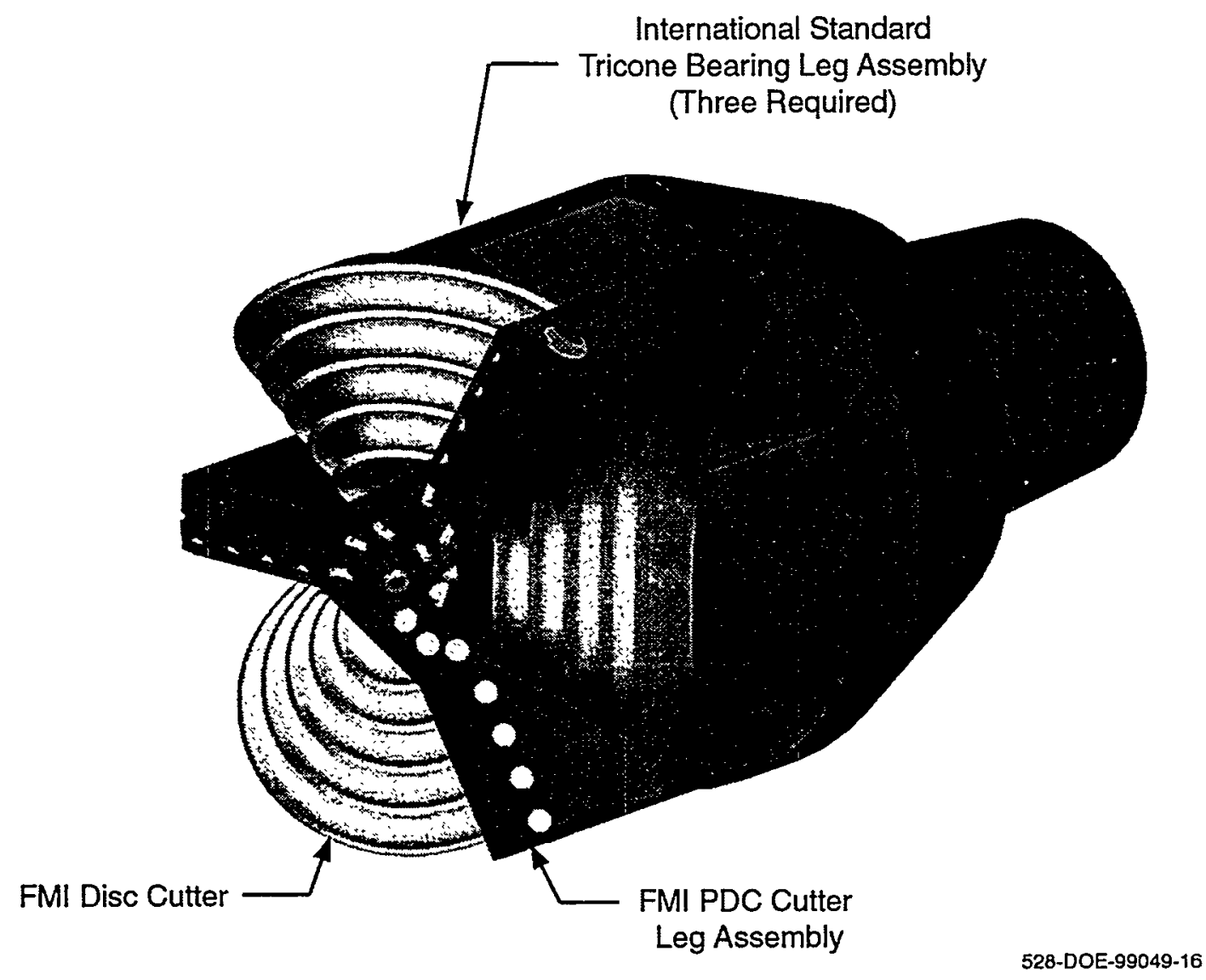

Figure 11. Conceptual design for Foster-Miller PDC hybrid roller cone bit assembly

Several design iterations were required to finalize the details of the interfacing, fabricating and manufacturing the bit assembly. The efforts had to be coordinated between Foster-Miller, Varel and Dennis Tool. The hybrid bit design was a team effort. Once Foster-Miller defined the conceptual design, Foster-Miller completed the detailed design of the central leg assembly and the disc cutters. Varel detailed the design changes to their bearing leg assemblies and Dennis Tool detailed cutter design. Figures 12,13 and 14 are design sketches of the Hybrid bit assembly.

Figure 12 illustrates that the individual bearing leg casting are machined to nest around the central leg and are then welded together to form the 7.875 in. diameter bit. These welding procedures are standard operations in bit fabrication. The central leg has four fluid passages, all of which are fed from the center cavity formed by the tricone bit legs (see Figure 13).

Figure 13 illustrates a section through a single bearing leg and bearing. The disc cutter is illustrated on the bearing and shows the flat bottom form to be the shape of the disc cutters. Immediately behind the disc cutter are the PDC cutters tracking in the roots of the disc cutter. The PDC cutters are supported by the central leg, which also houses the water jets. The water 


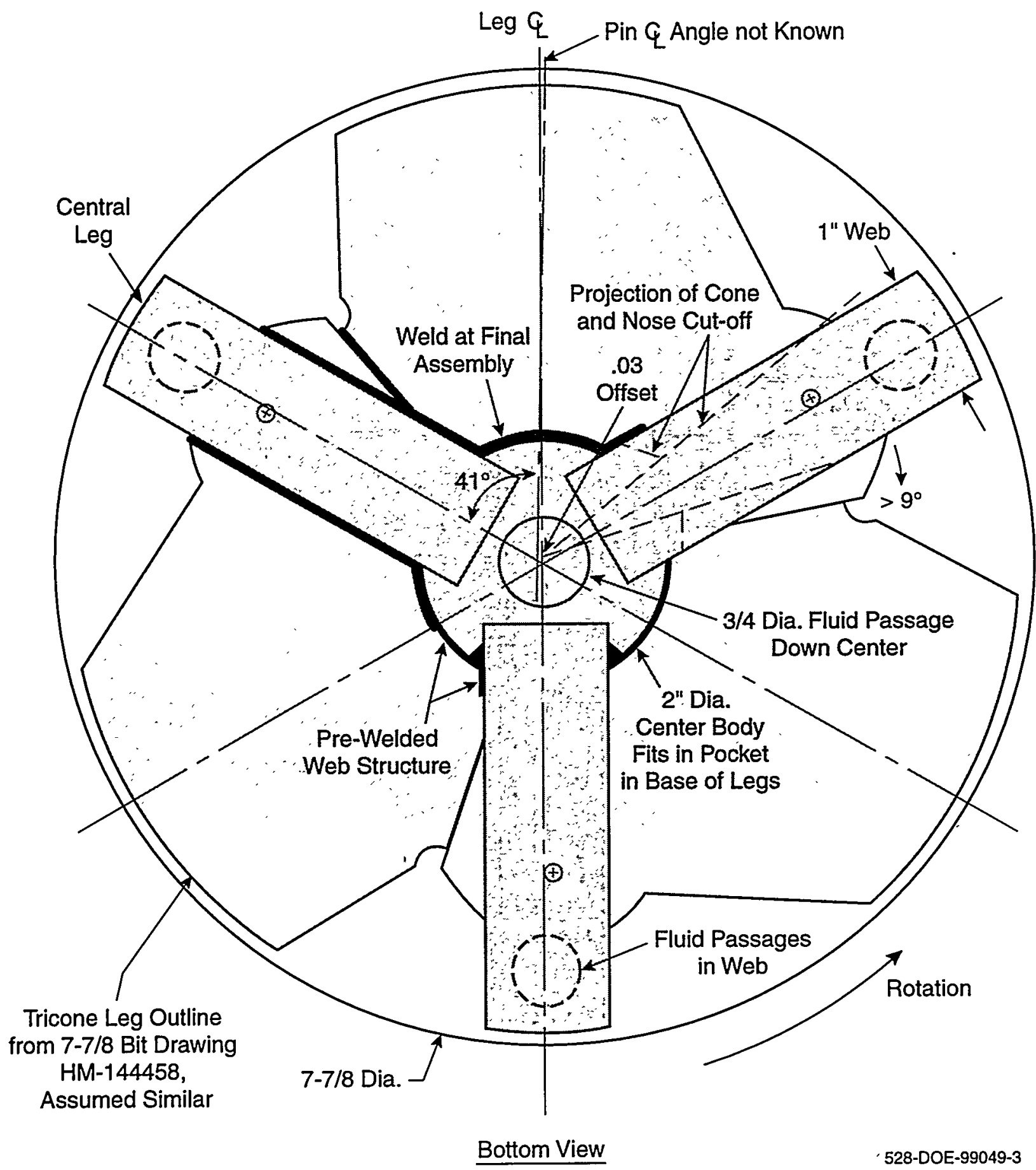

Figure 12. Design sketch of hybrid bit assembly (bottom view) 


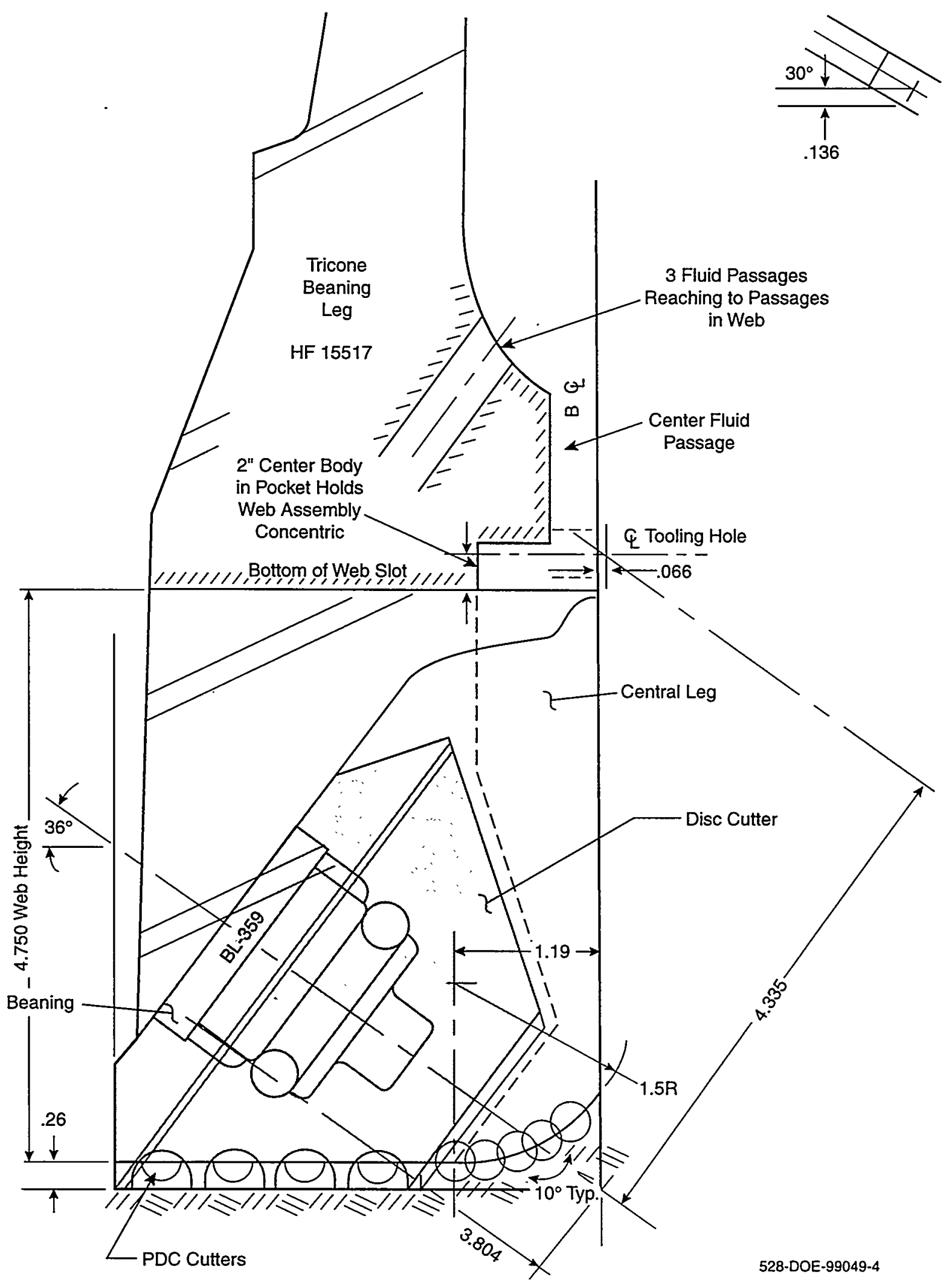

Figure 13. Design sketch of hybrid bit assembly (section through cutter) 


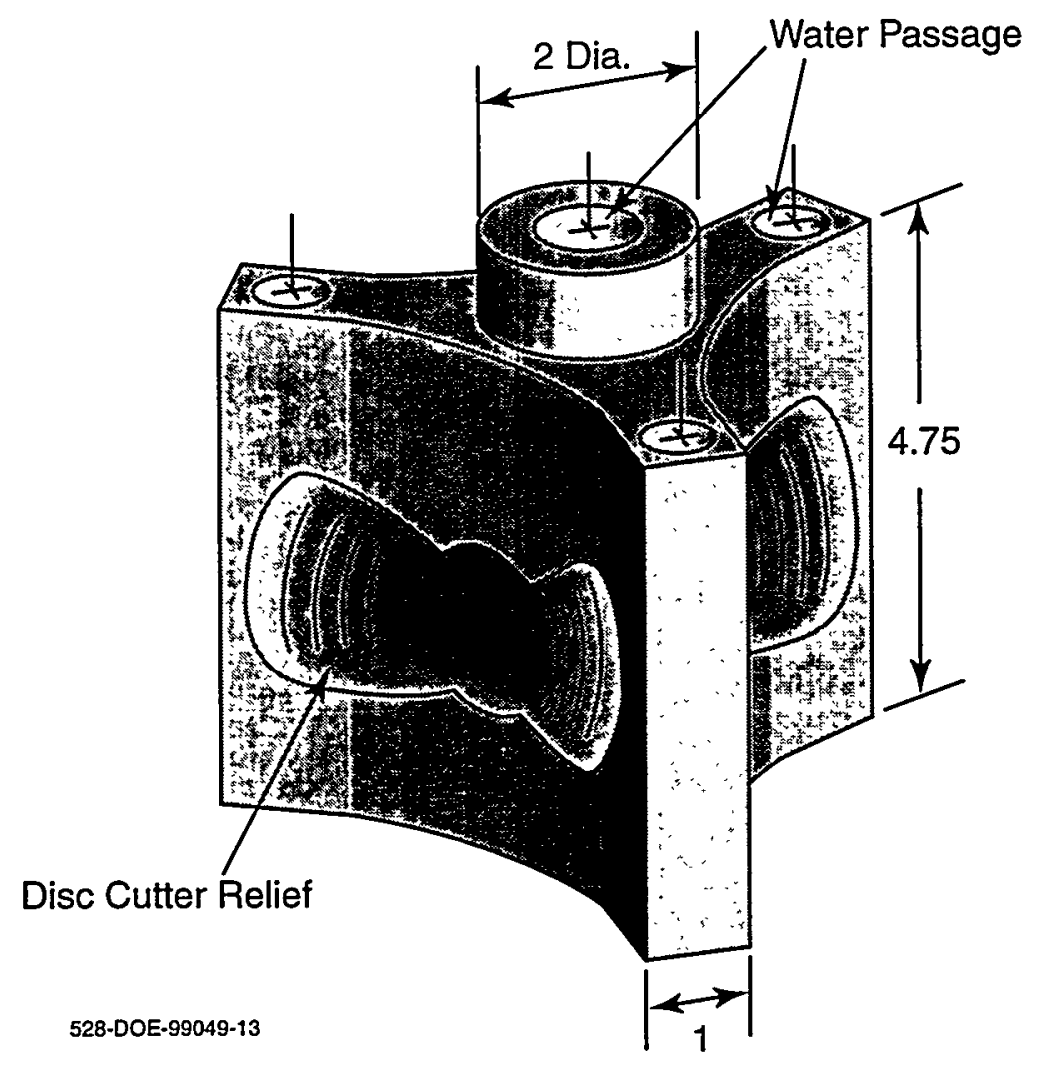

Figure 14. Design sketch of the central leg

jets are directed at the cutter tracks of the disc cutter thus providing flushing of the crushed stone generated by the disc cutter. The disc cutter protrudes into the central leg requiring a pocket to be cut into the central leg. The layout is based on a Varel HF 15517 bearing leg with a BC359 bearing at a $36 \mathrm{deg}$ bearing pin angle.

Figure 14 illustrates the major features of the central leg, which includes four water passages which communicate with the water jets and the cutter relief zones. Figure 15 illustrates the central leg detailed design that was fabricated. The central leg was fabricated from 9315 steel heat treated to Rockwell 40c. Figure 16 illustrates the detailed design of the Disc Cutter whose profile closely mimics a tricone cutter for a Varel bit. The Disc Cutter was fabricated from a 4140 steel. Although Varel supplied drawings to Foster-Miller for defining the leg modification, the actual drawings for the modified parts were produced by Varel and are confidential.

\subsubsection{Fabrication}

The conical bit was fabricated and the hybrid roller bit fabrication was started but was stopped when it became apparent that manufacturing difficulties would delay its completion beyond the available test dates. Dennis Tool was contracted to install PDC cutters on both bits, which included developing a cutter with an integral water nozzle and developing brazing techniques for a cutter with a nozzle. 


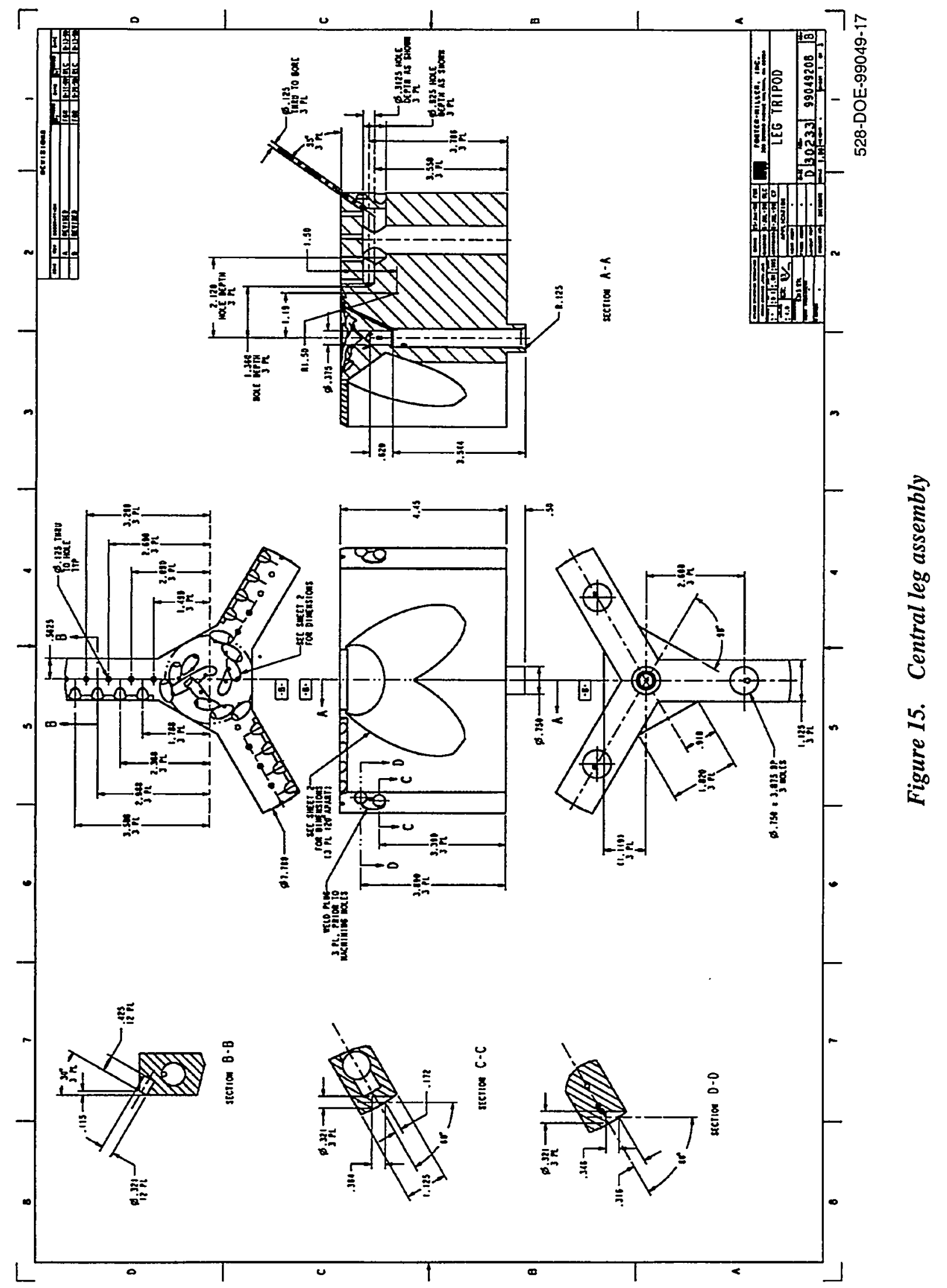




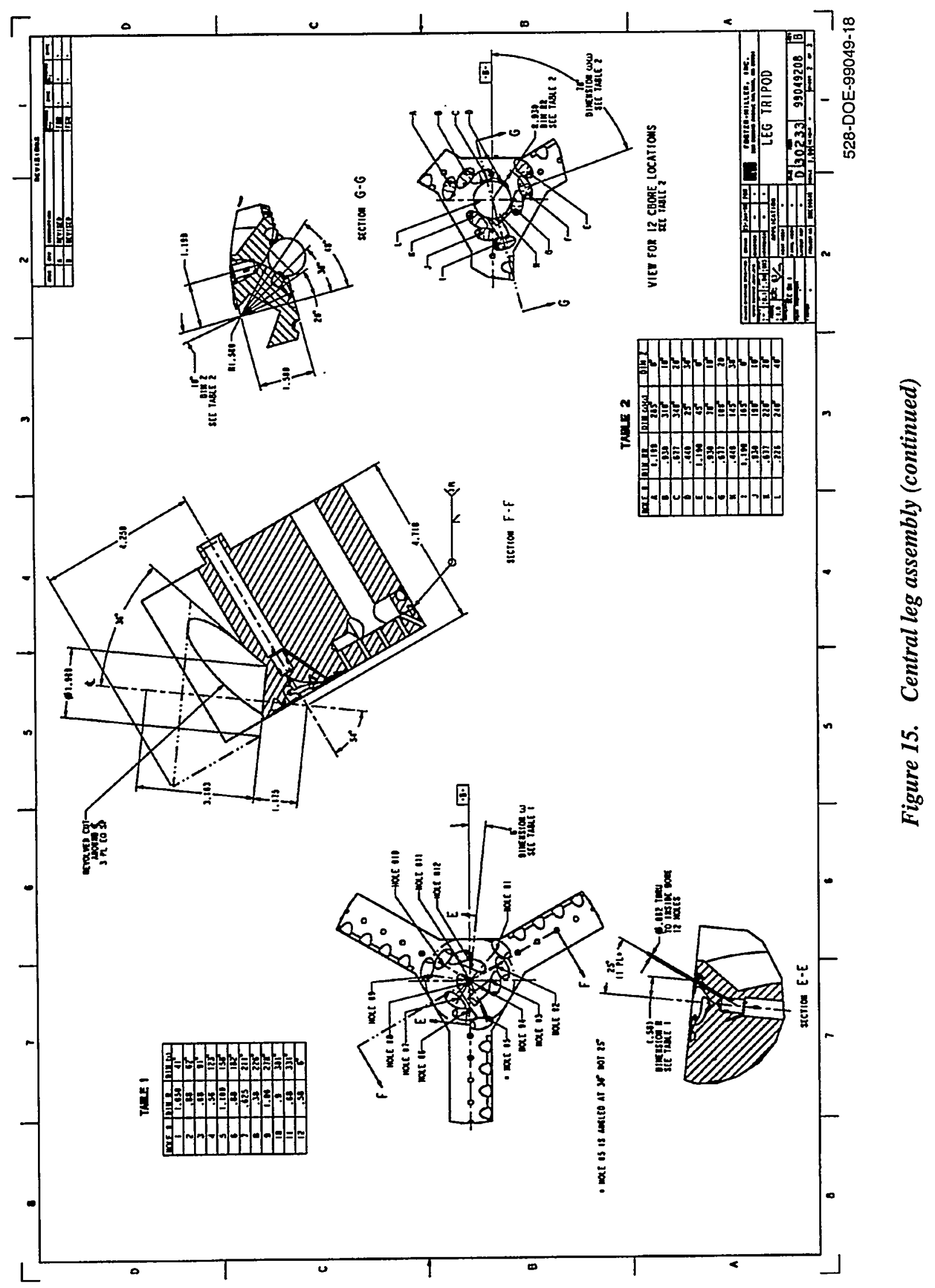




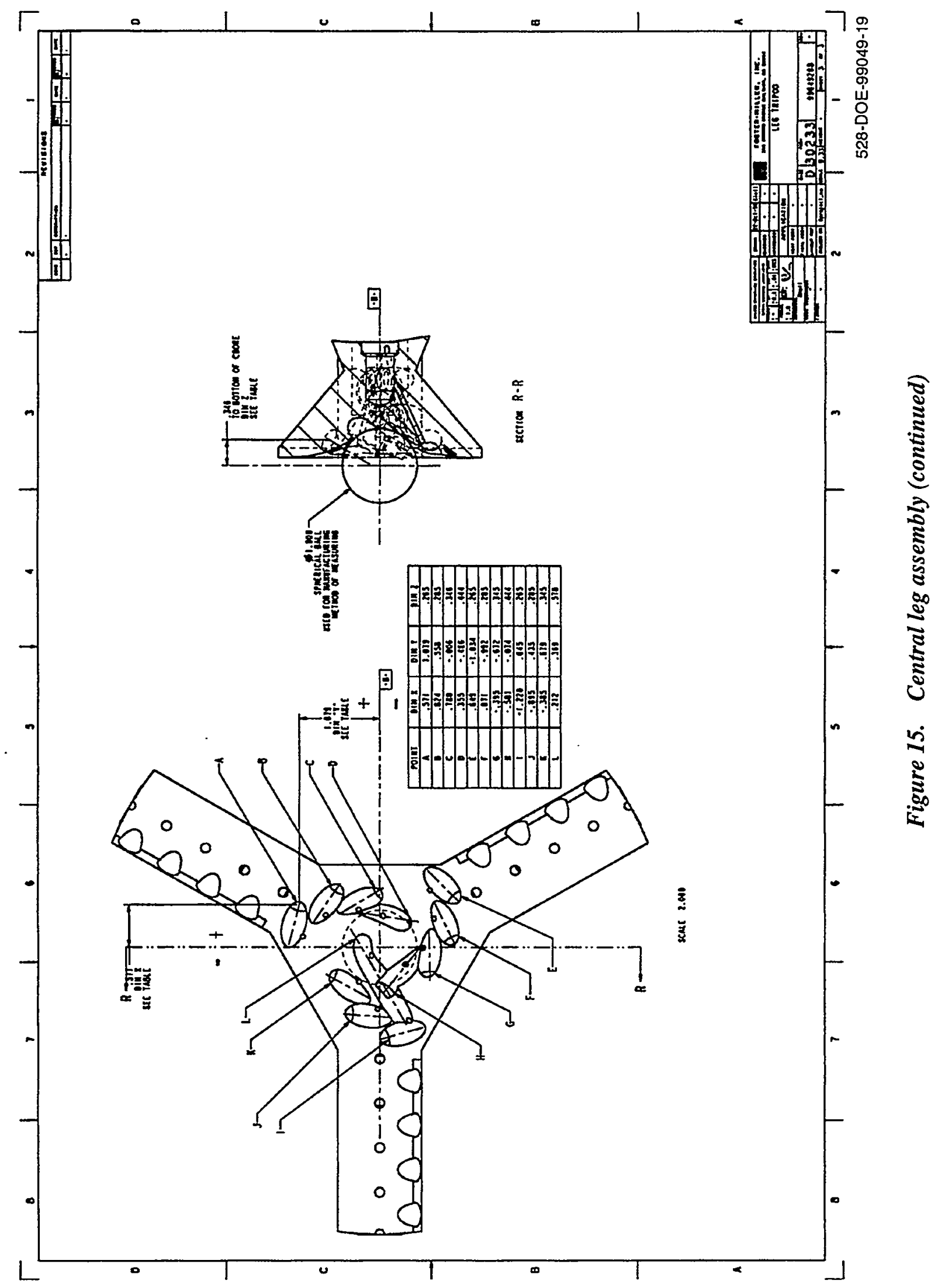




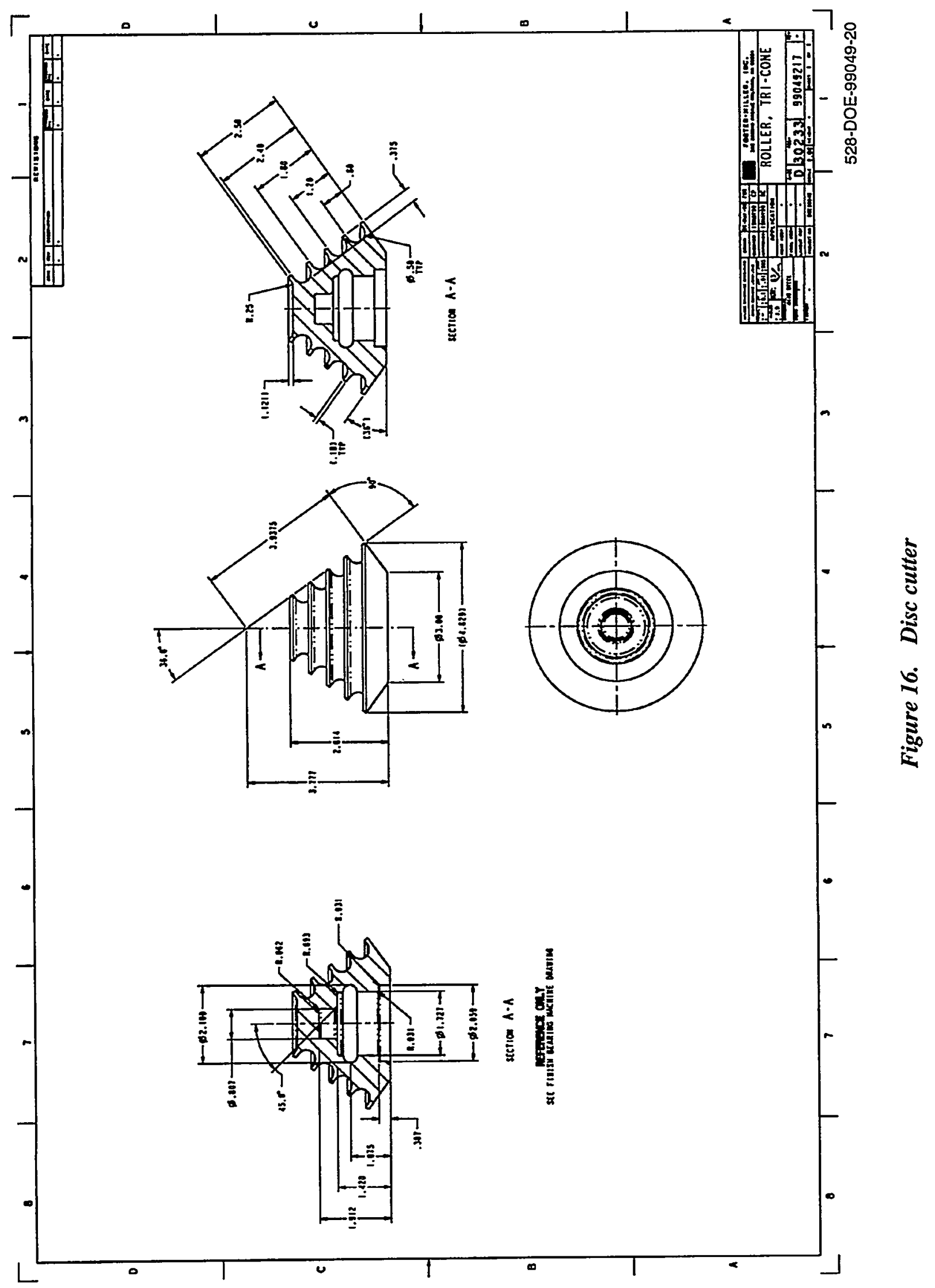




\subsubsection{Conical Bit Fabrication}

The Conical bit was fabricated as a two-part assembly at a shop local to Foster-Miller. Figure 17 and Figure 18 show the fabricated bit prior to brazing the cutters onto the bit. Figure 17 shows the bit body and the API threaded Sub that were threaded together to form the Conical bit assembly shown in Figure 18. The assembly was shipped to Dennis Tool Company where the two parts were welded together and the cutters were brazed onto the bit. Figure 19 shows the bit with the cutters brazed onto it. The cutter water nozzles are evident in the nose cutters. The other holes shown in the bit nose were added at Foster-Miller to achieve the desired water flow through the bit of $350 \mathrm{gpm}$ at 3000 psi.

The conical bit body proved to be a difficult part to fabricate. The machine shop used a fiveaxis CNC machine to fabricate the part. Programming the machine to produce the spiral cuts and pockets for the PDC cutters became a major stumbling block to fabrication. In the end, the machine programmed by manual digitizing points on the surface of the drill bit using the machine to record the point coordinates. The coordinates were then fed into the machine's program and the machine cut from point to point. A rapid prototype model of the part may prove helpful in programming the CNC machines.

Several brazing attempts were required before a proper brazing technique could be established for brazing PDC cutters with water jet holes in the cutter. In the end, several water jets had to be cleared using plunge EDM processes. Plunge EDM processes should be reviewed for future bits.

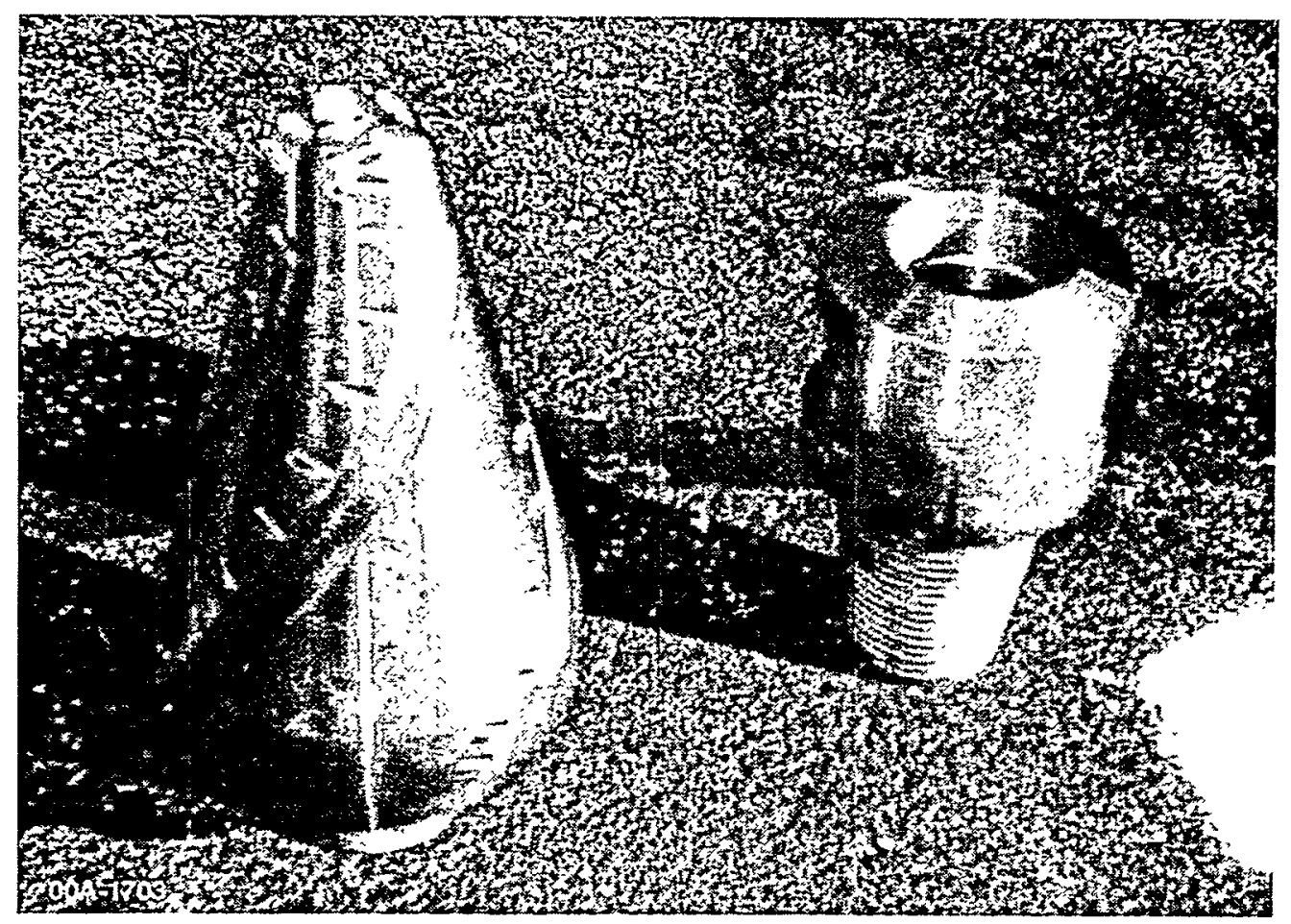

Figure 17. Conical bit and API threaded sub 




Figure 18. Assembled conical bit and API sub

\subsubsection{Hybrid Bit Fabrication}

Varel and Foster-Miller agreed that the Hybrid Bit fabrication would be done by machine shops local to Varel who were accustomed to bit manufacturing materials, heat treatments and procedures. Foster-Miller contracted one of the shops to fabricate the central leg of the bit and that was accomplished. Varel was contracted to fabricate the disc cutters and to modify the bearing legs for the bit.

Manufacturing procedures at Varel prevented the bearing legs from being fabricated. Two attempts at fabricating the bearing legs resulted in the legs being out of specification for production quality bits and the legs were rejected and recycled. Either loosing the specification or slightly modifying the manufacturing operation would have produced parts sufficient for the test bit. Unfortunately, this would have significantly delayed the testing and it was decided that the hybrid bit testing would be dropped from the program. 


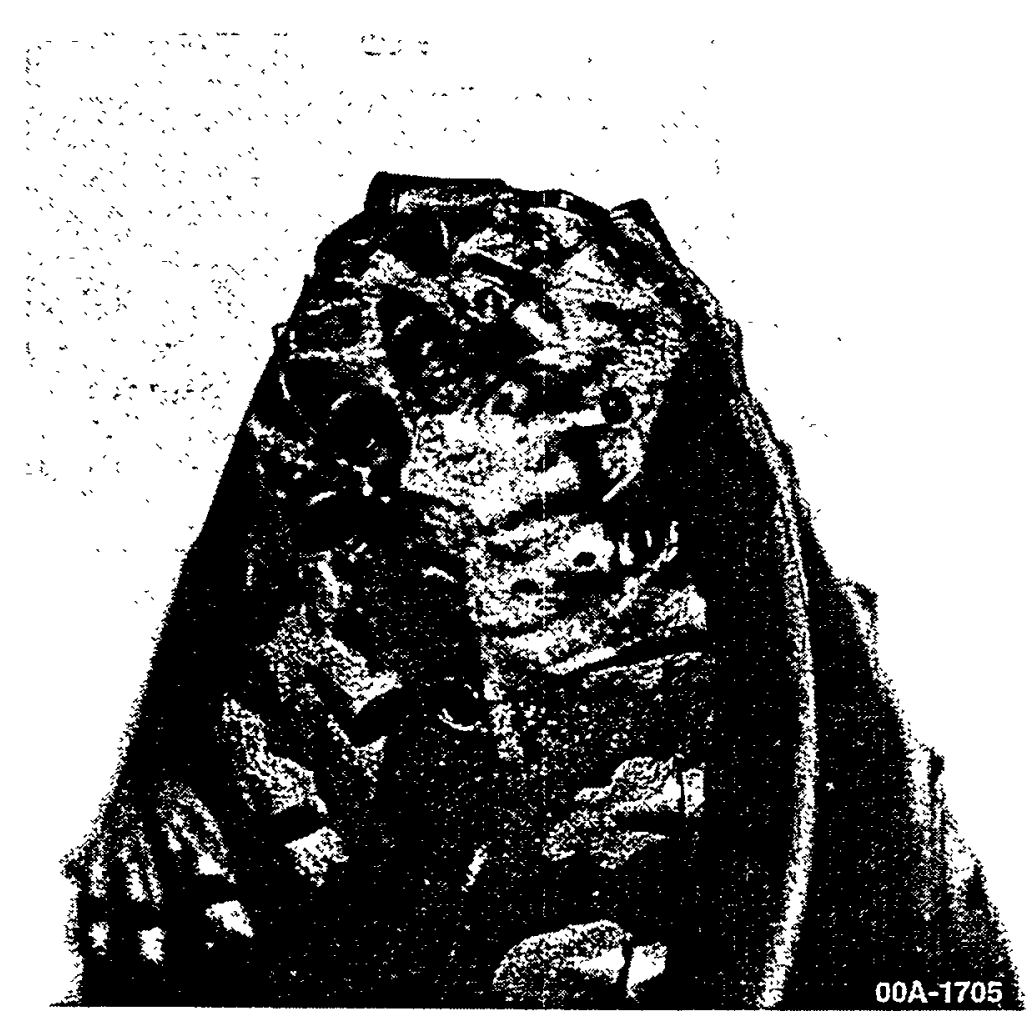

Figure 19. PDC cutters brazed onto the bit

If future development and testing can be funded then the Hybrid Bit will be fabricated and tested.

\section{$2.3 \quad$ Testing}

The original test plan called for testing at two test facilities. The critical nose section of the conical bit would be tested at Sandia National Laboratory (at no cost to the program) and the hybrid roller bit would be tested at Terra-Tek Drilling Laboratory. A description of the Terra-Tek facility is provided in Appendix A.

The Sandia test facility required significant upgrading to accommodate the hydraulic pressures needed to test the conical bit. Sandia personnel investigated the cost and effort required to upgrade the system and determined that it would not be feasible; hence, conical bit testing had to be done at the drilling laboratory. A full-scale bet was required for this testing and as discussed in the previous section a full-scale bit was designed and fabricated for this purpose. 
Alternative test sites were investigated. Our investigations showed that two facilities offer full-scale drill bit testing. Terra-Tek's Drilling Research Laboratory, Salt Lake City, UT offers a full range of laboratory testing. Gas Research Institute's Chattanoga Test facility near Tulsa, OK offers controlled field testing in different and known formations. The Terra-Tek facility was used in this program. A shore description of the Terra-Tek facility is provided in Appendix A. The GRI facility may be appropriate for Phase II testing.

Fabrication delays and test facility scheduling delayed testing until February 2000. Laboratory testing was started 28 February 2000 when all testing for one rock sample was completed. A failure of the motor controller of the facility's mud pump delayed the completion of the testing until April 18, 2000.

Prior to drill testing, low pressure flow tests were conducted at Foster-Miller to establish the flow characteristics of the drill bit.

\subsubsection{Calibration Testing}

The bit was fabricated with twelve 0.0625 in. diameter holes in the nose cutters and on $0.01 \mathrm{in}$. diameter hole on the centerline of the bit. By design, the flow area provided by these holes was insufficient to provide the $350 \mathrm{gpm}$ flow at $3000 \mathrm{psi}$. Due to the unusual flow configuration of the bit, the final flow area was determined through calibration testing.

Figure 20 is a schematic of the test stand used to determine the total required flow area for the conical drill bit. The drill bit was set up in a closed loop test stand and water was pumped through the bit. Pressure and Flow were measured and a nozzle flow coefficient of 0.588 was determined. The flow coefficient was then used to determine the additional flow area required to provide the desired $350 \mathrm{gpm}$ at $3000 \mathrm{psi}$. Figure 21 shows final flow nozzle pattern for the conical bit. The nozzle diameters and their associated flow areas are present in Table 1 . The flow across the bit was roughly distributed as 50 percent from the body nozzles, 30 percent from the nose perimeter nozzles and 20 percent from the central nozzles of the bit. The nose area was too congested to shift more of the flow area into the central nose area of the bit. Drilling laboratory test results showed a bit flow (including well screen) was $380 \mathrm{gpm}$ at $3150 \mathrm{psi}$ (see subsection 2.3.2).

\subsubsection{Laboratory Testing}

The general test plan included comparative testing of the two prototype bits against industry standard tricone and drag bits. For each test the following parameters will be varied at two levels.

- Bit weight (high and low).

- Bit rotational speed (high and low).

- Hydraulic horsepower (high and low).

- Rock (hard and moderately hard). 


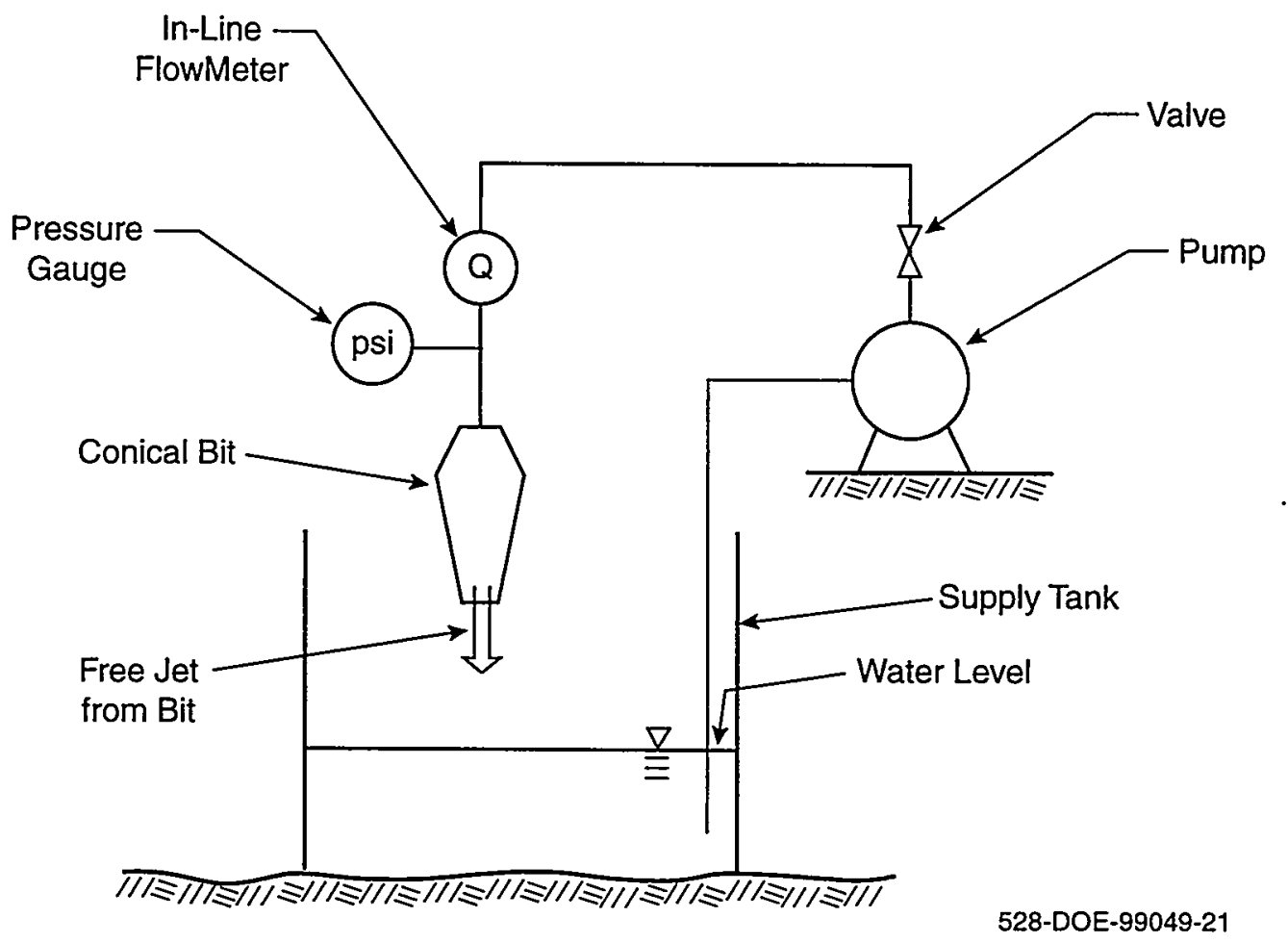

Figure 20. Flow calibration test stand

The results would be compared as Rate of Penetration (ROP) versus Weight on Bit to determine how the prototype bits compare to standard bits. Higher penetration rates at reduced bit weight would be a favorable result. The plots should also illustrate any benefit of near cutter water jets.

The major questions for these Phase I tests are:

- Do the bits drill rock?

- Do the bits have the potential to outperform the industry standard bits?

- How well do the bits survive?

As was discussed previously, in the end only the conical bit was tested.

Comparative drill testing was started on 28 February 2000. The testing was conducted at Terra-Tek in Salt Lake City, Utah. A two day test program was planned and was eventually completed. The first day's testing went very well and data was collected from drilling a Carthage Marble rock. The second day's testing was aborted when the mud pump failed. Foster-Miller and Terra-Tek agreed that Terra-Tek would complete the test program when the pump was repaired. Repairs to the pump were completed and the second day's testing was finished in midApril 2000. Sierra White Granite was the rock drilled in April. 


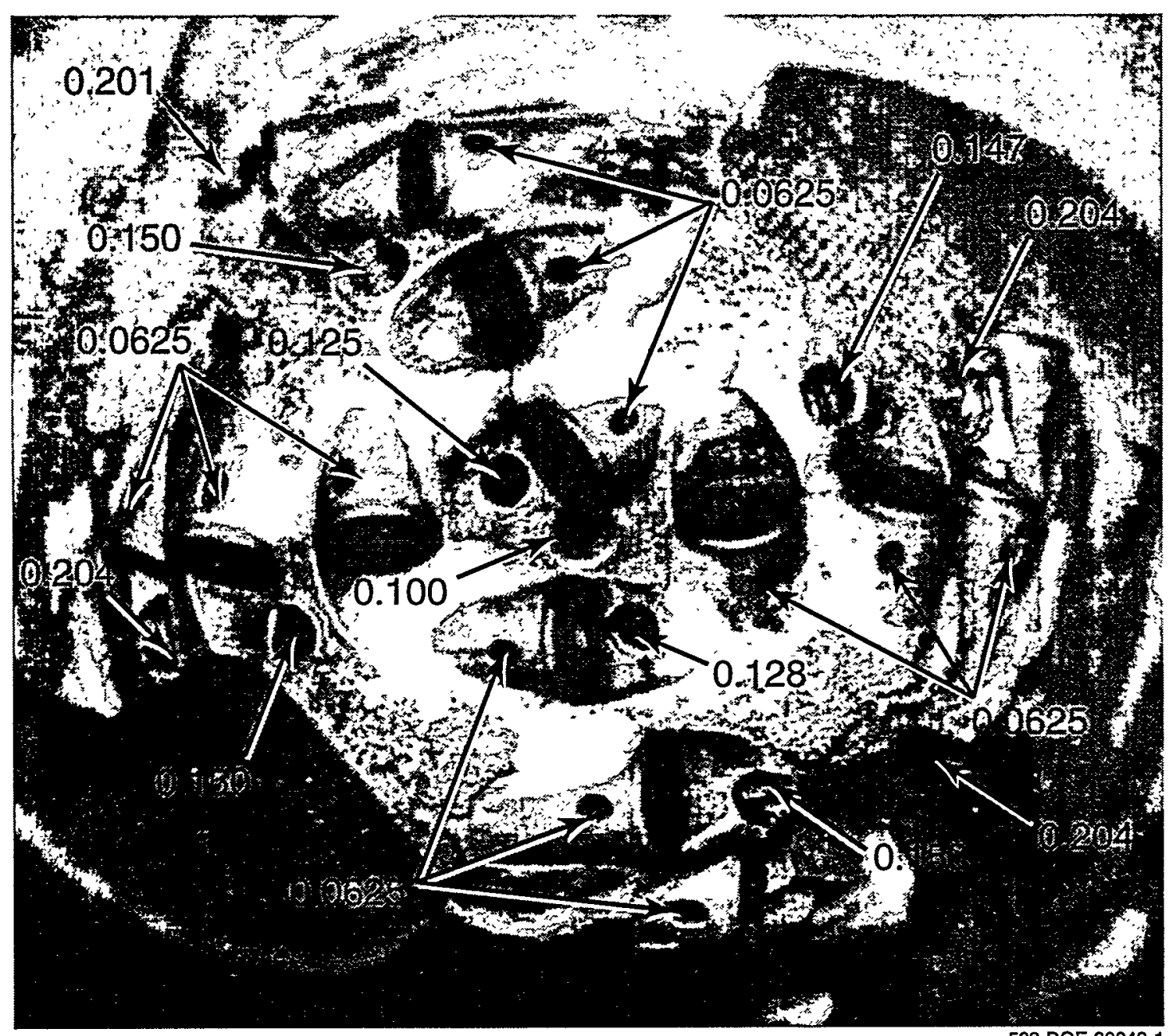

Figure 21. Conical bit flow nozzle pattern

Table 1. Summary of conical bit nozzles

\begin{tabular}{lccccc}
\hline \multicolumn{1}{c}{ Description } & Quantity & $\begin{array}{c}\text { Jet Diameter } \\
\text { (in.) }\end{array}$ & $\begin{array}{c}\text { Jet Area } \\
\text { (in. }{ }^{2} \text { ) }\end{array}$ & $\begin{array}{c}\text { Total Jet Area } \\
\text { (in. }{ }^{2} \text { ) }\end{array}$ & $\begin{array}{c}\text { Percent Total } \\
\text { Area }\end{array}$ \\
\hline Nozzle & 12 & 0.0625 & 0.00307 & 0.0368 & 13.6 \\
Center & 1 & 0.100 & 0.00785 & 0.00785 & 2.9 \\
Off-Center & 1 & 0.125 & 0.01227 & 0.01227 & 4.5 \\
Off-Center & 1 & 0.128 & 0.01287 & 0.01287 & 4.8 \\
Nose Perimeter & 3 & 0.150 & 0.01767 & 0.05301 & 19.6 \\
Nose Perimeter & 1 & 0.147 & 0.01697 & 0.01697 & 6.3 \\
Body & 4 & 0.204 & 0.03268 & 0.13074 & 48.3 \\
Total & 23 & & & 0.27051 & 100.0 \\
\hline
\end{tabular}


The following test matrix was executed (see Table 2).

The bit weights and rotational speeds are all within the operating envelopes recommended by Varel for their bits. All bits were spudded into the rock according to Varel's recommendations.

Figure 22 shows Terra-Tek's Laboratory test rig. All drilling operations were controlled from the drilling control room (see Figure 23). Appendix A provides a description of the Terra-Tek Laboratory Drilling Facility. The three test bits are shown in Figure 24. The conical bit is shown with the makeshift screen that was used during the February test when the rigid well screen was lost in shipping. A rigid well screen was used during the April testing.

For each test, a test bit was mounted on the drill string (see Figure 25) and the water box, which returned the drilling fluid to the pump sump, was locked down on the rock (see Figure 26). The bit was then spudded into the rock at reduced speed and load and full fluid flow. Once the bit was completely engaged in the rock, the bit weight and rotary speed were increased to test conditions and held at each test conditions for steady-state sampling. The data points were quickly collected and the range of conditions was quickly adjusted from the control station.

\subsubsection{Test Results}

The summary test data from both the February and the April tests are presented in Table 3. A total of seven drilling tests were completed. Test 5 a was a flow test used to determine the pressure drop across the well screen used in the April testing. Table 3 lists the date, time, test number, bit, bit diameter, rock, rock compressive strength, drill fluid, data point, fluid flow, pressure, hydraulic horsepower per square inch (hole area), rotational speed, bit weight per inch diameter of bit, rate of penetration ( $\mathrm{ft} / \mathrm{hr}$ and in./rev), bit torque. Each data point listed is an average of hundreds of sample points. The data collected for each point was collected over several inches of drilling depending on the drilling rate.

\subsubsection{Hydraulic Horsepower}

The hydraulic horsepower values listed in Table 3 are correct for the Varel bits, however for the conical bit, these values include the pressure drop across the screens, which for the February tests were significant. The test results were reviewed to determine the pressure drop across the different screens and subsequently across the conical drill bit. The results are summarized in Table 4. In April a length of Johnson Well Screen was used as the water filter upstream of the conical bit. Tests 1 and 5 were run with only Varel's PDC bit the flow and pressure drop measured was the PDC bit only and was fairly consistent. An average flow coefficient of 20.86 was determined from the following relationship

$$
\mathrm{GPM}=\mathrm{C} \sqrt{\mathrm{PSI}}
$$

The PDC bit coefficient was used to estimate the pressure drop due to the bit alone in test 5a. The difference in pressure drop between the bit and bit with the well screen was the estimated pressure drop across the well screen. From this information, a flow coefficient of 18.94 was 
Table 2. Drilling test matrix

\begin{tabular}{|c|c|c|c|c|c|c|c|c|c|c|c|c|}
\hline Parameter & \multicolumn{12}{|c|}{ Items } \\
\hline Bits tested & \multicolumn{4}{|c|}{$\begin{array}{c}\text { Foster-Miller Conical Bit } \\
6.25 \text { in. diam }\end{array}$} & \multicolumn{4}{|c|}{$\begin{array}{l}\text { VarelPDCBit } \\
6.00 \text { in. diam } \\
\end{array}$} & \multicolumn{4}{|c|}{$\begin{array}{c}\text { Varel L121 Mill Tooth } \\
6.25 \text { in. diam } \\
\end{array}$} \\
\hline $\begin{array}{l}\text { Weight on Bit } \\
(\mathrm{klb})\end{array}$ & 2 to 15 & 2 to 15 & 6 to 11 & 6 to 12 & 6 to 14 & 6 to 9 & 6 to 14 & 6 to 9 & \multicolumn{2}{|c|}{6 to 20} & \multicolumn{2}{|c|}{6 to 12} \\
\hline $\begin{array}{l}\text { Flow Rate } \\
\text { (gpm) }\end{array}$ & $\begin{array}{c}260 \text { to } \\
320\end{array}$ & $\begin{array}{c}260 \text { to } \\
320\end{array}$ & $\begin{array}{c}380 \text { to } \\
400\end{array}$ & $\begin{array}{c}380 \text { to } \\
400\end{array}$ & 352 & 352 & 352 & 352 & 250 & 350 & 250 & 350 \\
\hline $\begin{array}{l}\text { Pressure } \\
\text { Across Bit } \\
(\text { psi })^{\star}\end{array}$ & $\begin{array}{c}3000 \\
\text { to } \\
5000\end{array}$ & $\begin{array}{l}3000 \\
\text { to } \\
5000\end{array}$ & $\begin{array}{l}3200 \\
\text { to } \\
4800\end{array}$ & $\begin{array}{l}3200 \\
\text { to } \\
4800\end{array}$ & 287 & 287 & 280 & 280 & 480 & 950 & 480 & 950 \\
\hline $\begin{array}{l}\text { Rotation } \\
\text { Speed } \\
(\mathrm{pm})\end{array}$ & 80 & 120 & 80 & 120 & 80 & 120 & 80 & 120 & & 0 & 12 & \\
\hline $\begin{array}{l}\text { Rock Type } \\
\text { Compressive } \\
\text { (psi) }\end{array}$ & \multicolumn{2}{|c|}{ Marble 14,500} & \multicolumn{2}{|c|}{ Granite 28,200} & \multicolumn{2}{|c|}{ Marble 14,500} & \multicolumn{2}{|c|}{ Granite 28,200} & \multicolumn{4}{|c|}{ Marble 14,500} \\
\hline
\end{tabular}




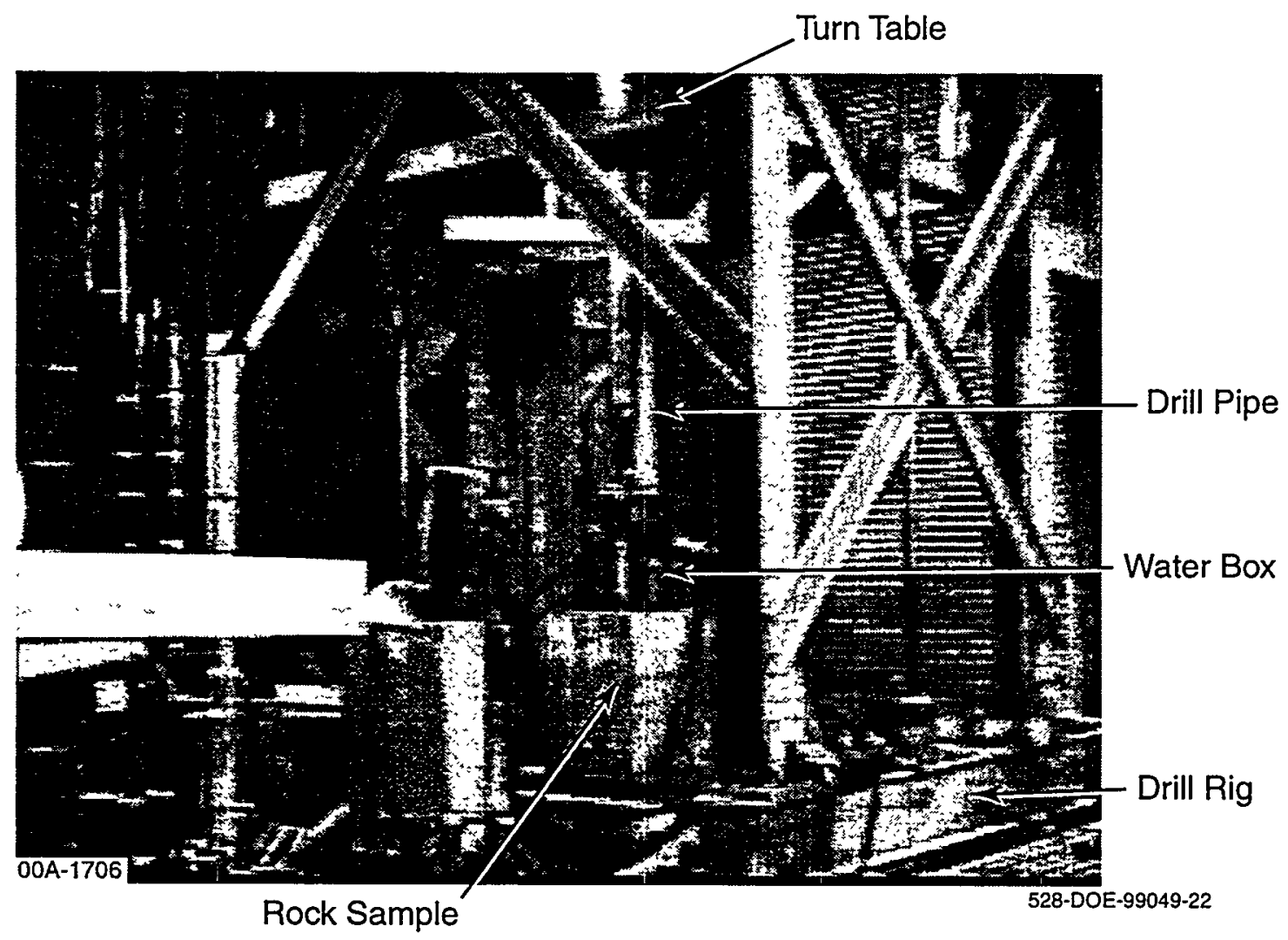

Figure 22. Terra-Tek's laboratory drilling test rig

determined for the well screen. Based on this coefficient, the pressure drop across the well screen was estimated for tests 6 and 7 . The pressure drop across the bit was determined and the corrected hydraulic horsepower was calculated. Table 4 shows that for tests 6 and 7 that the pressure drop across the screen was ranged from 401 to 451 psi thus reducing the hydraulic horsepower available at the bit.

The makeshift bit screen used during the February tests collapsed during testing and was suspected of significantly reducing the pressure available to the bit, thus mitigating the benefits realized from the increased hydraulic horsepower. Pressure drops across the bit was estimated for tests 3 and 4 . Comparing the bit pressure drop to the total pressure drop across the screen and the bit shows that at least half of the total pressure drop occurred at the screen. Thus, the screen did significantly affect the hydraulic horsepower available to the bit. The makeshift screen was required when the rigid well screen was lost during shipment to the test site. The rigid well screen was replaced for the April testing. 

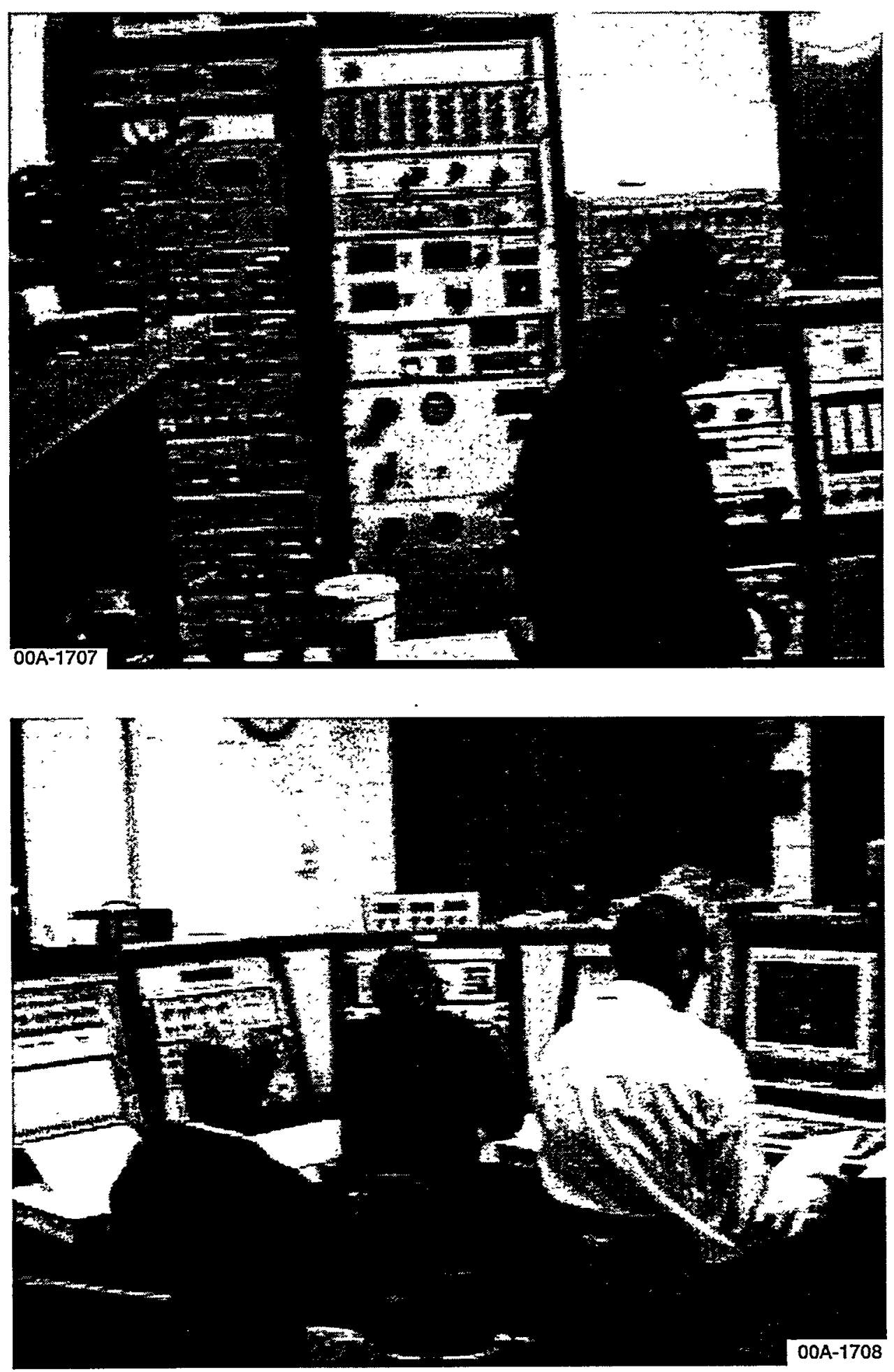

Figure 23. Drilling laboratory's control room 



Figure 24. Test bits (Foster-Miller conical bit with well screen (top), Varel PDC bit (left), Varel L121 Tricone bit (right)) 


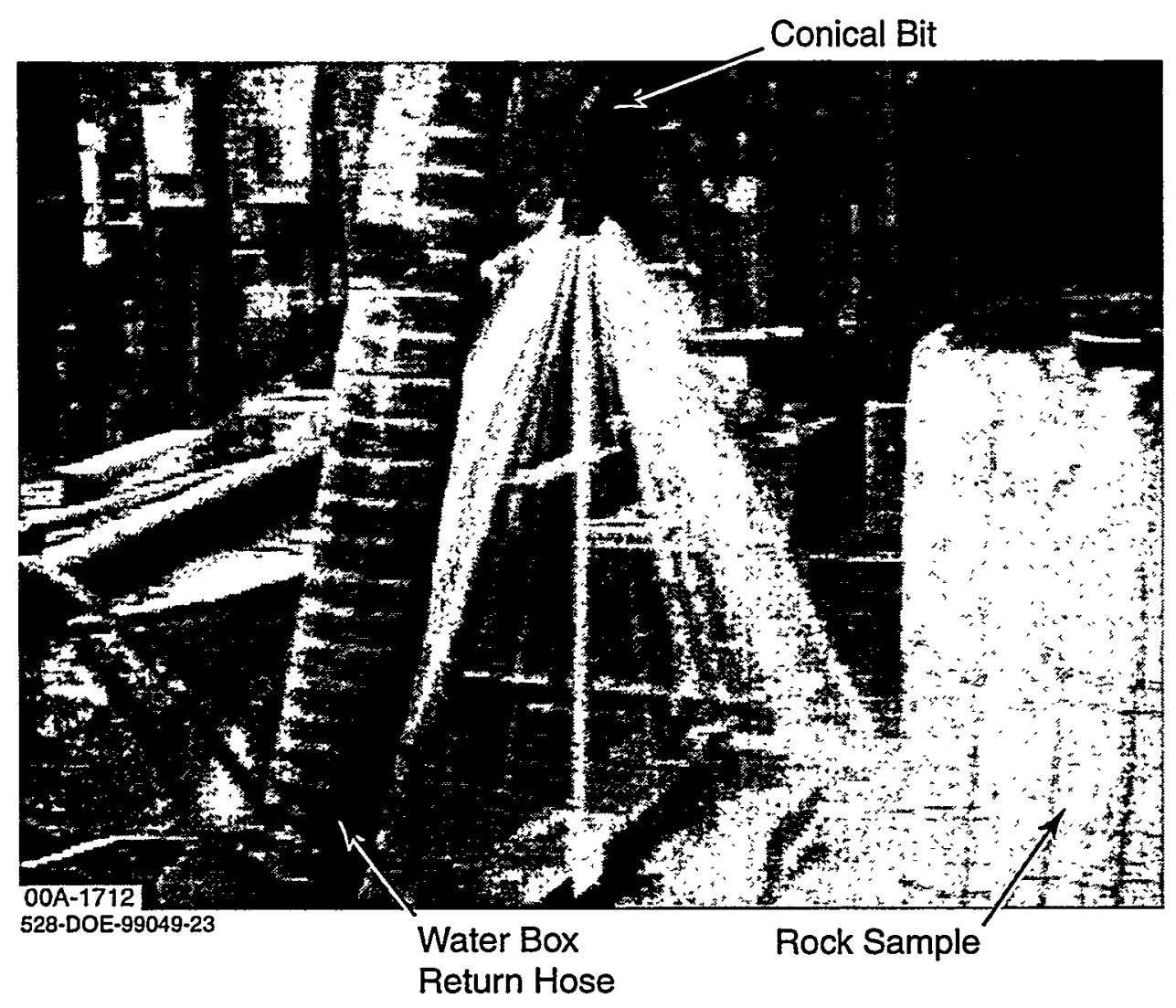

Figure 25. Conical bit on drill string at full flow

\subsubsection{Carthage Marble Results}

Results from the Carthage Marble testing are summarized in Figures 27, 28 and 29. Figure 27 shows the Rate of Penetration ( $\mathrm{ft} / \mathrm{hr}$ ) as function of Weight on Bit (lb/in. of bit diameter). Figure 28 shows the Rate of Penetration (in./rev) as a function of Weight on Bit (lb/in. of bit diameter). Figure 29 shows Torque (ft-lb) as function of Weight on Bit (lb/in. of bit diameter).

At first glance, two results are clearly evident from Figure 27. First the PDC cutter bits out drilled the Mill Tooth Tricone bit and second the conical bit drill as well as the Varel PDC bit at $80 \mathrm{rpm}$.

A closer look at Figure 27 shows that the Varel PDC bit had higher penetration rates at the higher rpm. The tricone bit also had higher penetration rates at the higher rpm for the higher hydraulic horsepower. At the lower horsepower rating, the increased penetration rate for increased rpm is not clearly evident. Ignoring any possible effects from hydraulic horsepower 


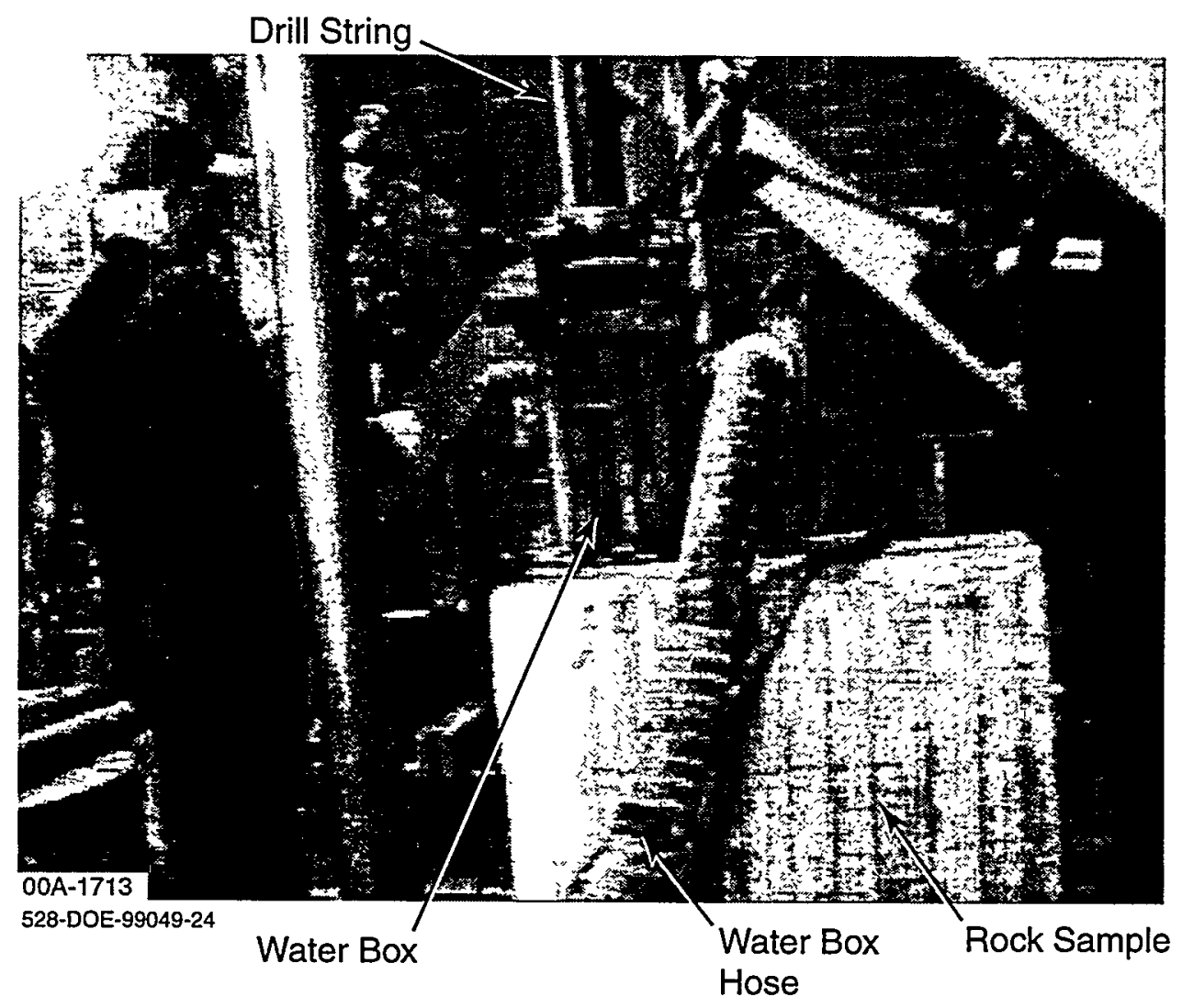

\section{Figure 26. Water box locked down during testing (hose returned flow to the pump sump)}

and averaging all the $80 \mathrm{rpm}$ data and the $120 \mathrm{rpm}$ data, the tricone bit does exhibit an increased penetration rate with increased rpm. The Conical PDC Bit did not demonstrate an increased penetration rate with increased rpm and did not demonstrate any favorable effects from the increased hydraulic horsepower. As has been discussed, the hydraulic horsepower across the bit was greatly affected by the makeshift screen. Some insight to what occurred with the penetration rate can be gained from Figure 28 .

In Figure 28 the penetration rate is presented as inches per revolution. The plot again shows that the conical bit matches the drilling rate for the Varel PDC bit up to approximately $1500 \mathrm{lb} / \mathrm{in}$. weight on the bit. Here, the slope of the Conical Bit's penetration curve reduces and drops below that of the Varel PDC Bit. At the $1500 \mathrm{lb} / \mathrm{in}$. bit weight, the penetration rate is on the order of $0.25 \mathrm{in}$. per revolution. For an $8 \mathrm{~mm}(0.31 \mathrm{in}$.) diameter cutter a $0.25 \mathrm{in}$. penetration is on the order of the cutter projection from the body of the bit. Hence, at this penetration rate the bit could have been foundering on the body of the bit. A look at the torque plots in Figure 29 illustrates at a bit weight of $1500 \mathrm{lb} / \mathrm{in}$., the conical bit's torque curve sharply increases which may be an indication of foundering. 


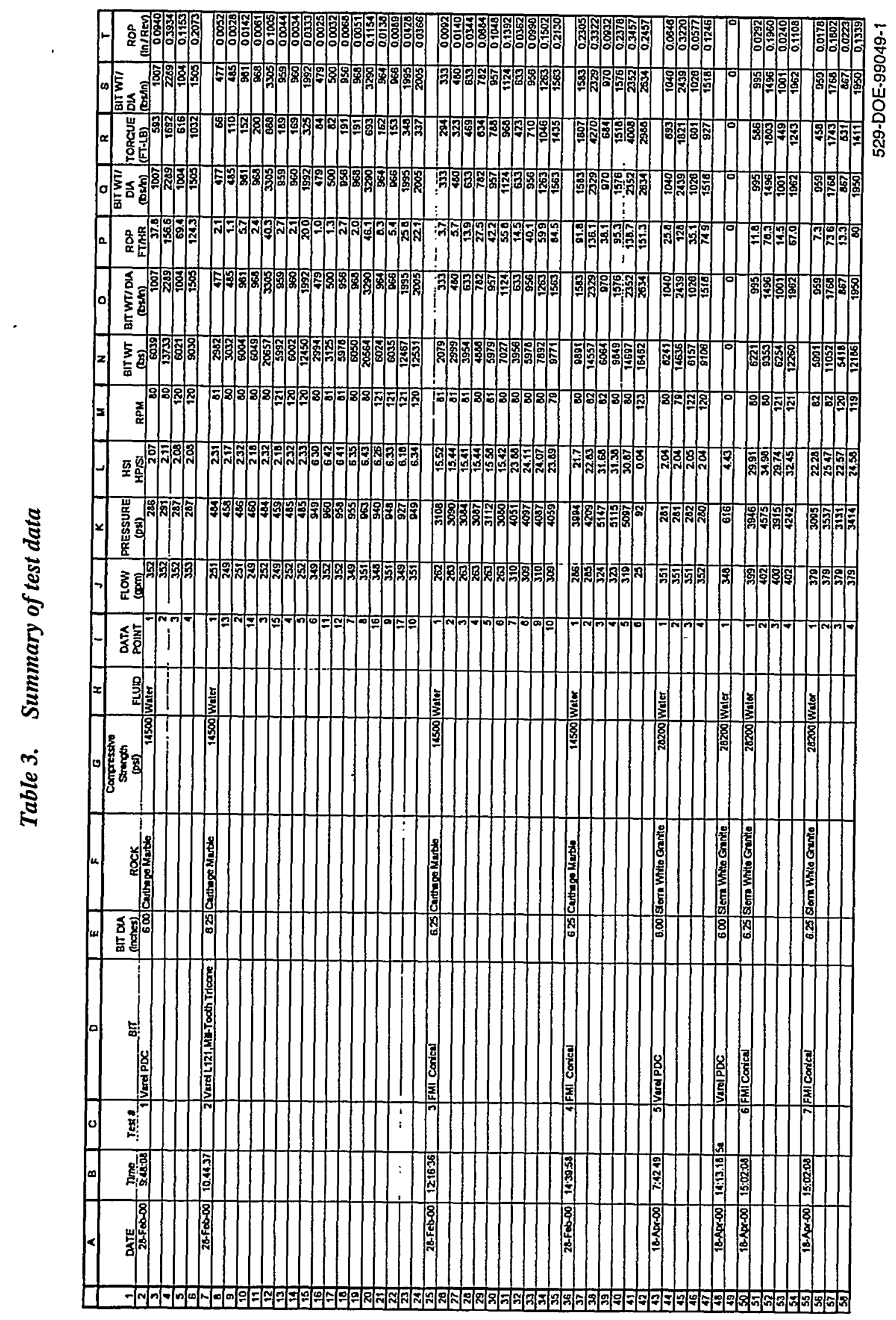




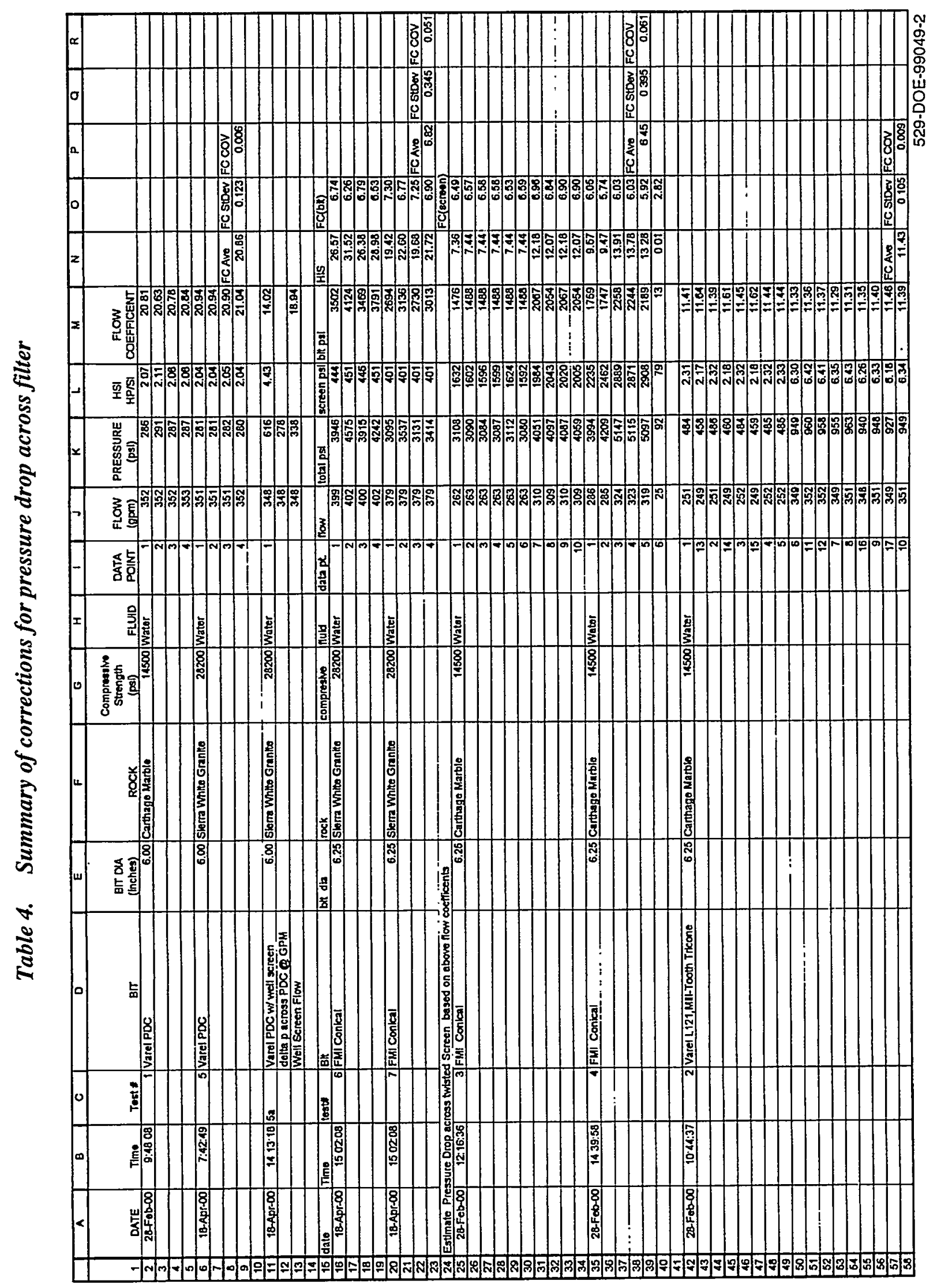


Bit Comparison in Carthage Marble (14500 psi) ROP vs. WOB

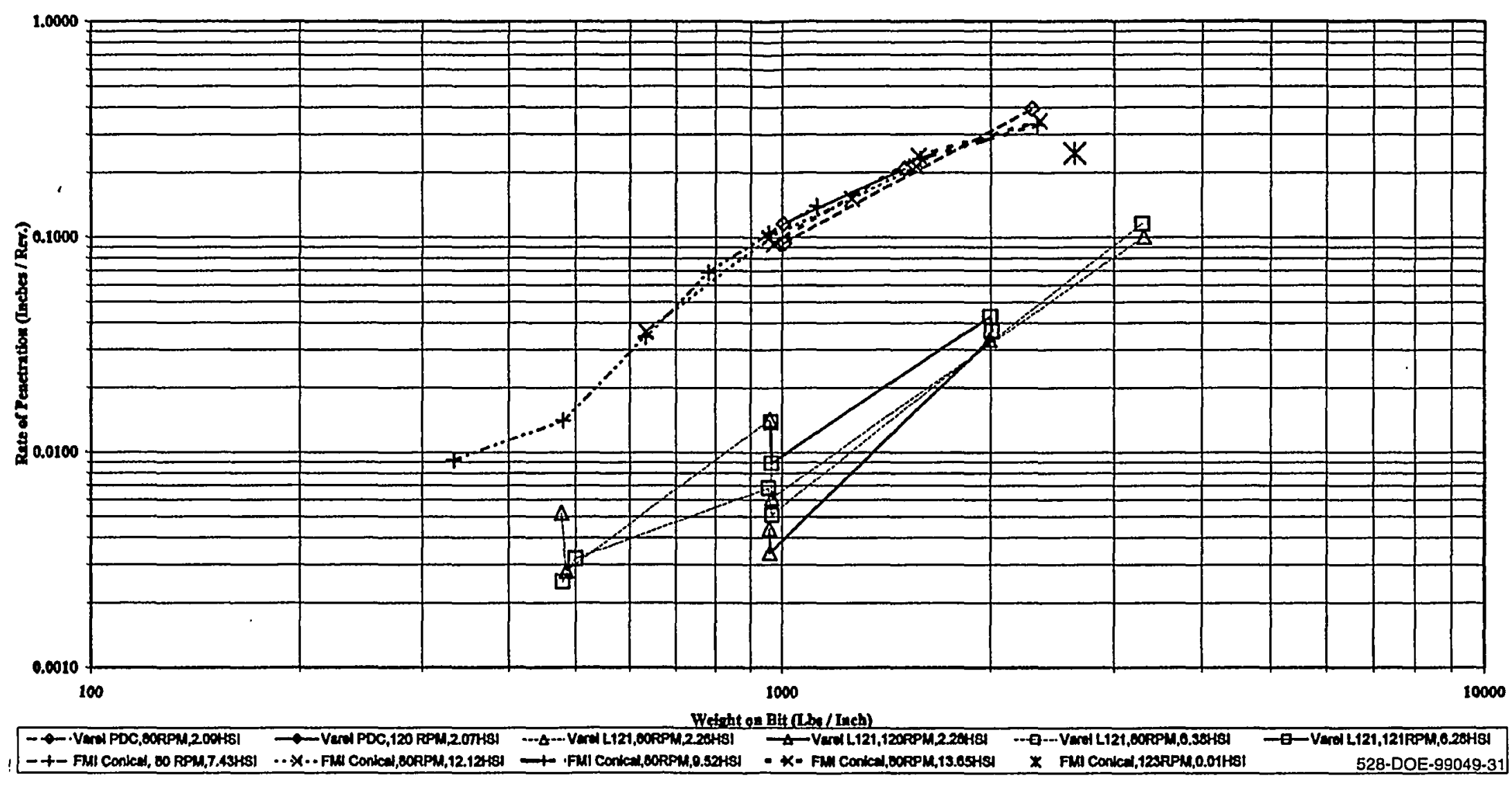

Figure 27. Bit comparison, penetration rate in feet per hour (Carthage Marble) 
Bit Comparison in Carthage Marble (14500psi)

ROP vs. WOB

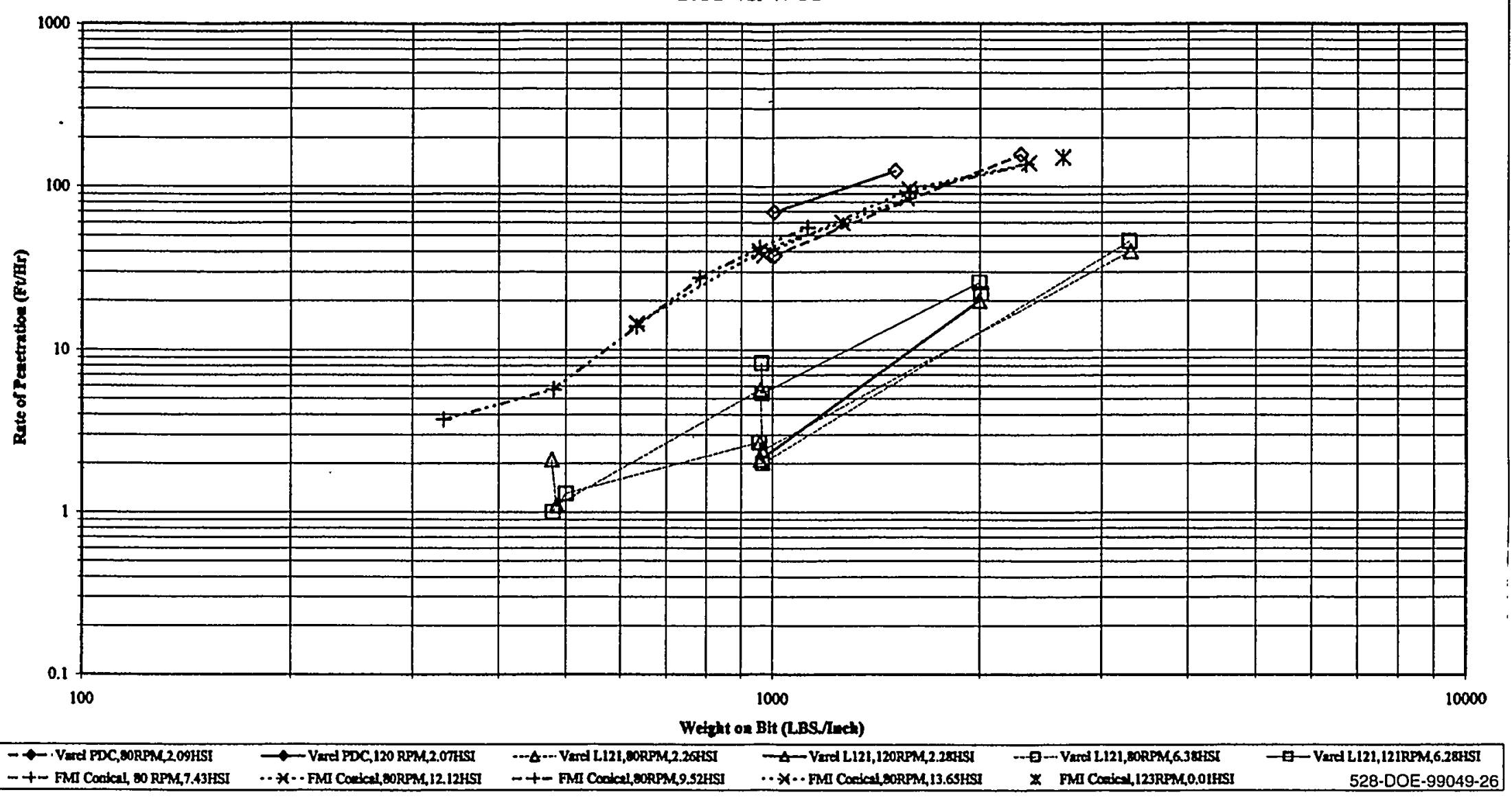

Figure 28. Bit comparison, penetration rate in inches per revolution (Carthage Marble) 


\section{Bit Comparison Carthage Marble (14500 psi)}

Torque vs WOB

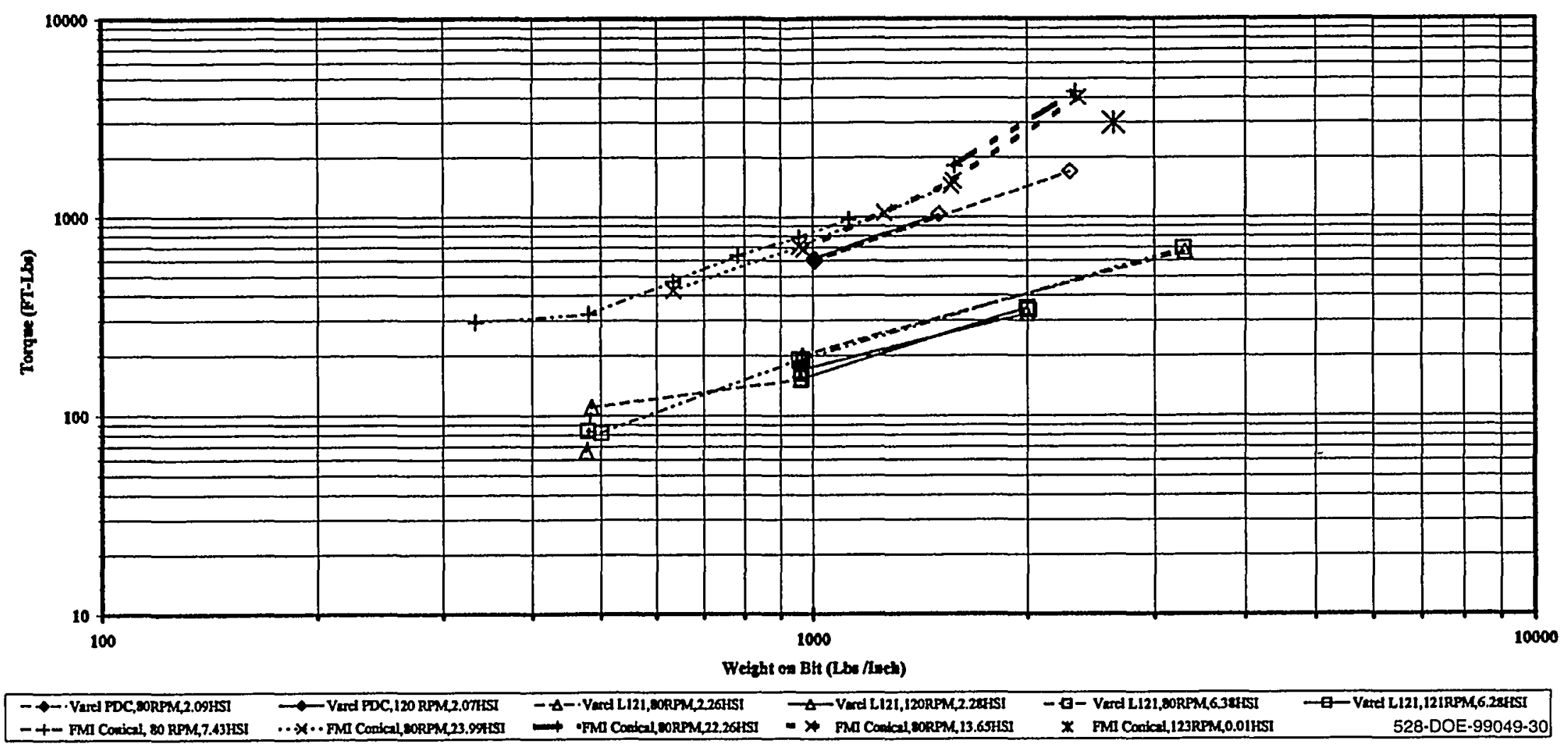

Figure 29. Bit comparison, torque (Carthage Marble) 
The Conical bit's torque was slightly higher than the Varel PDC Bit up to $1500 \mathrm{lb} / \mathrm{in}$. bit weight. The roller bit required the least torque for drilling Carthage Marble.

The Conical bit sustained minor damage (a small chip) to one nose cutter during the marble testing.

\subsubsection{Sierra White Granite Results}

Figures 30, 31 and 32 show the results of the drilling tests in Sierra White Granite. Again the results are presented as penetration rate $(\mathrm{ft} / \mathrm{hr})$, penetration rate (in./rev) and torque $(\mathrm{ft} / \mathrm{lb})$ all plotted as a function of weight on the bit (lb/in. diameter). A quick look at Figure 30 shows that the Varel PDC Bit out drilled the conical bit. As would be expected the PDC bit did demonstrate increased drilling rate with increased rpm.

Figure 30 also shows the conical bit appeared to have an increase in drilling rate with increased hydraulic horsepower. This data is confused by the fact that nose cutters sustained damage during the granite drilling tests. It cannot be determined when the damage occurred. A review of Figure 31 illustrates that there is significant drift in the conical bit data even under similar conditions. This drift could be an indication of the cutting structure changing due to cutter damage. Cutter damage could also cause the bit founder on the body thus limiting the penetration per revolution. The conical bit achieved its highest penetration rates at $80 \mathrm{rpm}$. At a bit weight of $1000 \mathrm{lb} / \mathrm{in}$., conical bit penetration rate was approximately $0.25 \mathrm{in} . / \mathrm{rev}$, however, the bit did not run very smoothly and smoothed out at the higher bit weights. Figure 32 shows that the torque values are on the order of those for the PDC bit except at the highest penetration rates.

Figure 33 compares the conical bit prior to any drill testing to the bit after drilling the Sierra White Granite. The damage was mostly sustained during the granite testing. Only minor damage to one cutter was noted after the marble testing. 
Bit Comparison in Sierra White Granite (28,200 psi) ROP vs. WOB

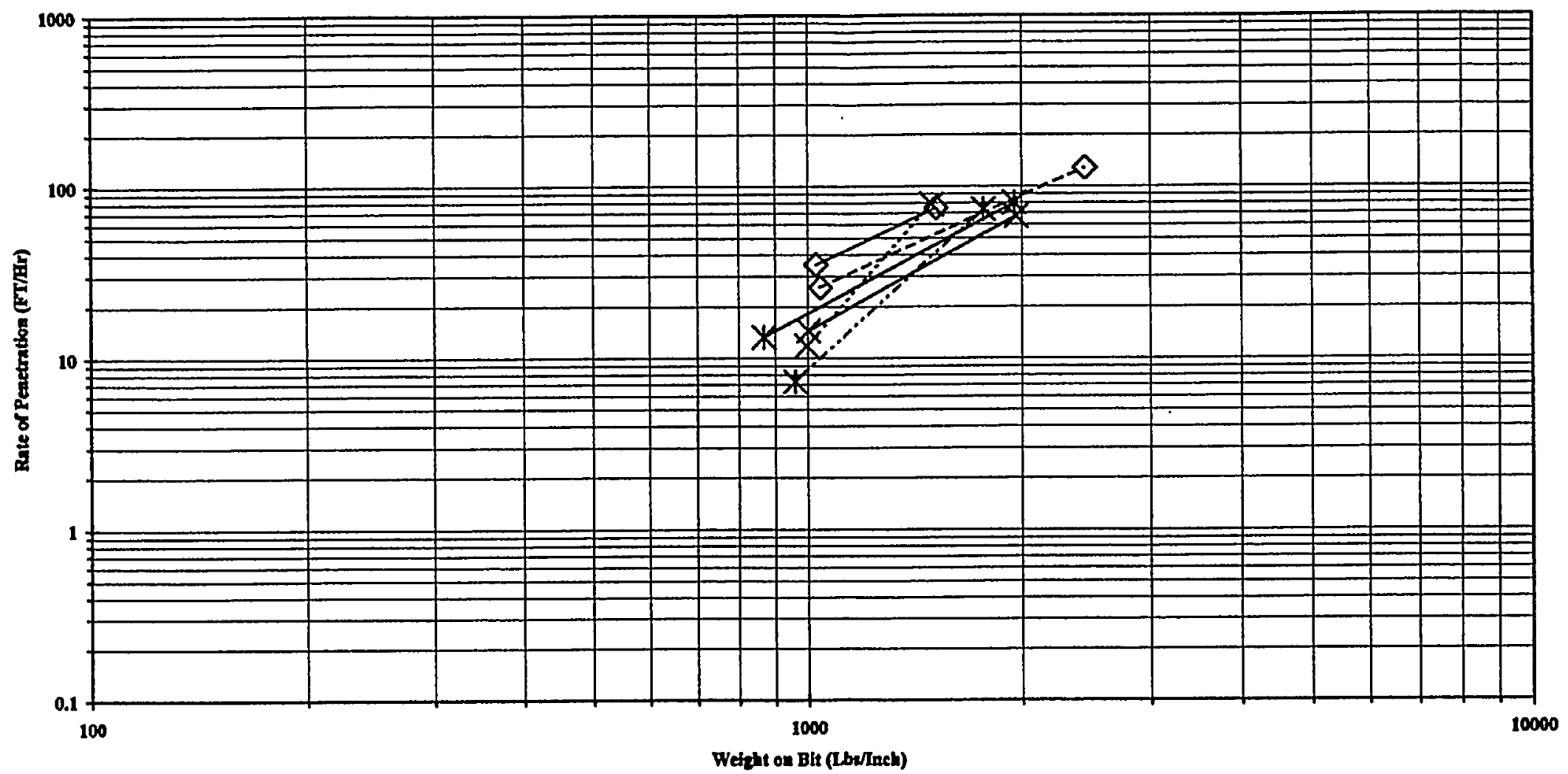

- 4 VelPDC

Figure 30. Bit comparison, penetration rate in ft/hr (Sierra White Granite) 


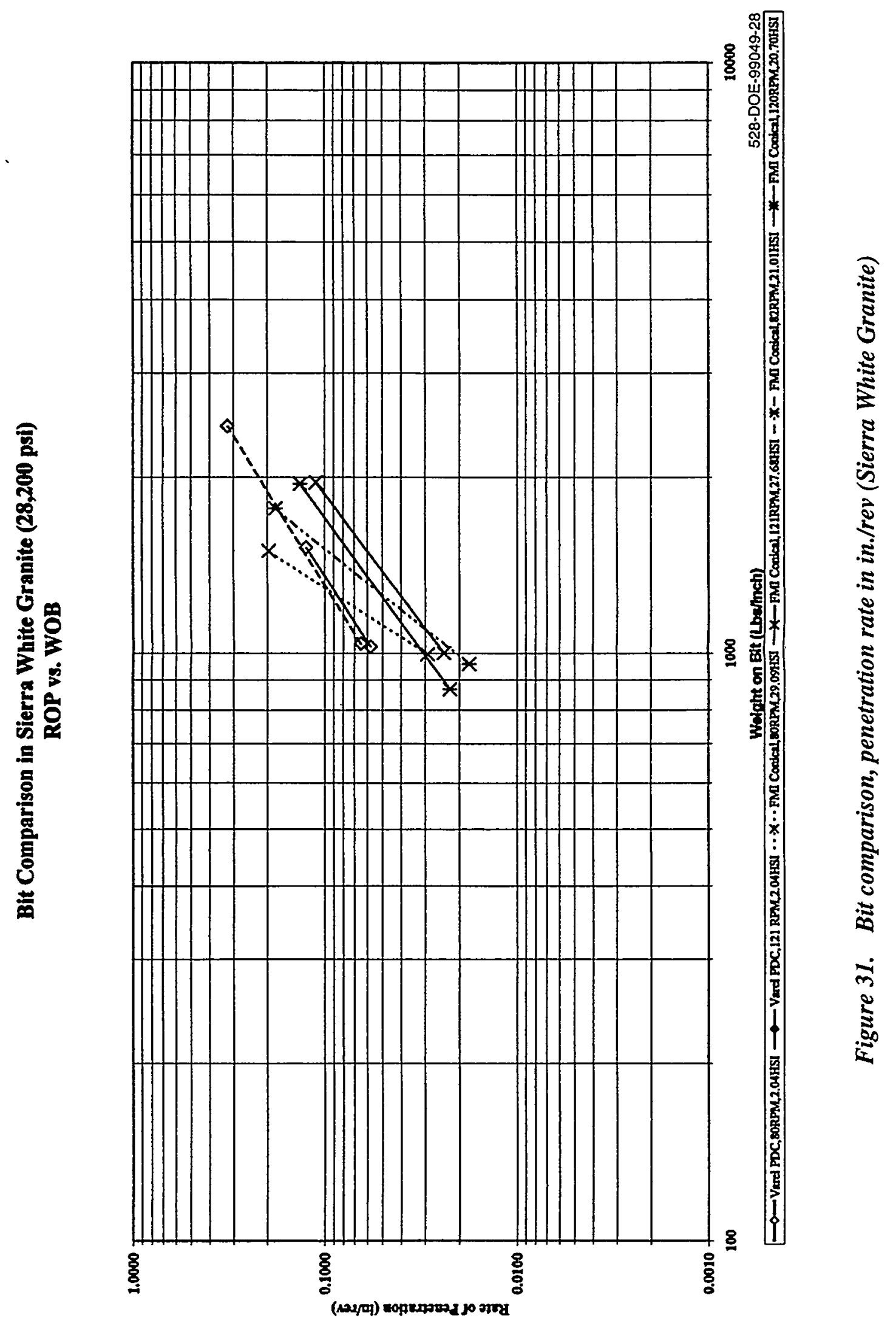




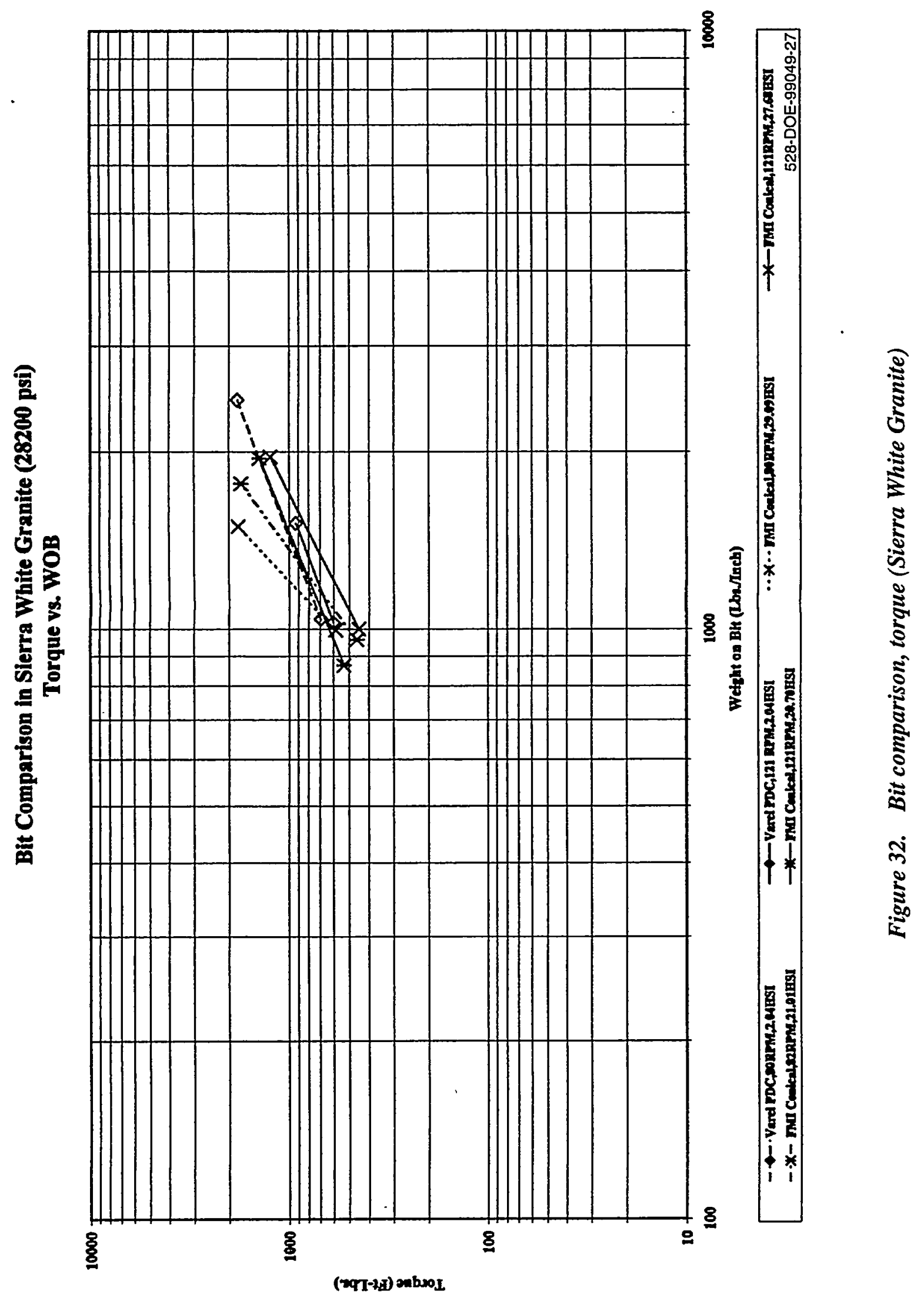



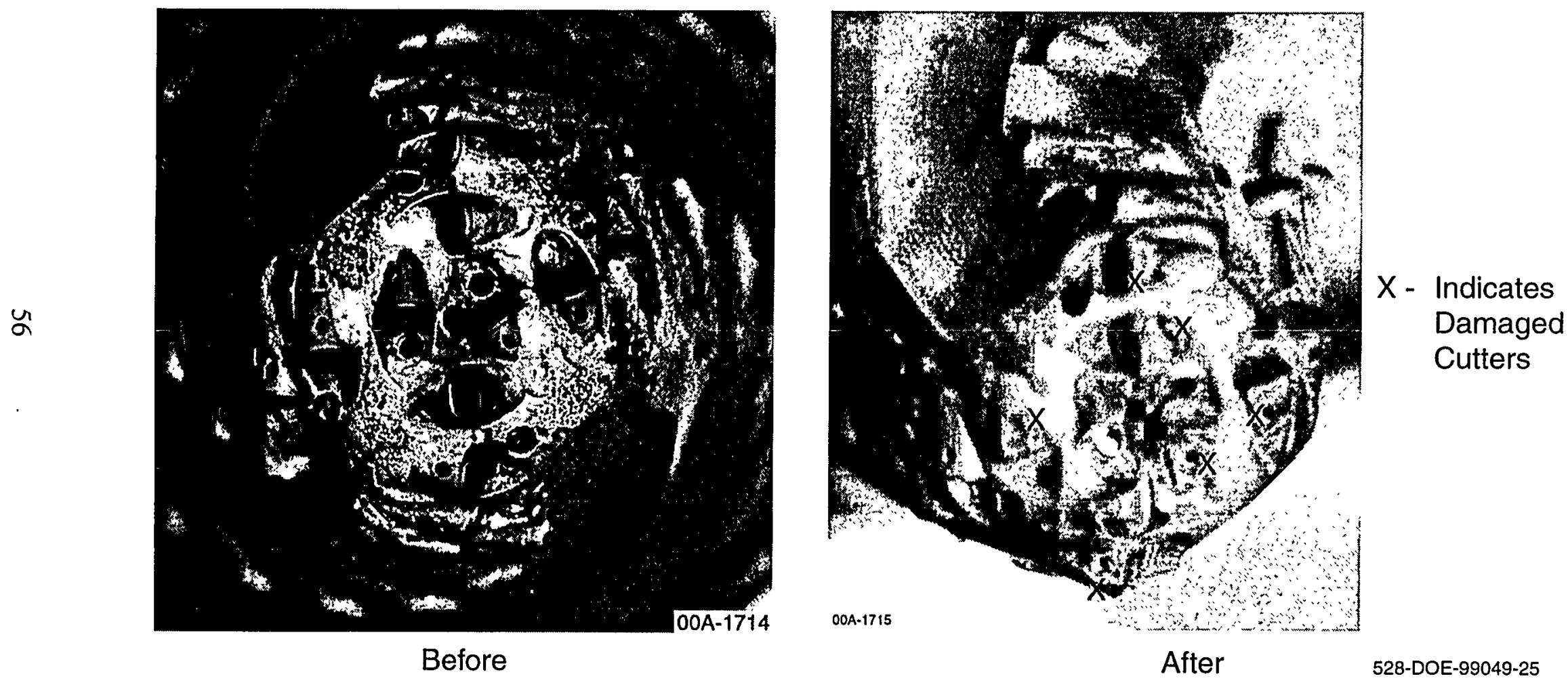

Figure 33. Comparison of new bit nose cutters to tested bit nose cutters 


\section{CONCLUSIONS}

The test results demonstrated that the conical drill bit was structurally rugged enough to withstand the stresses of rock drilling. In marble, the drilling rate matched the rate for a Varel PDC bit and surpassed the rate of a Varel Mill-Tooth tricone bit while demonstrating slightly higher torque requirements. The granite drilling results were clouded by bit damage sustained during the drilling tests, however, the torque requirements were on the order of those of the Varel PDC bit except at the higher penetration rates.

Results of the granite drilling tests hint at an increased drilling rates with increased hydraulic horsepower. Since cutter damage occurred during the granite tests it is not clear how much of the apparent increase is due to increased hydraulic horsepower and how much is due to damage cutting structure. No benefit from increased horsepower was evident during the marble testing due to the very high pressure drop across the makeshift screen filter used during the testing.

The limited drilling offered by laboratory testing is insufficient to evaluate or estimate drill bit life. Test facilities that offer instrumented and controlled fielded testing are better suited for this task.

The small nose area of the conical bit required a very careful spudding operation. This could be a practical limitation of this particular conical bit design. However, conical bit with a larger nose area may not have this limitation.

The hybrid roller bit was never tested due to problems in manufacturing the bearing legs. These manufacturing problems can be easily overcome and are not a roadblock to future test bit fabrication. 


\section{RECOMMENDATIONS}

Further laboratory testing of both bits is recommended. The results for the conical bit hint at the potential for near cutter jets and demonstrated promising drilling rates in the marble. The test results are too sparse to make any definite judgements on the conical bit concept and near cutter jets. The hybrid roller bit was not ever tested and should be fabricated and tested.

\subsection{Conical Bit}

Future development of the conical bit should isolate the different features to determine the benefits of each. The test bits should be fabricated so each should mimic the cutting structure of a commercial PDC bit. For example, a conventional PDC bit design, similar to the Varel PDC bit test, could be modified to incorporate first near cutter water jets, then skewed gage cutters and finally the truncated cone shape except with a larger nose area. The approach will evaluate each feature on common cutting structure. If that cutting structure already mimics an existing bit design, the transition to a production bit that incorporates all the beneficial features will be straightforward.

These investigations should be done through a series of laboratory tests very similar to those conducted during this initial evaluation. Rigid Well Screens should be used for all bits including the commercial bits to produce common test conditions.

If warranted, a field-worthy bit should be produced for field testing. This testing could be done at the Gas Research Institutes Chattanooga Test facility where the formations can be selected.

\subsection{Hybrid Roller Bit}

The Phase I prototype bit should be fabricated and laboratory tested. Based on the results of the initial testing, subsequent laboratory testing can be completed. Again, if warranted, a fieldworthy bit should be fabricated and tested.

\subsection{Design for Manufacturing}

The last phase of the development effort will be to design the bits for manufacturing. This will be a task left to the bit manufacturer. By working with the manufacturer throughout the development program, the final development bit should be very close to the design required for the manufactured bit with minor changes to accommodate manufacturing procedures. 


\section{APPENDIX A}

LABORATORY TEST FACILITY 


\section{Drilling and Completions Laboratory provides facilities for:}

Large Scale Drilling and Coring

Testing

Mud Spurt-loss Testing

Cutter Performance and Wear

Testing

Other Testing

3-D Hydraulic Fracturing Simulation
Completions Testing in: Large Block Stress Frame

Small-Block Stress Frame

WellboreSimulator

CT-Scanner Vessel

The Drilling Laboratory facilities include a wellbore simulator pressure vessel, drilling rig, mud pumping capabilities for measuring the performance, wear, deviation, and dynamics of full size drill bits tested at overbalanced or underbalanced drilling conditions at simulated depth. The effects of drilling and coring fluids on drilling performance, bit balling, formation damage, coring and core invasion are determined. In addition, mud spurt-loss and PDC bit cutter wear measurements are made with smaller equipment.

The Completions Laboratory facilities include a large block stress frame for conducting large scale underbalance and high overbalanced perforating tests, test to investigate and predict sand production, well kill and clean up testing, hydraulic fracturing stimulation and cutting reinjection experiments, and downhole screen loading and collapse tests. In addition, smaller scale experiments are performed with individual perforating charges, for sand production, prediction and other completion related issues.

The Hydraulic Fracturing modeling software, TerraFrac $\frac{\text { TM }}{}$, is an advanced,

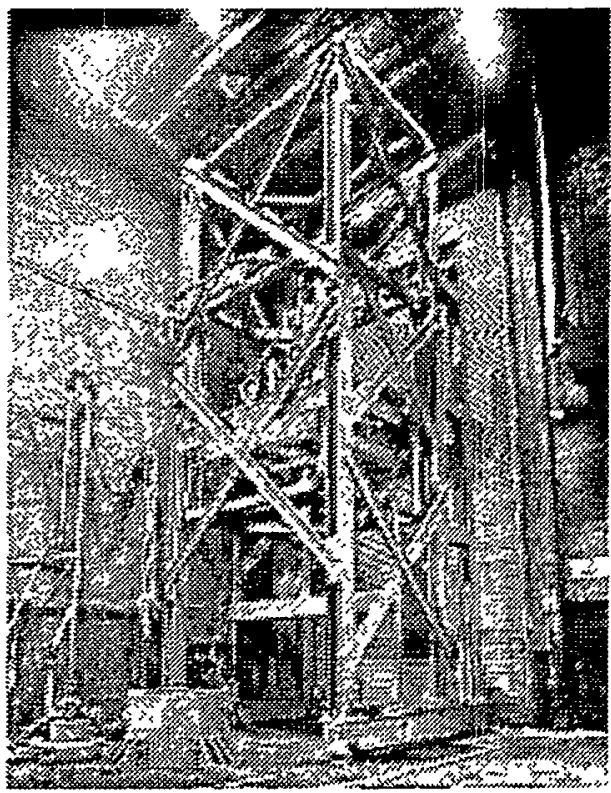
fully 3-D fracturing code capable of predicting fracture geometry, fluid and proppant transport, temperature distribution, poroelastic and thermoelastic effects and after shut-in conditions in complex reservoir formations.

\section{Large-Scale Drilling and Coring Testing}

- Full-Size Bit Performance including measurement of rate of penetration, torque and mechanical horsepower versus weight on bit, rotary speed, flow rate, simulated depth and rock type.

- Overbalanced and Underbalanced Drilling Performance including measurement of rate of penetration and formation damage versus differential pressure between borehole and formation pore fluid.

- Drilling Performance and Bit Balling in Shale as functions of drilling fluid, simulated depth, bit type and drilling conditions.

- PDC Bit Wear Testing in abrasive and fractured rocks.

- Full-Size Coring Performance and Core Damage Testing measuring the effects of core bit Design, coring fluid and coring conditions on core invasion.

- Novel Bit Testing including high-pressure jet cutting, improved nozzles and hydraulics, and unconventional cutting structures.

- Bit Deviation and Walking Tendencies of Bits measured while drilling in rock formations with different bedding plane orientations at simulated depth and in bit side-loading tests.

- Vibration and Dynamic Bit Performance measurements made with near bit weight-on-bit, torque, bending, and accelerometer sensors. 
Borehole Pressure 12,000 psi

Confining Pressure 20,000 psi

Overburden Stress $30,000 \mathrm{psi}$

Back (Pore) Pressure 4,000 psi

Mud Flow Rate $600 \mathrm{gpm}$

Mud Temperature $1500 \mathrm{~F}$

Drilling Stroke 6 feet

Rate of Penetration $200 \mathrm{ft} / \mathrm{hr}$

Rotary Speed $1,000 \mathrm{rpm}$

Torque $10,000 \mathrm{ft} \mathrm{lb}$

Weight on Bit $100,000 \mathrm{lb}$

Bit Size $121 / 4$ " diam

Rock Sample Size $201 \frac{1}{2}$ " by 60 "long

\section{Small-Scale Mud Spurt-Loss Testing}

- Mud Spurt-loss measured as a function of mud composition, rock properties, simulated depth and drilling conditions.

- Spurt-loss Testing to decrease core invasion and formation damage, and to increase drilling rate.

\section{Maximum Capabilities:}

Borehole Pressure ............. 1,000 psi

Pumping Pressure ............... 1,000 psi

Back (Pore) Pressure .......... 1,000 psi

Mud Flow Rate ................... 3 gpm

Mud Temperature ................. $150^{\circ} \mathrm{F}$

Drilling Stroke ................... 4 inches

Rate of Penetration ........... $300 \mathrm{ft} / \mathrm{hr}$

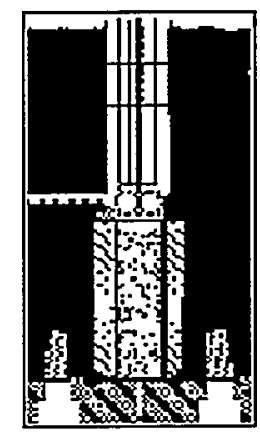

click on image to view full screen

Rotary Speed $1,000 \mathrm{rpm}$

Torque $1,000 \mathrm{ft} \mathrm{lb}$

Weight on Bit .. 1,000 lb

Bit Size 1 " diameter

Rock Sample Size 1 " diameter

\section{Small-Scale Cutter Performance and Wear Testing}

- PDC Diamond Cutter Performance measurements verses PDC design and size, back and side angles, and drilling conditions and simulated depth in various rock types.

- PDC Diamond Cutter Wear in abrasive rock measured as a function of rock volume removed and drilling conditions at simulated depth. 
Borehole Pressure 5,000 psi

Confining Pressure 5,000 psi

Overburden Pressure $6,000 \mathrm{psi}$

Back (Pore) Pressure 4,000 psi

Mud Flow Rate $25 \mathrm{gpm}$

Mud Temperature $150^{\circ} \mathrm{F}$

Drilling Stroke 18 inches

Rate of Penetration $300 \mathrm{ft} / \mathrm{hr}$

Rotary Speed $1,000 \mathrm{rpm}$

Torque

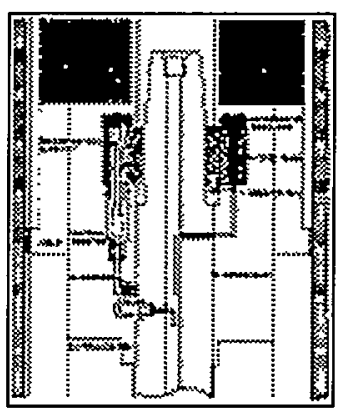

Weight on Bit $1,000 \mathrm{ft} \mathrm{lb}$

Bit Cutters $3,000 \mathrm{lb}$

Rock Sample Size 5 (1 instrumented) $10 \frac{1}{2} "$ OD x 3" ID x 18"

\section{Design of Specialized Drilling and Completions Test System}

- Drilling Laboratory Equipment

- Completions Laboratory Equipment

- Borehole Stability Tester

- High Pressure/High Temperature Mud Pumps (small and large capacity)

- Stress Frames (small and large block)

- Cutter Testers

- Spurt-Loss Tester

\section{Wide Variety of Unique Rock Samples Available to Industry Research and Testing Laboratories}

Shales $500-10,000$ psi unconfined strength $<10-9$ to $<10-6$ permeability Medium strength shale-siltstone with $2 \%$ montmorillonite-Mancos shale Low to medium strength shale with $7 \%$ montmorillonite-Wellington shale Low strength claystone with $20-30 \%$ montmorillonite-Pierre 1 shale Very low strength claystone with $50-60 \%$ montmorillonite-Pierre 2 shale
High Pressure Pumping System

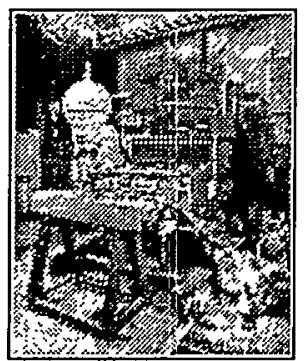

click on image to view full screen

Sandstones 200-21,000 psi unconfined strength, 10-5 to 2 Darcies permeability

High strength, abrasive-Nugget sandstone, Tennessee quartzite

Medium strength, low permeability-Torrey Buff sandstone, Red sandstone

Medium strength, high permeability-Berea sandstone, Bentheimer sandstone

Low strength, high permeability-Castlegate sandstone, Saltwash North and Saltwash South sandstones

Low strength, high permeability-Castlegate sandstone, Saltwash North and Saltwash South sandstones

Limestones and Dolomites 2,000-25,000 unconfined strength, 10-9 to 10-2 darcies permeability

High strength, low permeability dolomite-BonneTerre dolomite

High strength, low permeability limestone-Carthage limestone, Birdseye marble

Medium strength, medium permeability limestone-Lueders limestone, Indiana limestone

Low strength, low permeability limestone-Austin chalk

Other rocks such as granite, quartzite, basalt, tuff, andesite, anhydrite and gneiss 


\section{(800)372-2522 (801)584-2400}

fax: (801)584-2406

terratek@terratek.com

\section{Return to [Home Page I Services I Software I Testing Equipment Sales I Contact} Drilling\&Completions] 


\section{Well Bore Simulator}

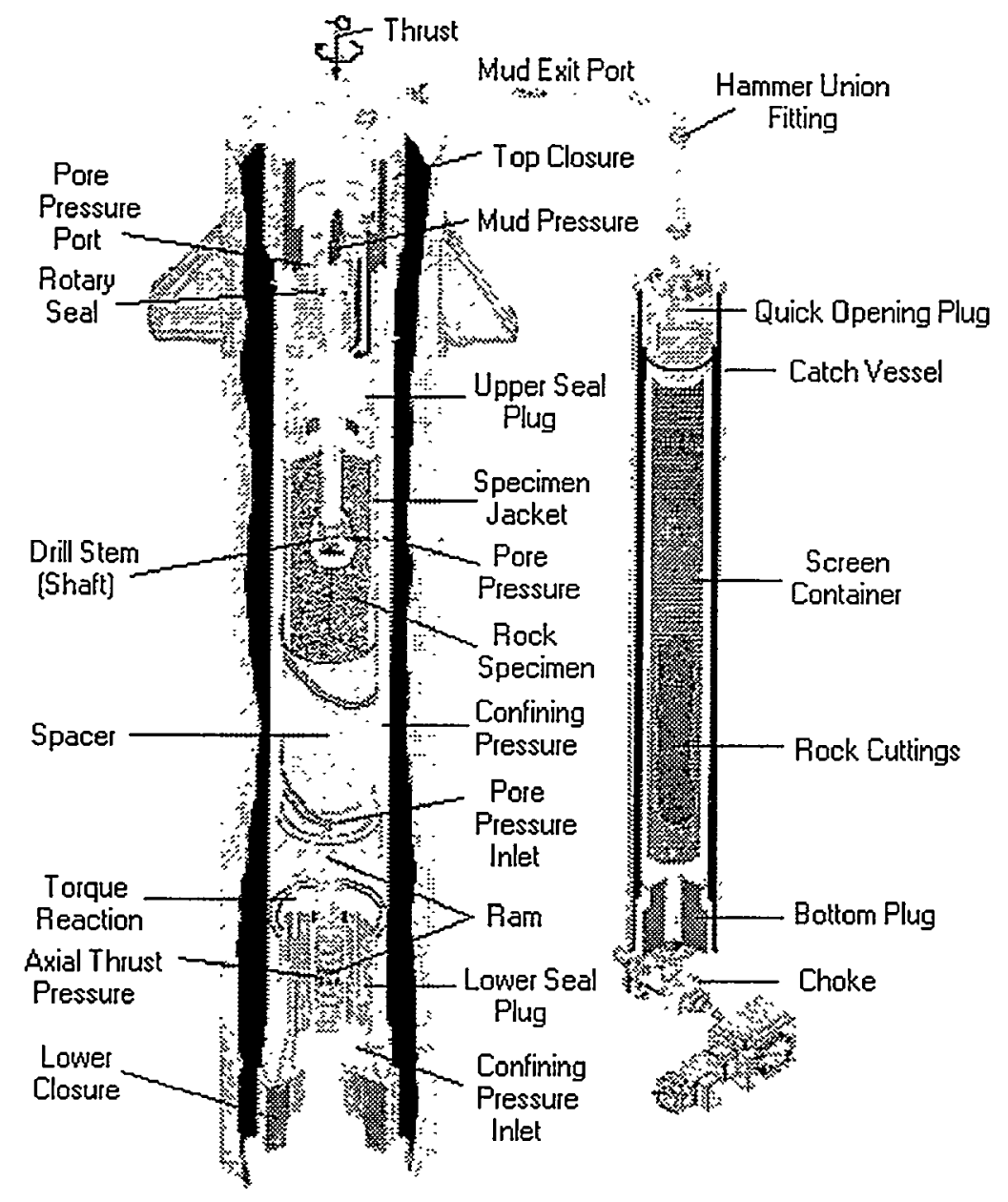




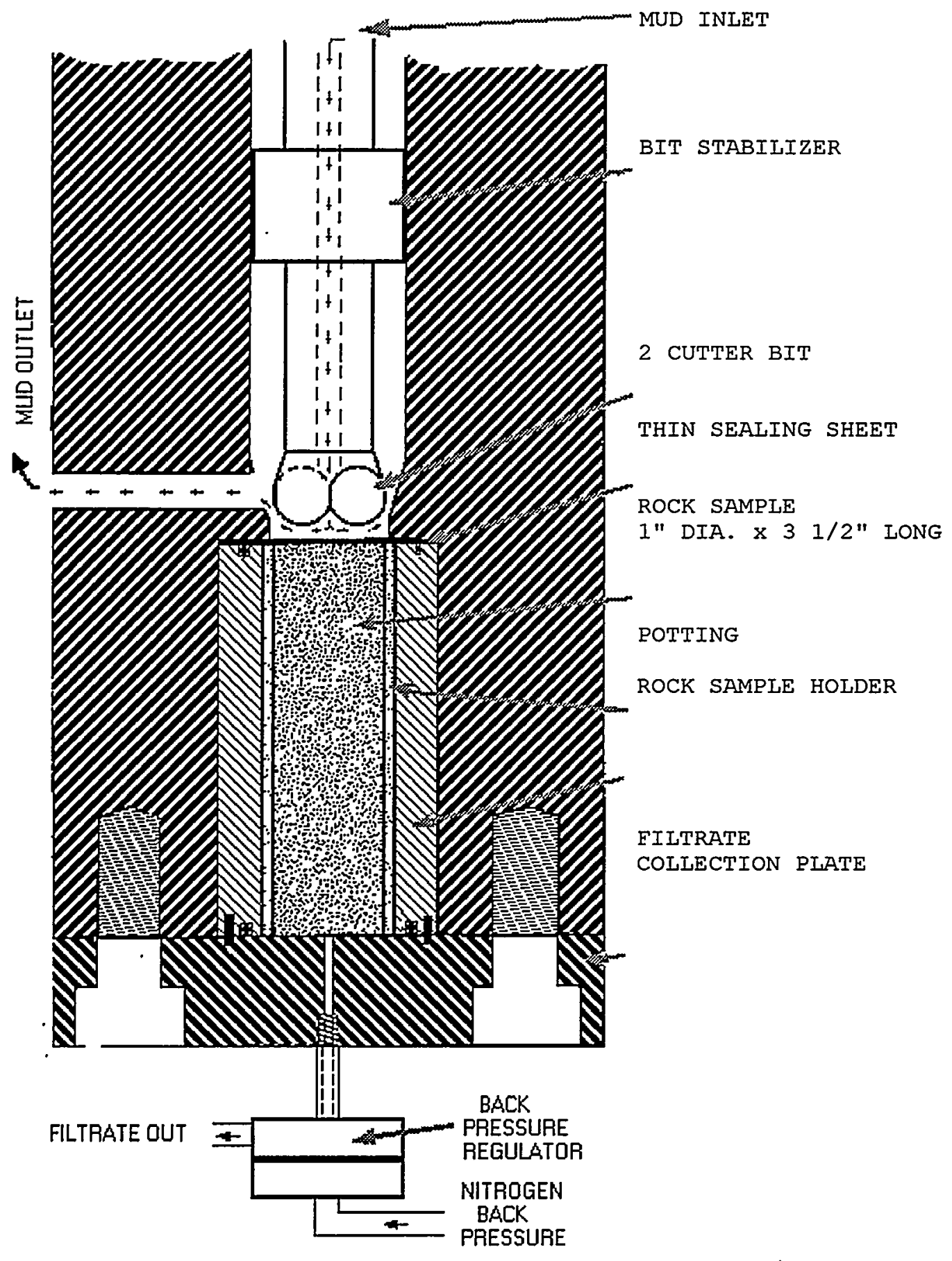




\section{CTF Instrumented Cutter Fixture}

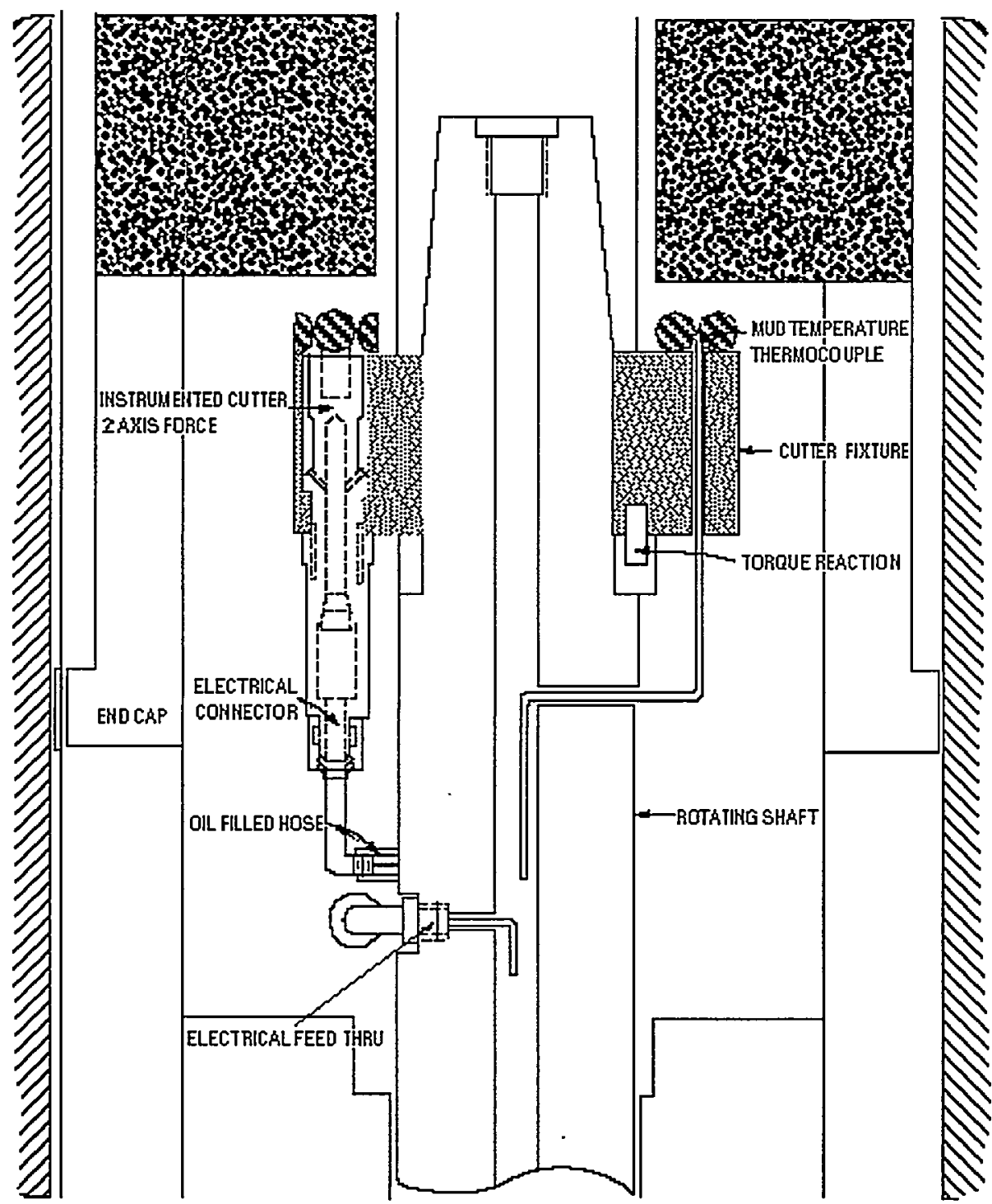




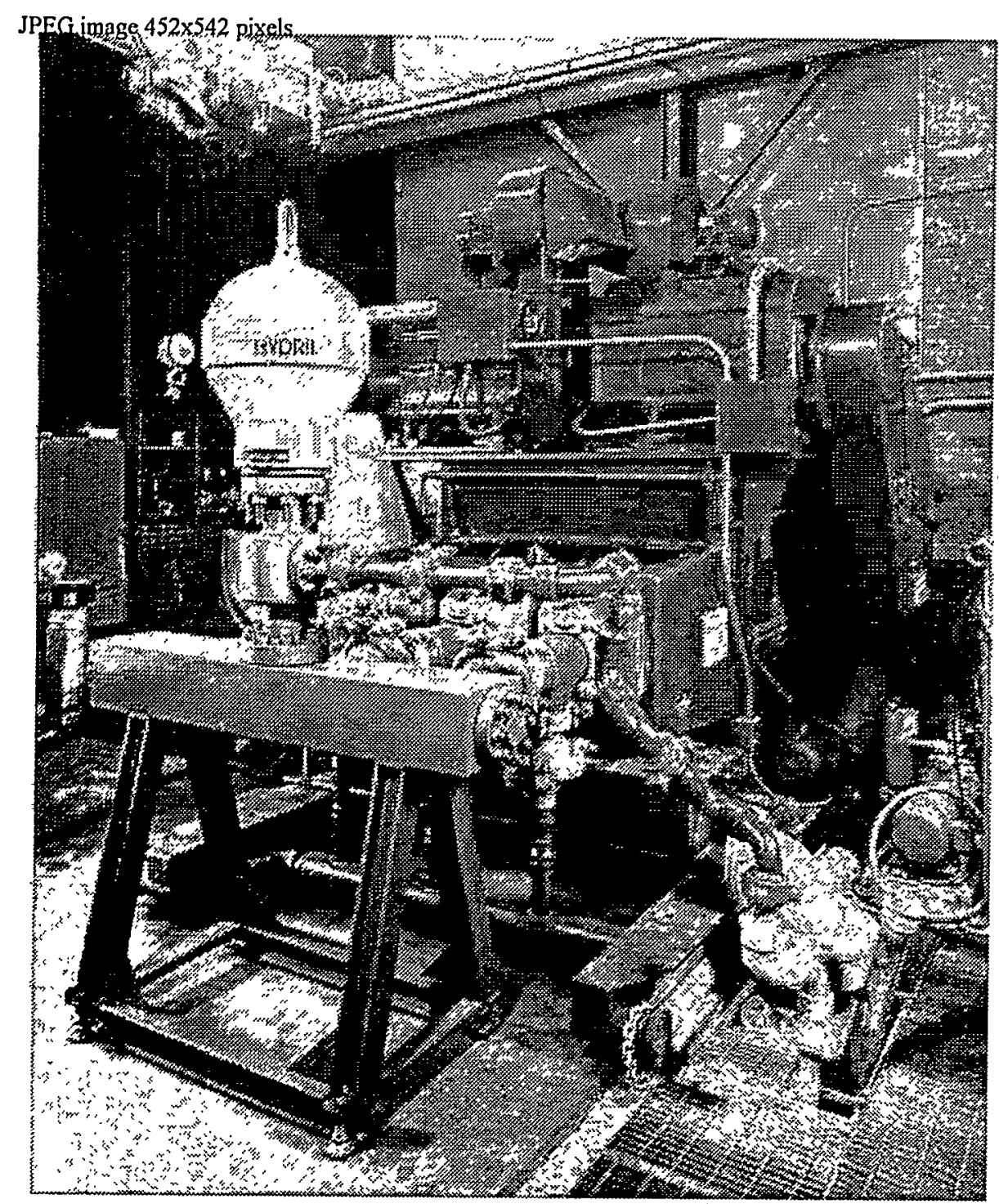

